XX11I.

\title{
Die Beckenbrüche mit Bemerkungen über Harnröhren- und Harnblasenzerreißnngen.
}

Yon

Prof. Dr. P. Stolper-Göttingen.

(Mit 35 Abbildungen.)

Unsere Kenntnis der Beckenverletzungen stiitzt sich im großen ganzen auf eine verhältnismäßig geringe Zahl von klinisch und pathologisch-anatomisch untersuchten Fällen. Auch die neueren Lehrbücher der Chirurgie greifen deshalb notgedrungen auf das alte Lehrbuch der Frakturen und Luxationen des verdienstvollen Malgaigne zurïck, dessen Name bis auf diesen Tag mit einem immer noch für eigenartig gehalten 'Typ von Beckenbrüchen verknüpft wird.

Messerers Experimentalstudien über die Elasticität und Festigkeit der Knochen (1879), die Kusmin (18\$2) besonders für das Becken erweitert hat, lielien erwarten, dali man allgemein auch fïr das Becken sich daran gewöhnen würde, die verschiedenen rerletzungen desselben, wie mannigfach sie sich auch in Bezug auf Sitz und Grölie darstellen mochten, genetisch einheitlicher aufzufassen. Rose, der den Begriff des Beckenringbruches schon 1865 einführte und sich damit ein unbestreitbares Verdienst erwarb, ist von den spä.teren Bearbeitern des Gebietes wohl nicht ganz verstarden worden, wie man aus der Tatsache entnehmen muk, daß zahlleiche neue I ehrbïcher rein theoretisch, aber sicher nicht aus praktischen anatomischen Studien heraus eine ganze Reihe von verschiedenen Formen von Beckenluxation aufstellen. Salleron schrieb noch 1871 eine Monographie lediglich über die Luxationen des Beckens, über eine For'm der Beckenverletzungen, die es nach meiner Erfahrung rein überhaupt nicht gibt. Hoffa (Frakturen und Luxationen 1904) gibt 12 Abbildungen von Beckenbrïchen, hat aber die Oppelsche theoretisierende Einteilung acceptiert. 
Auf große Eigenerfahrung gründet sich die Darstellung der Beckenbrüche in dem alten trefflichen und soeben wieder neu erschienenen Lehrbuch von König, und über eine große Anzahl von Beckenverletzungen berichtet Bartels in seiner Arbeit über "Die Traumen der Harnblase", ebenso Martens, "Verletzungen und Verengerungen der Harnröhre". Wenn ich noch der Arbeit von Katzenelson und der Bearbeitung des Kapitels durch Steinthal im Handbuch der praktischen Chirurgie gedenke, so sind die Namen derjenigen angeführt, die sich eingehender mit den Beckenbrüchen und den dabei vorkommenden Harnblasen- und Harnröhrenverletzungen beschäftigt haben. Freilich kommen dazu noch eine Menge kasuistischer Beiträge, die ich indes unberücksichtigt lassen muß, um den Umfang der Abhandlung nicht über Gebühr auszudehnen.

Das in der Literatur niedergelegte Erfahrungsmaterial entspricht meines Erachtens bezüglich der pathologisch-anatomischen Untersuchung der Beckenverletzungen noch nicht der praktischen Bedeutung und Häufigkeit derselben. Gerade diese Lücke aber glaube ich einigermaßen ausfüllen zu können, da es mir gelungen ist, eine größere Sammlung von Beckenbrüchen zusammen zu bringen, über die ich teils in Zeichnungen, teils in Photographien, teils in Skizzen in dieser Arbeit, zugleich beschreibend, berichten will. Ich habe die Präparate zum größeren Teil, 33 an Zahl, vor einem großen Kreise von Chirurgen auf der Naturforscher-Versammlung in Karlsbad 1902 bereits demonstriert. Die Mehrzahl habe ich als Assistent des heimgegangenen Geheimrats Professor D. W. Wagner in Königshütte a. S. durch Obduktion gewonnen. Ein Teil und zwar besonders wertvolle Präparate von geheilten Frakturen stammt aus meiner früheren Arbeitsstätte, aus der Sammlung des Breslauer pathologischen Instituts. Für die Erlaubnis zu ihrer Verwertung bin ich meinem früheren Chef, Herrn Geheimrat Professor Dr. Ponfick zu großem Danke verpflichtet.

Den Schwerpunkt meiner Mitteilungen sehe ich in der möglichst genauen Beschreibung dieser zahlreichen Präparate, weil ich weiß, daß selbst bei Obduktionen noch vielfach Beckenfissuren übersehen werden. Denn es geht mit ihnen wie mit den Schädelbrüchen, man kann die Zahl der Fissuren und ihre Ausdehnung erst am macerierten Präparat ganz übersehen.

Bei der eingehenden Betrachtung der Bilder wird man trotz aller Verschiedenheiten in der Form und dem Verlauf der Fissuren sich der Tatsache einer gewissen Gesetzmäßigkeit nicht verschließen können. Das Material scheint mir zwar nicht wesentlich neue Ge- 
sichtspunkte für die Lehre von den Beckenbrủchen beizubringen, wohl aber das Verständnis für den Mechanismus der Beckenringbiegungsbrüche, des interessantesten und häufigsten Typus, besser als alle Experimente zu veranschaulichen und damit auch die klinische Diagnose der Beckenverletzungen zu fördern.

Gerade letzterer Umstand scheint mir recht wünschenswert, denn ich habe bei den sehr zahlreichen Untersuchungen von Unfallverletzten in Königshütte, in der Heilanstalt für Unfallverletzte in Breslau wie in meiner hiesigen Tätigkeit als Kreisarzt über Erwarten oft die Erfahrung gemacht, daß viele Beckenbrüche lange unerkannt blieben. Herr Dr. Löwe vom Institut für Unfallverletzte in Breslau weiß mir diese Erfahrung besonders zu bestätigen. Hatten wir doch dort unter 1648 zur Nachbehandlung aufgenommenen berufsgenossenschaftlichen Unfallverletzten im Jahre 1902, also unter durchweg schwerverletzten, 24 geheilte Beckenbrüche, von denen nur 11, also knapp die Hälfte, als solche vorher diagnostiziert waren.

Die Bedeutung der Beckenbrüche ist in der Praxis danach eine größere, als dies nach den häufig citierten Zahlen von Bruns (0,3 Proz. aller Knochenbrüche) und Golebiewski ( 1 Beckenbruch auf 4000 Verletzungen überhaupt) scheinen mag.

Ieh werde im ersten Teil der Arbeit (A) vorwiegend die anatomischen Verhältnisse, im zweiten (B) die klinischen und im dritten (C) die Hauptcomplikationen der Beckenbrüche, die dabei vorkommenden Harnröhren- (C I) und Harnblasenverletzungen (C II) behandeln.

\section{A.}

Ich unterscheide im folgenden, festhaltend an dem von Rose für die Chirurgie aufgestellten Prinzip, daß die Summe aller das Becken zusammensetzenden Knochen als einheitliches Ganzes, als "Beckenring" aufzufassen ist:

I. indirekte Beckenringbiegungsbrüche,

II. direkte Beckenrandbrüche.

Die Schußfrakturen des Beckens, wie auch die Pfählungsverletzungen lasse ich mangels genügender Eigenerfahrungen unberücksichtigt.

Unter den Beckenrandbrüchen sind als die häufigsten anzusehen die isolierten Frakturen der Darmbeinschaufel, die 
isolierten Querfrakturen des Kreuz-Steißbeins und endlich eine durch ihre Entstehungsart wohlcharakterisierte, meist mit schwerer Quetschung der Harnröhre einhergehende einfache nder doppelte Fraktur am Schambogen, d. h. an einem oder beiden Schenkeln desselben. Der Abbruch von Dornfortsätzen des Kreuzbeins durch direkte Gewalt spielt praktisch keine Rolle.

Bei diesen drei Untergruppen ist immer eine direkte Gewalt mit umschriebener Einwirkungsstelle der Anlaß. Ein Hufschlag beispielsweise gegen die Darmbeinschaufel bricht am Rande des Beckens ein Stück heraus, ohne doch die Continuität des Beckenringes aufzuheben. Beim Fall auf der Höhe auf das Gesäß kommt es, ohne daß dabei der ganze Beckenring birst, zu einer Querfraktur des Os sacrum, wenn dieses z. B. auf einen aus dem Boden hervorragenden Stein aufschlägt. Die Fissur zieht von einem Foramen sacrale der einen Seite zu dem korrespondierenden der anderen Seite, oder einem höheren oder tieferen und beiderseits darüber hinaus. Hierher zählt auch der Abbruch, bezw. die Lockerung des Kreuzbeinanhanges, des Os coccygis. Die dritte Unterart, die isolierte Fraktur am Schambogen, kommt zustande durch Fall mit gespreizten Beinen rittlings auf einen harten Gegenstand. Ein Becken mit ausgeheilter Fraktur dieser Art ist später abgebildet. Solche Verletzungen habe ich z. B. bei Bergleuten des öfteren beobachtet, die über das hohe Gestänge einer Grubenförderbahn hinliefen, d. h. auf Eisenbahnschienen, welche über hohe, in weiten Zwischenräumen aufgestellte Holzböcke führten. Ausgleitend kommen sie rittlings mit der ganzen Wucht ihres Körpergewichts auf die Schiene zu sitzen. Dabei bricht unter der direkten Quetschung meist einer der beiden Schenkel des Schambogens, also der Ramus descendens ossis pubis, bezw. seine Fortsetzung, der Ramus ascendens ossis ischii, gelegentlich auch beide Schambogenschenkel. Es ist fast die Regel, daß dabei auch die unter dem Schambogen herziehende Harnröhre beschädigt wird und zwar meist, ohne daß die äußeren Weichteile eine Zusammenhangstrennung aufweisen. Nur ein durch Blaufärbung und Schwellung sich kennzeichnender subkutaner Bluterguß und starke Druckempfindlichkeit deutet unmittelbar nach dem Unfall auf den Ort der stattgehabten Verletzung hin. Eben dieser Bluterguß läßt über die Frage, ob eine Fraktur oder eine einfache Contusion des Knochens stattgehabt hat, vielfach im unklaren.

Die der Art ihres Zustandekommens wie ihrer anatomischen Erscheinungsform nach wohlcharakterisierte häu- 
figste Frakturform ist der Beckenringbiegungsbruch, der Haupttypus der Beckenbrüche, der Beckenbruch $x \alpha \tau^{2} \dot{\varepsilon} \xi o \chi \dot{\eta} \boldsymbol{\nu}$.

Der Beckenringbruch kommt nicht durch direkte Gewalt, sondern durch indirekte zustande, und zwar durch Pressung (Compression) des Beckenringes, sei es in frontaler, sei es in sagittaler Richtung oder in einer dazwischenliegenden diametralen. Im Momente der Maximal-Biegung des elastischen Ringes kommt es an bestimmten Lieblingsstellen zu Zusammenhangstrennungen und, wie fast jedes der Präparate zeigt, an mehreren, meist weit von einander gelegenen Linien. An den leichter verletzten Becken kommt es auch in der Art der Fissuren zum Ausdruck, daß diese typischen Beckenbrüche nach den Gesetzen der Biegungsspannung zustande kommen, wie dies schon Kusmin auf experimentellem Wege fand. Ich habe mehrere Präparate, an denen ein langer dünner Span an der Innenseite des Beckenringes, an dem Innenrande des Ramus horizontalis ossis pubis abgesplittert ist. Der Splitter hängt nach der Darmbeinschaufel zu mit dem Knochen noch zusammen, während die Lamelle mit dem nach der Symphyse hin gelegenen Ende ganz losgelöst ist und in das Beckeninnere hineinbiegt. Es liegt nahe, von dieser freien Spitze des Fragments Gefahr für die Harnblase im Moment der Zusammenpressung des Beckens zu befürchten.

An die Spitze meiner Abbildungen stelle ich ein Präparat, welches - an der rechten Darmbeinkante - die Wirkung der direkten Gewalt, aber an 6 anderen Stellen die der Biegungsüberspannung aufs deutlichste zeigt.

Fall 1 (Fig. 1). Multiple Fissuren am Becken eines zwischen zwei Förderwagen zusammengequetschten, alsbald verstorbenen Bergmanns. Tod durch Brusţ̣uetschung.

Ich fand 1. entsprechend einer starken Weichteildurchblutung Fissuren am rechten Darmbeinkamm,

2. Fraktur des rechten aufsteigenden Sitzbeinastes,

3. Fraktur des linken absteigenden Schambeinastes,

4. Schrägbruch des rechten horizontalen Schambeinastes, dicht an der Symphysis pubis; in der Nähe des spitzen Fragments die Harnröhre durchrissen, dicht an der Prostata. Große Wundhöhle mit Urin durchmischt;

5. klaffende Fraktur den ganzen linken Kreuzbeinflügel durchsetzend;

6. Fissur im rechten Kreuzbeinflügel, nur $2 \mathrm{~cm}$ in die Tiefe und nach unten bis zum obersten rechten Foramen sacrale reichend;

7. leichte Infraktion am linken horizontalen Schambeinast.

Das Präparat ist in jeder Weise typisch, denn es läßt nicht bloß den Lieblingssitz der Fissuren bei indirekten erkennen, sondern es demonstriert auch die Zusammenpressung des Ringes durch 
Die Beckenbrüche m. Bemerkgn. üb. Harnröhren- u. Harnblasenzerreißungen. 503

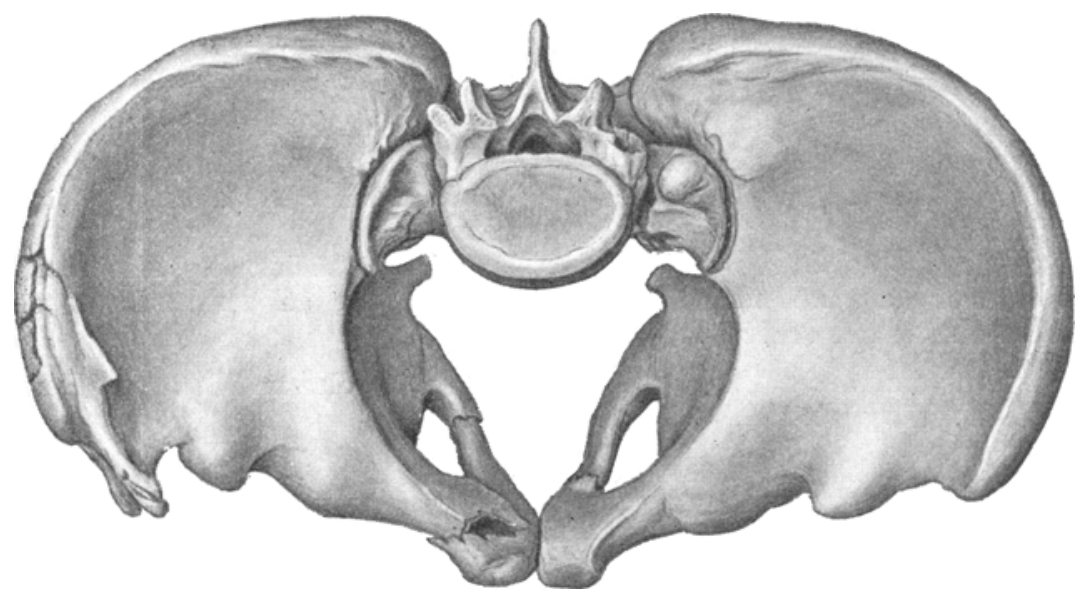

Fig. 1.

die Infraktion, durch die nach innen abspringenden Fragmentspitzen, durch den Einbruch der beiden Kreuzbeinflügel an der Innenseite. Das Gleiche gilt von dem durch Skizze nur wiedergegebenen folgenden Präparat.

Fall 2 (Fig. 2). Typische Beckenringfraktur, gleichseitige Fissuren an der vorderen und hinteren Beckenhälfte.

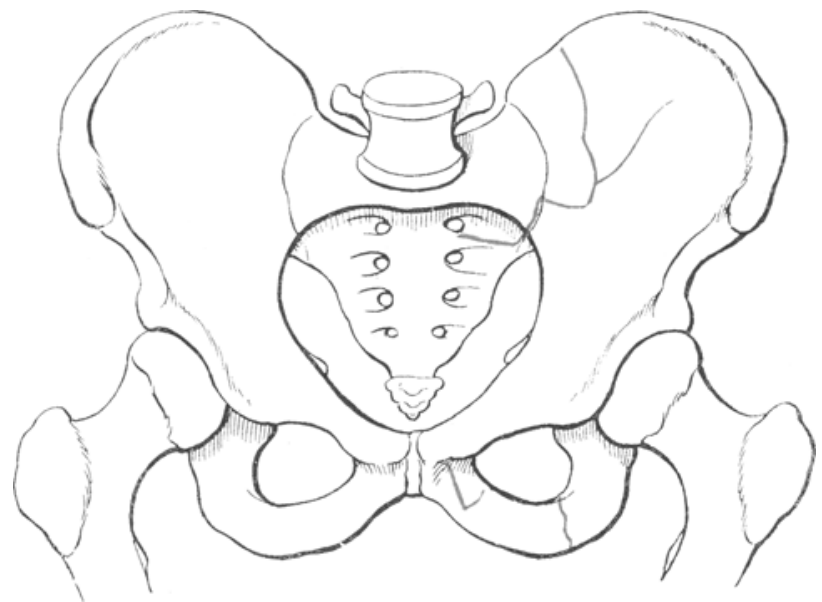

Fig. 2.

Das Präparat stammt von einem verschütteten Bergmann, der unter dem Gestein erstickt ist. Es ist ein verhältnismäBig leichter Beckenbruch; eine Fissurlinie zieht linkerseits median vom Tuber ischii zum Foramen 
obturatorium, eine zweite, ihre Fortsetzung, beginnt etwas oberhalb am Rande dieses Foramens und durchsetzt den horizontalen Ast des Schambeines.

Ebenfalls auf der linken Seite sehen wir eine Fissur von dem 1. Foramen sacrale zur Synchondrosis sacroiliaca sinistra ziehen, in dieser ein Stück fortlaufen und dann in 2 sich gabelnden Ästen durch das linke Darmbein gehen.

Die Betrachtung von hintenher läßt keine Läsion des Kreuzbeins, wohl aber eine klaffende unregelmäßige Sprengung an der Rückseite der Darmbeinschaufel erkennen.

(Präparat des pathol. Instituts zu Breslau, diesem 1880 von Herrn Prof. W. Wagner-Königshütte übersandt.)

So sahen wir als Lieblingssitz der Fissuren die zarten Knochenspangen der Schambogenschenkel, die horizontalen Äste des Schambeins an der vor-

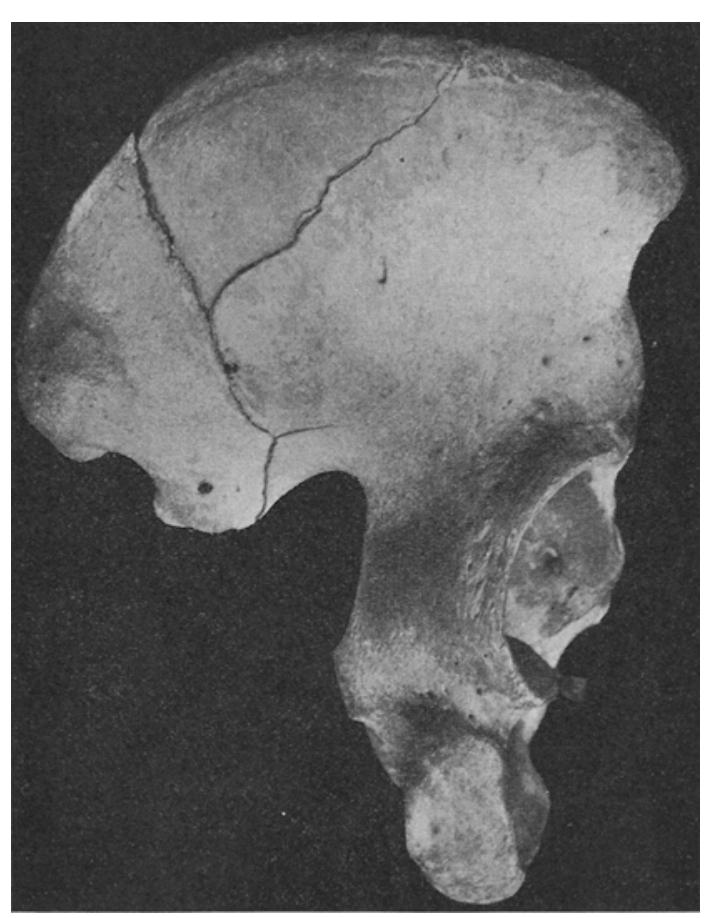

Fig. 3.

Abbruch des hinteren Darmbeinflügels. deren Beckenhälfte und die Nachbarknochen der Kreuzdarmbeinfugen hinten.

Als Schambogenschenkel möchte ich der Kürze halber den Ramusdescendens ossis pubis und den Ramusascendens ossis ischii bezeichnen. Hier finden wir bei allen schwereren Frakturen die Kontinuität einseitig oder beiderseitig von der Symphyse ganz durchtrennt, so zwar, daß die obere Umrandung des Foramen obturat., also der Ramus horizontalis, wie auch die untere fissuriert ist, also die Spange vom Angulus bis zum Tuber ischii. Manchmal sitzt eine Fissur hinter dem Tuber an dem Ramus descendens ossis ischii. In jedem Falle muß man die Fissur sich mitten durch das Foramen obturatorium 
Die Beckenbrüche m. Bemerkgn, üb. Harnröhren- u. Harnblasenzerreißungen. 505

hinlaufend denken. Sind die genannten Knochenspangen beiderseitig von der Symphyse gebrochen, so ist der Sitz der Fissuren fast immer ganz symmetrisch.

Daß die Bruchfigur im linken Darmbein des Falles 2 etwas typisches ist, des zum Beweise füge ich das Photogramm des rechten Darmbeins eines anderen Beckens (Fall 3) bei. Ich nenne das "Abbruch des hinteren Darmbeinflügels" (Fig. 3).

Fall 4 (Fig. 4). Augenfällige Symmetrie im Sitz der Bruchlinien am vorderen Beckenbogen. Einfache Fissur in der hinteren Beckenhälfte linkerseits.

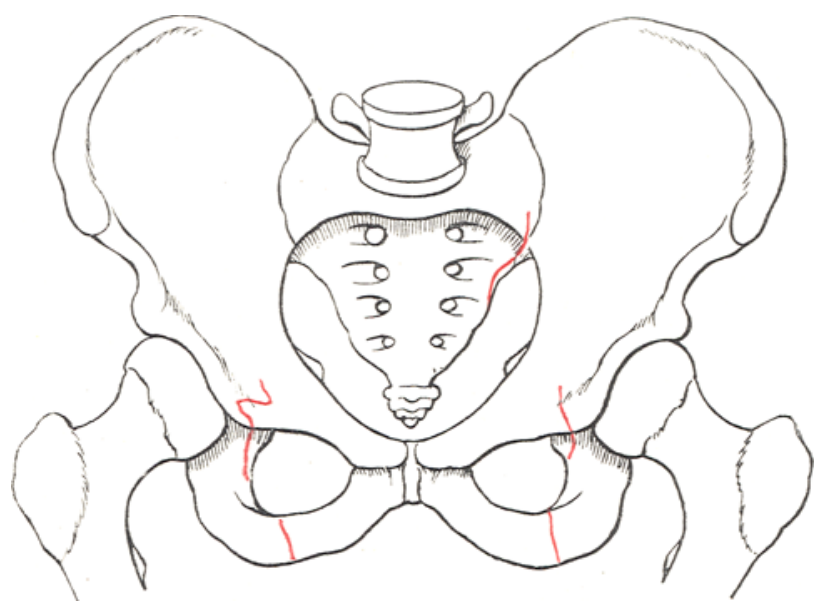

Fig. 4.

All einem von seinem Wagen wahrscheinlich abgestüraten, überfahrenen und durch zahlreiche schwere Quetschungen Getőteten wiesen die Weichteilverletzungen darauf hin, daß ihm ein Rad aber den rechten Trochanter gegangen sein mußte.

Die Bruchlinien gehen fast genau an korrespondierender Stelle durch den horizontalen Schambeinast, da wo der Knochen zum Tuberculum ileopubicum anzuschwellen beginnt. An der linken Seite handelt es sich eigentlich nur um eine Infraktion. Der Schambeinast ist in die laterale Knochenanschwellung sichtlich hineingeprebt. Weiter abwärts durchsetzt die das Foramen obturatorium überspringende Bruchlinie beiderseits den aufsteigenden Sitzbeinast dicht vor dem Sitzbeinhöcker. An der Schambeinfuge war eine nicht bis in das Foramen obturat. reichende Fissur rechterseits sichtbar; die Harnröhre hier eingerissen, aber nicht ganz durchgequetscht. In der Zusammenfügungslinie zwischen dem Kreuzbein und der linken Darmbeinschaufel war die Einwirkung der Gewalt nur an der Absprengung minimaler Knochensplitter vom äuBersten Rande des Kreuzbeins erkennbar. Die ganze Synchondrosis sacroiliaca sinistra war nicht gelockert. 
Fall 5 (Fig. 5 u. 6). Beckenringbiegungsbruch, doppelseitig, mit gleichzeitigem Beckenrandbruch.

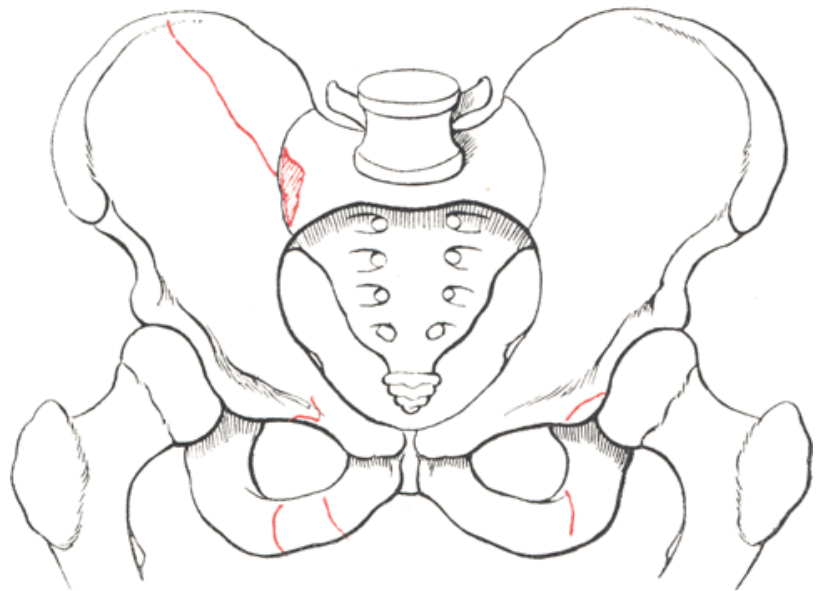

Fig. 5 .

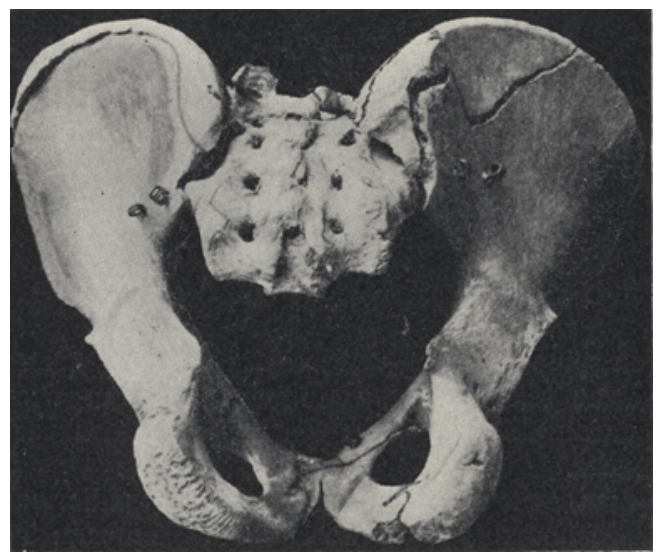

Fig. 6.

Mehrfache symmetr. Fraktur, vorn Fraktur des r. hint. Darmbeinflügels.

Das Präparat, entstammend einem Individuum, für dessen Verletzungen ich Angaben über das Zustandekommen nicht machen kann, zeigt ebenfalls die Symmetrie des Sitzes der Bruchlinien am Scham- und Sitzbein, fast an gleicher Stelle wie in Fig. 4. Die Rückansicht des Beckens zeigt mehrere kleine Fissuren im Kreuzbein, einen Beckenrandbruch am rechten Darmbein und Fissuren an der Symphysis pubis, nur an deren Innenseite erkennbar (Photographie). 
Fall 6 (Fig. 7). Vorn doppelseitige symmetrische Fissuren; hinten Fissur durch sämtliche Foramina sacralia rechterseits.

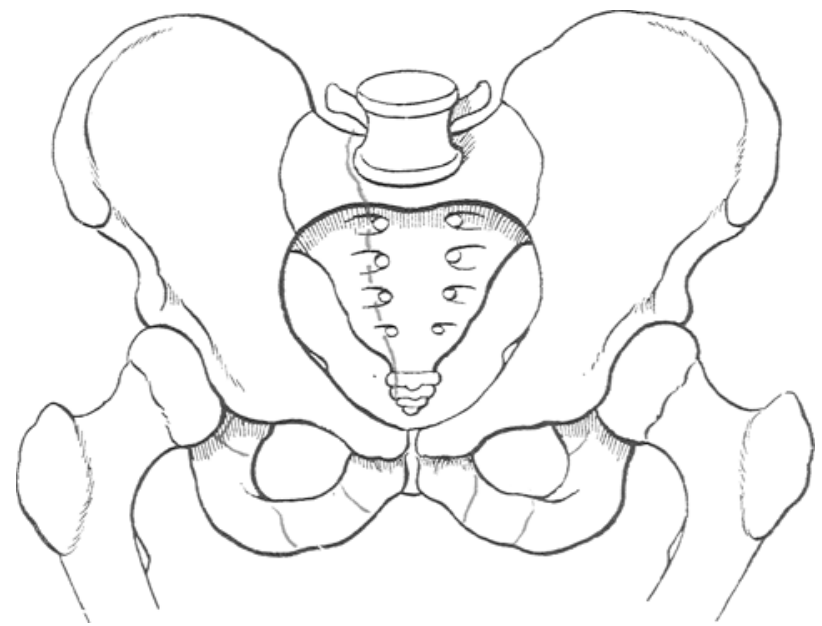

Fig. 7.

Die Symmetrie im Sitz der Fissuren durch die Schambogenschenkel und den horizontalen Schambeinast, hier ganz in der Nähe der Huftgelenke, ist eine auBerordentlich in die Augen fallende. Die durch das ganze Kreuzbein hinziehende Fissur ist auch an der Rückseite sichtbar.

Nähere Angaben über die Entstehung der Fraktur kann ich für dieses Präparat nicht machen.

Fall 7 (Fig. 8). Beckenringfraktur: vorn beiderseits symmetrisch sitzende Fissuren, hinten beiderseits Kreuzbeinlängsfissuren und links Beckenwandbruch (Abbildung s. nächste Seite).

Das von einem durch Üherfahren getöteten Mann herstammende Becken zeigt vorn jederseits eine durch den Ramus horizontalis und den Ramus ascendens ossis ischii fast genau symmetrisch ziehende Fissur. Auch hinten sitzen die Sprünge beiderseits; rechts läuft ein solcher durch die Foramina sacralia, und zwar ist er an der Räckseite des Kreuzbeins noch deutlicher sichtbar als vorn, hier im oberen Ausläufer eine Strecke durch die Synchondrosis sacroiliaca hinlaufend. Auch linkerseits zieht ein Sprung vom 3. Foramen sacrale zur Fuge hin. Die linke Darmbeinschaufel endlich zeigt $(a-b-c)$ einen unregelmäBig verlaufenden Bruch des Beckenrandes, die ganze Crista ist hier abgesprengt, offenbar durch direkte Gewalt.

Die in diesen Präparaten immer. wiederkehrende Symmetrie der Knochensprünge spricht deutlich dafür, daß diese Beckenbrüche nach gewissen Gesetzen, eben denen der Biegungsspannung zustande kommen. Nur in wenigen selteneren Fällen und bei besonders eigenartiger Einwirkung der Gewalt rückt die Fissurlinie an der vorderen Beckenhälfte mehr lateral, nach dem Hüftgelenk 
zu oder sie läıft gar, eine verhängnisvolle Complikation, durch die Hüftgelenkspfanne einer Seite, wie dies 6 meiner Präparate zeigen.

Dreimal sieht man an meinen Präparaten die Schambeinfuge (Symphysis pubis) gelöst, die sie zusammensetzenden beiden Knochen gegeneinander dislociert, einmal in starker Dislokation verheilt.

Nach der alten Terminologie, die ja besonders von unserem alten Lehrmeister in Knochenverletzungen, von Malgaigne, begründet ist, spricht man von Luxationen in der Symphysis pubis, von Frakturen- mehrfachen, symmetrischen, asymmetrischen- des Schambeins, des Sitzbeins 11.s.f. Bei der Analyse der Beckenringfraktur wird

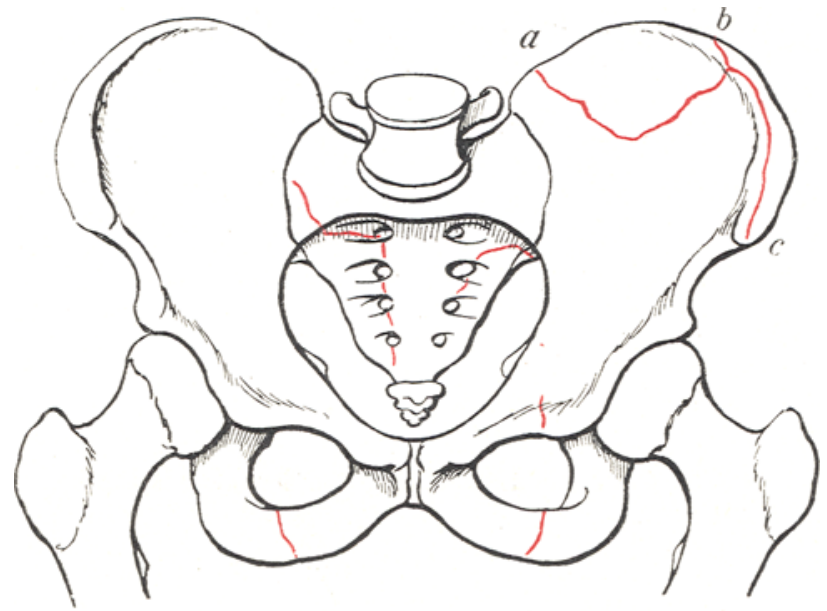

Fig. 8.

man gewiß auch auf diese Lokalisation der einzelnen Fissuren Wert legen, aber es wird nicht immer möglich sein, intra vitam jede Fissur mit Sicherheit festzustellen. Viel wichtiger ist es, sich immer gegenwärtig zu halten, daß bei Beckenbrüchen, die unter akuter Zusammenpressung zustande kommen, die Fissuren an der vorderen Hälfte des Beckenringes der Regel nach multiple sind, ob man sie intra vitam nachweisen kann oder nicht.

Aber mit den Fissuren der vorderen Beckenringhälfte la ufen bei den typischen Beckenringfrakturen auch so gut wie immer Läsionen an derhinteren Beckenringhälfte einher. Das sind Lockerungen in der einen oder in beiden Kreuzdarmbeinfugen (Symphyses sacroiliacae) oder Fissuren in ihrer Nachbarschaft, also in Kreuzbein oder im Darmbein wenigstens einer Seite, wenn nicht beider. 
Die Beckenbrüche m. Bemerkgn. üb. Harnröhren- u. Harnblasenzerreißungen. 509

Fall 7. 8. 9. 10. 11 (Fig. 9. 10.11.12.13). Beckenringfrakturen, welche den mannigfachen Sitz der Bruchlinie an der Rückseite des Beckens veranschaulichen, mehrfach mit Beckenrandbrüchen kombiniert.

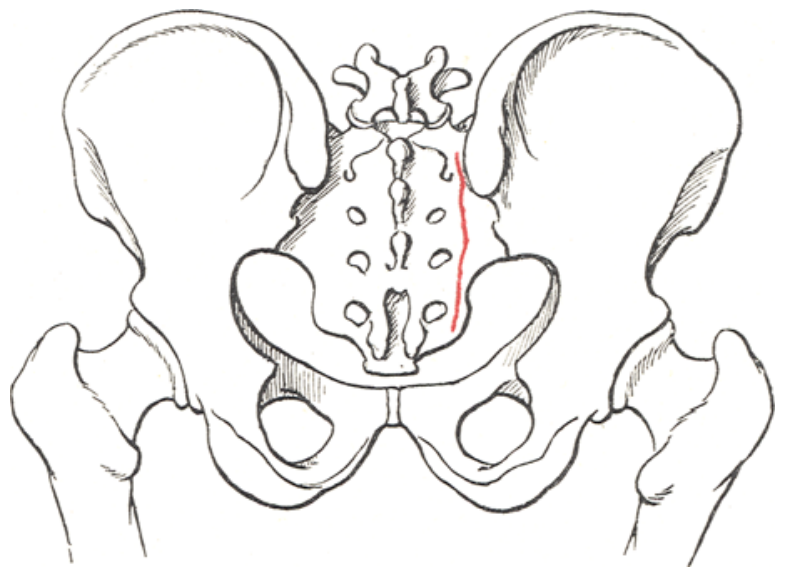

Fig. 9.

Im Präparat 9 läuft die Fissur seitlich von den Foramina sacralia fast durch die ganze Länge des Kreuzbeins, ohne doch dasselbe in sagittaler Richtung ganz zu durchsetzen, denn in der Excavatio, d. h. von vorn

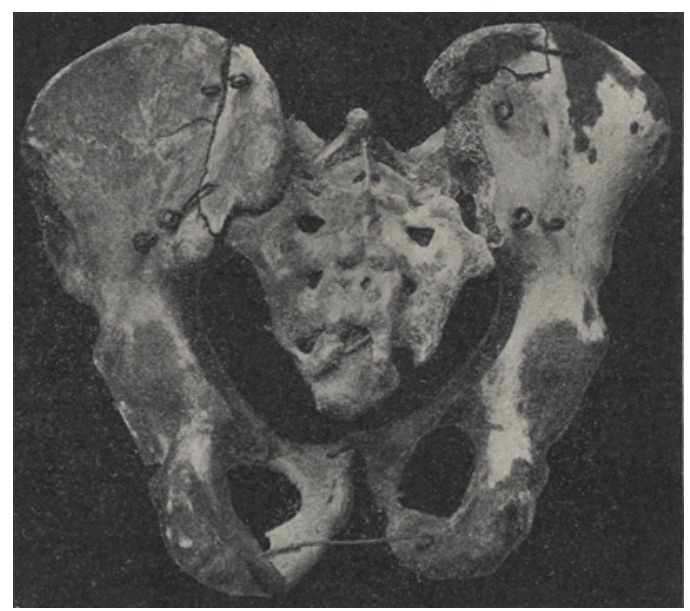

Fig. 10.

Mehrfache Beckenringfraktur vorn a. an beiden Ossa ilei. Kreuzbeinflïgel rechts geborsten. her konnte eine Fissur nicht entdeckt werden. Präparat 10 zeigt ebenso wie Präparat 11 annähernd symmetrisch sitzende Bruchlinien durch beide Darmbeine, in dem einen näher an der Synchondrose, in 9 rechts sogar 
ein Stück in dieser hinlaufend, in dem anderen ziehen die Sprünge fast durch die Mitte der Darmbeine hin.

An allen 3 Becken fanden sich am Schambein und Sitzbein Fissuren mit typischem Sitz (beiderseitig bei Präparat 9 und 10), nur rechtsseitig bei Präparat 11.

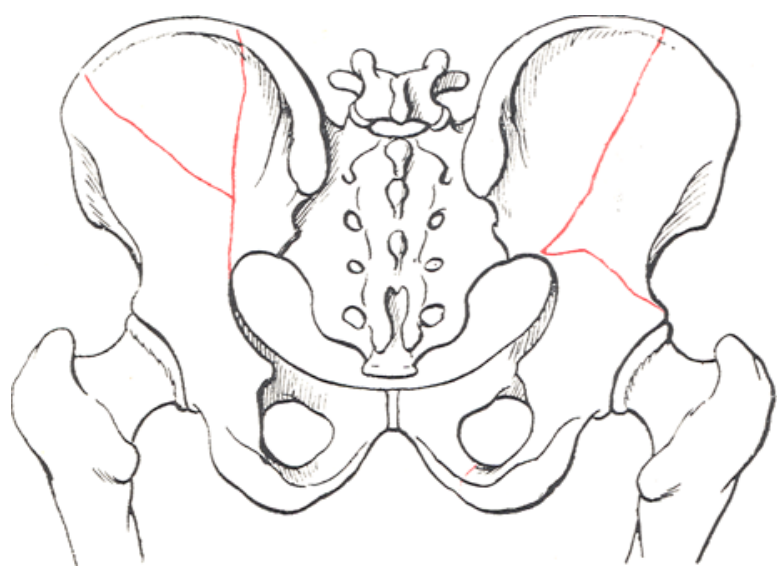

Fig. 11.

Präparat 9 stammt von einem verschütteten Grubenarbeiter, der durch anderweitige Verletzungen sofort getötet war. Präparat 10 stammt von einem "Gepufferten", d. h. er wurde beim Rangieren der Eisenbahnwagen zwischen zwei solchen zusammengequetscht und sofort getötet. Präparat 11 gehört einem durch Überfahren alsbald Getöteten. In diesem Falle liegt für die linke Beckenhälfte eine Form vor, die man nach Malgaigne als „doppelte Vertikalfraktur" bezeichnen mübte, um so mehr, als hier der ganze Huftgelenksapparat mit dem Fragment nach oben geschoben bezw. nach abwärts gezogen werden konnte.

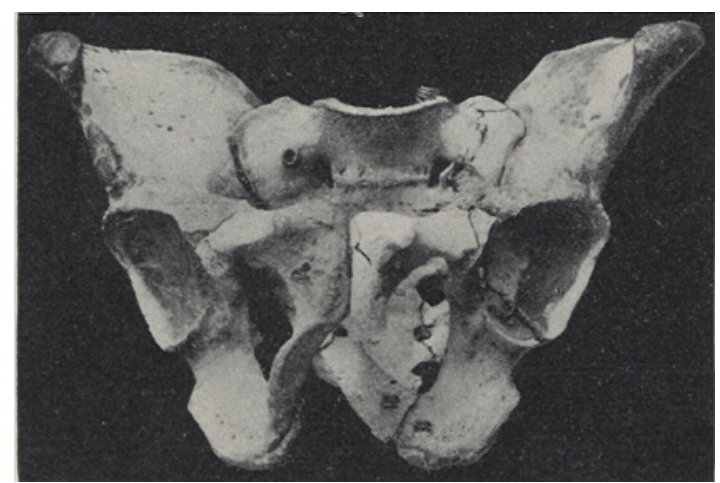

Fig. 12.

Zahlreiche Frakturen am vord. Becken, links Pfannenbruch. Linksseit. Bruch des Os sacrum durch sämtl. Foramina links.

Fig. 12. An einem bei gebucktem Stehen verschütteten Bergmann, der alsbald infolge zahlreicher schwerer Körperverletzungen starb, fand ich am Becken vorn fünf Bruchlinien von typischem Sitz am Schamund Sitzbein beiderseits, davon eine kleine Fissur durch den Ramus horizont. in die linke $\mathrm{Hüft}$ gelenkpfanne ziehend.

Am Kreuzbein läuft - am Bild zum Teil 
verdeckt - links eine lange Bruchlinie durch alle Foramina sacralia ziehend, rechts ein kleiner Sprung am hintern Flügel des Darmbeins.

Präparat 13. Ein sehr typischer Beckenringbruch von einem Manne, der von einem fahrenden Lastwagen an einem Pfeiler vorbeigequetscht und so um sich selbst gedreht wurde, zeigt vorn am Ramus horizontalis ossis pubis und am ascendens ossis ischii dext. Bruchlinien, auch links am Schambogenschenkel eine Fissur, die in gröBerer Ausdehnung an der Innenseite, parallel zur Symphysenlinie laufend, sichtbar ist.

Die Rückansicht(Fig.

13, Photographie) zeigt

die Absprengung des rechten hinteren Darmbeinflügels durch eine steile Fissurlinie.

Erst bei näherem Zusehen bemerkt man auch am linken Darmbein eine den Knochen nicht ganz durchsetzende Fissur, so daB letztere nur bemerkt wird, wenn man in den Winkel zwischen Kreuzbein und Darmbein von hinten her hineinsieht. Leicht ubersehbar ist endlich eine Knickungslinie durch die rechte Kreuzbeinhälfte, die nur von vorn her erkennbar

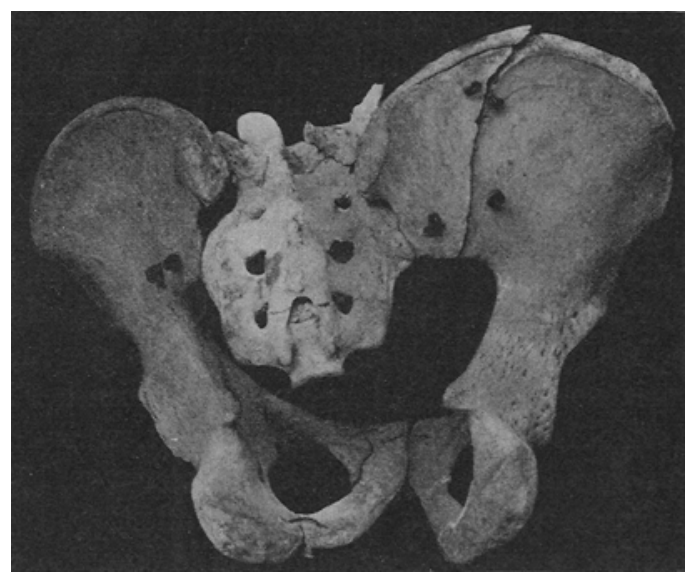

Fig. 13.

Mehrfache beiderseitige Fraktur vorn. Unregelm. Querfraktur d. Kreuzbeins, Fraktur des r. Os ilei, hint. Flügel. ist und ungefähr von

Foramen zu Foramen läuft; an der Rückseite ist nur rechts oben und zwischen den beiden untersten Foramina sacr. je eine zarte Quertissur auch auf dem Photogramm eben noch erkennbar, alles Zeichen mächtiger Zusammenpressung dieses zwischen die Darmbeine eingeschalteten Knochens. Auch dieser Beckenbruch wäre nach Malgaigne eine "doppelte Vertikalfraktur."

Gestützt auf meine Erfahrungen am Obduktionstisch wie auf allgemeine Erwägungen halte ich reine Lösungen in den Symphyses sacroiliacae, Luxationen oder Diastasen im Sinne der alten Terminologie, für überaus selten, wenn überhaupt vorkommend. Ich habe keine solchen beobachtet. Ihnen funktionell gleichstehend sind sehr häufig zu beobachten Fissuren längs durch die Massae laterales des Kreuzbeins hinziehend (7 mal an den 33 Becken). Ebenso häufig (auch 7 mal) fand ich Längsfissuren des Kreuzbeins durch die Foramina sacralia hinlaufend und zwar 4 mal doppelseitig, 3 mal einseitig. Aber oft sitzt die sehr 
lange Fissur, die den hier sehr breiten Beckenring durchsetzt, außerhalb der Kreuzdarmbeinfuge in der Darmbeinschaufel, nämlich 11 mal, davon 3 mal doppelseitig.

Die Tatsache, daß in der Regel bei den Beckenbrüchen durch Compression Läsionen an der vorderen und an der hinteren Hälfte des Beckenringes zustande kommen, scheint mir ebenso wie die Multiplizität der Fissuren überhaupt nicht genügend beachtet worden zu sein. Wir pflegten bei Frischverletzten, bei denen man nach der Anamnese einen Beckenbruch zu vermuten Anlaß hatte, in der Wagnerschen Schule den Sitz mehrfacher Frakturen zunächst dadurch festzustellen, daß wir an dem in Rückenlage liegenden Patienten mit beiden Händen einmal auf die Spina ossis ilei anterior beiderseits einen leichten Druck ausübten und den Kranken fragten, ob dies weh tue. Dann pflegt derselbe zu antworten: „Da wo Sie drücken nicht, aber hier vorn (am Schambogen) und hinten (in der Gegend einer oder beider Kreuzdarmbeinfugen)." Danach drückt man mit der Hohlhand beiderseits gegen die Darmbeinkante nach vorn, so das Becken mehr von hinten her zusammenpressend. Auch so erhält man die gleiche Antwort, weil durch den erwähnten Druck auf den Beckenring von vorn oder von hinten her die Diastase der Fissuren vermehrt, bezw. vermindert und so Schmerz an den Bruchstellen ausgelöst wird. Diese gewiß vielenorts geübte Untersuchungsmethode verdient jedenfalls allgemeinere Anwendung.

Was die Läsionen am Kreuzbein, als Teilerscheinungen der typischen Beckenringbrüche, anbelangt, so erklärt sich ihre Erscheinungsform aus der Bedeutung des Kreuzbeins für den Beckenring uberhaupt. Er ist als ein Schaltknochen in den Ring eingefïgt, der sich nicht mit biegt, dessen Seitenteile aber vornehmlich unter seitlicher Pressung oft bersten. Die Läsionen sind Compressionsfrakturen verschiedenen Grades, durch Druck in frontaler Richtung; das Os sacrum wird also in anderer Richtung zusammengepreßt als die Wirbelkörper, bei denen die Compressionsfrakturen durch Druck, vornehmlich in vertikaler Richtung, zustande kommen. Daß die aus den Foramina sacralia austretenden Nervenwurzeln dabei zu Schaden kommen können, ist naheliegend. Darüber an anderer Stelle.

Bei leichteren Frakturen ist es die Regel, daß die Fissuren der vorderen und der hinteren Beckenringhälfte auf derselben Seite sitzen, also rechts am Scham-, bezw. Sitzbein und rechts in der Gegend der Kreuzdarmbeinfuge - gleichseitig. Aber auch gekreuzt rechts vorn, links hinten sieht man sie (4mal). Bei schweren 
Die Beckenbrüche m. Bemerkgn. üb. Harnröhren- u. Harnblasenzerreißungen. 513

Fällen können sie vorn oder hinten oder vorn und hinten doppelseitig sitzen, dann sind sie vorn wie hinten meist auf beiden Seiten symmetrisch. Vorn symmetrische fand ich nicht weniger als 12 mal. Sechsmal lief die Fissur vorn durch eines der Hüftgelenke.

Fall 12 (Fig. 14 und 15). Typische Beckenringfrakturen mit gekreuzter (diametraler) Anordnung der Fissuren, rechts vorn und links hinten oder umgekehrt. Dabei ein Beckenrandbruch.

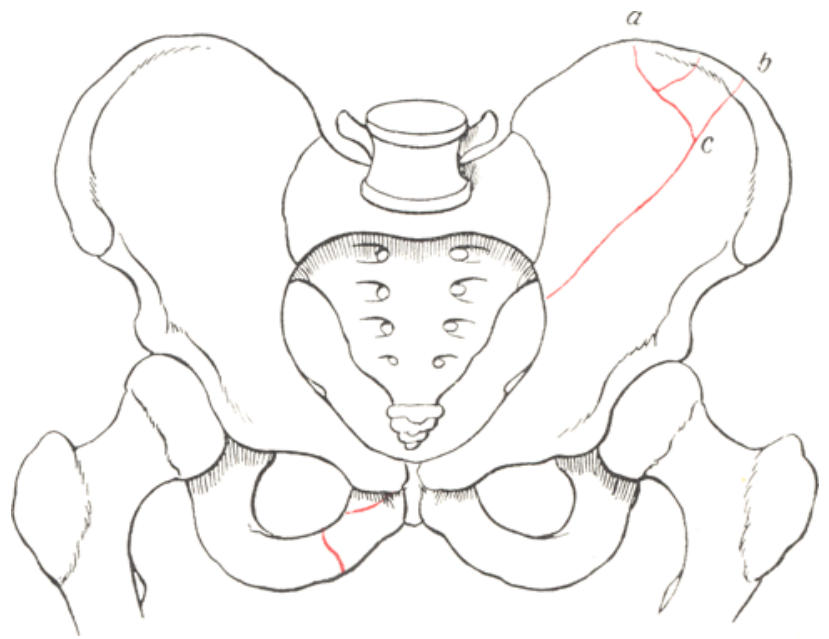

Fig. 14 .

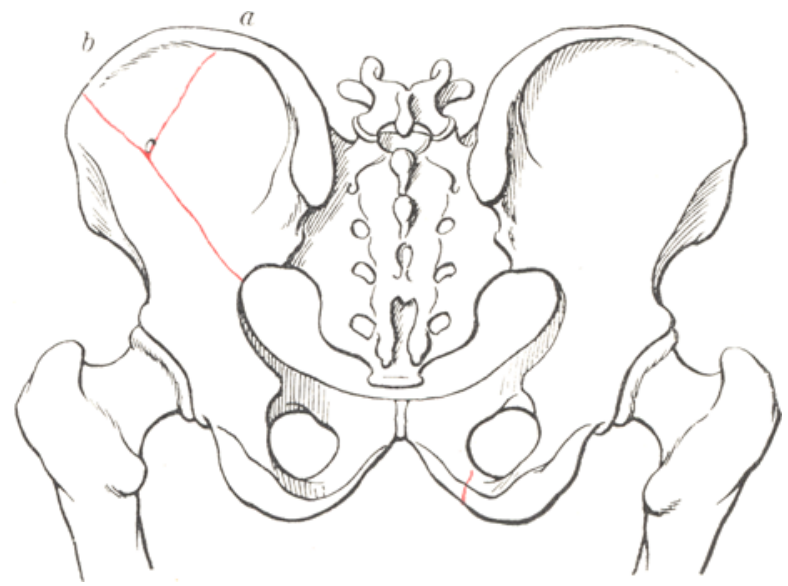

Fig. 15.

Dies Präparat stammt von einem durch Steinfall (Schädelbruch) getöteten Arbeiter, der in den Weichteilen uber dem linken Darmbeinkamm 
und über dem Lendenteil der Wirbelsäule ausgedehnte subcutane Blutergüsse zeigte. Er war in gebückter Stellung auf Rücken und Hinterkopf getroffen worden. Das dreieckige Fragment der linken Darmbeinschaufel (Beckenrandbruch) $(a, b, c)$ ist also vermutlich durch direkte Gewalt entstanden; dafür spricht auch der Abbruch des linken Querfortsatzes am 4. Lendenwirbel. Gewissermaßen in der Diametralen des Beckenringes liegt, fernab von der Einwirkungsstelle der Gewalt, auf der rechten Seite eine durch das Foramen obturat. dext. unterbrochene Fissur, welche den Ramus horiz, und den Schambogenschenkel durchsetzt. Hier ist die Schamfuge von der Fissur berührt, aber nicht im ganzen durchgebrochen.

Fall 13 (Fig. 16). Beckenring mit gekreuzter Anordnun'g der Fissuren in der vorderen und hinteren Beckenhälfte.

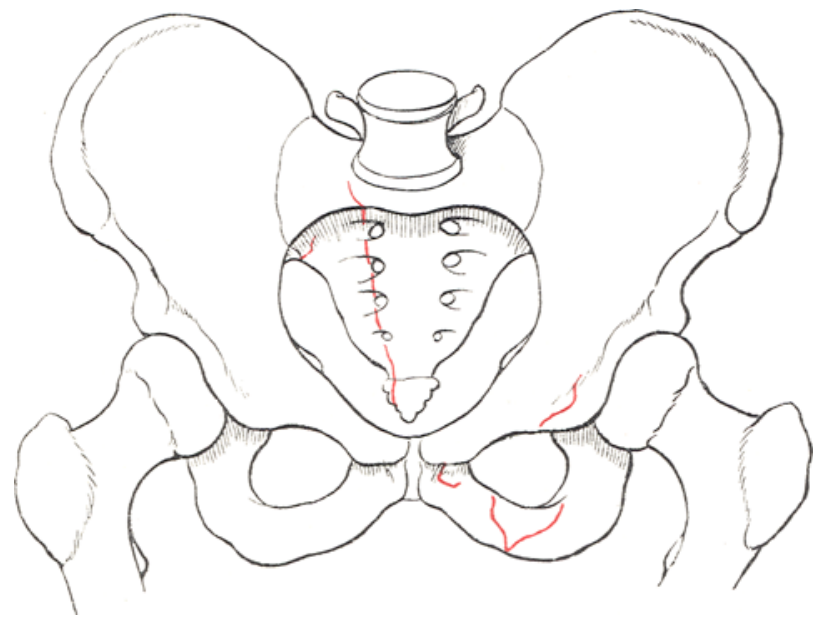

Fig. 16.

Von der Art des Zustandekommens ist nichts bekannt. Lange Fissur hinten durch die Foramina sacralia der rechten Seite des Kreuzbeins hinlaufend. Vorn sitzen die Fissuren linkerseits, und zwar im Ramus horizontalis nahe dem Hüftgelenk, im linken Schambogenschenkel eine doppelte Fissur. Außerdem ist eine leichte Splitterung links von der Symphysis pubis und hinten rechts dicht an der Zusammenfügung des Kreuzbeins mit der rechten Darmbeinschaufel sichtbar. An der langen Einknickungslinie, die durch das Kreuzbein zieht, ist das Moment der Compression direkt sichtbar. Es ist mehr eine Infraktion als eine Fraktur, denn an der Rückseite besteht die Fissur nicht.

Die Dislokation der Fragmente ist zwar vorwiegend schweren Fällen eigen, aber man sieht doch erhebliche Verschiebungen auch bei Fällen, die zur Ausheilung kommen. Wenn eine Dislokation z. B. an den Fissuren des linken Scham- und Sitzbeins 
nach unten statt hat, so rückt damit, auch ohne daß in der Kreuzdarmbeingegend eine wesentliche Verschiebung vorliegt, der ganze linke Hüftgelenkapparat ein wenig nach unten, das linke Bein erscheint verlängert. Solche scheinbare Verlängerung um $1-3 \mathrm{~cm}$ sieht man nicht selten bei ausgeheilten Frakturen, man findet dann in Gutachten über Unfallverletzte recht oft eine irrtümliche Auffassung der stattgehabten Verletzung. Die Messung von der Spina ilei ant. zum Kniegelenksspalt oder zum Malleolus internus ergibt an beiden Beinen gleiche Maße. Und doch hat der Patient selbst die Empfindung, daß sein linkes Bein seit der Verletzung länger ist. Betrachtet man ihn im Stehen von rückwärts, dann steht die Gesäßfalte links etwas tiefer, auch der Sitzbeinknorren ist links deutlich tiefer zu fühlen.

Diese Verlängerung oder Verkürzung des Beins kann noch größer sein, wenn in der vorderen und hinteren Fissurlinie eine Dislokation der Fragmente in höherem Grade stattgehabt hat.

Das ist bei der viel zitierten "doppelten Vertikalfraktur" von Malgaigne der Fall. Diese Frakturform ist im Grunde nichts Besonderes; sie ist nichts anderes als eine Beckenringfraktur, bei der sowohl die vordere, den Ring durchsetzende Fissurlinie wie auch die hintere ungewöhnlich nahe an den Hüftgelenksapparat herangerückt sind, so diesen in dem umschlossenen Segment herausschneidend. Kommt solche Fraktur z. B. durch Fall auf die Füße bei durchgedrückten Beinen zustande, wie dies von mir und auch früher schon beobachtet wurde (Fahrstuhlverletzung), dann ist eine Dislokation des ganzen Bruchstückes samt dem Hüftgelenk nach oben, also eine Verkürzung des Beins ohne weiteres erklärlich. Ich halte die alte Bezeichnung "doppelte Vertikalfraktur" für unzweckmäßig; die von Malgaigne unter diesem Namen beschriebene Frakturform ist weder dem Zustandekommen nach noch anatomisch etwas wesentlich anderes, als die Beckenringbiegungsbrüche überhaupt. Wollte man eine besondere Art anerkennen, so wären es die seltenen Fälle, bei denen durch Fall auf den Trochanter major der Oberschenkelkopf in die Pfanne so heftig hineingetrieben wird, daß diese birst oder durchbohrt wird. Dabei ziehen in der Regel auch Fissuren durch den ganzen Beckenring hindurch. Aber ganz isoliert, d. h. ohne sonstige Biegungsfissuren, dürfte dieser isolierte Pfannenbruch doch nur ganz ausnahmsweise zur Beobachtung kommen. 
Fall 14. 15. 16 (Fig. 17. 18. 19). Typische Beckenringbrüche; von Malaigne als "doppelte Vertikalfraktur des Beckens" bezeichnet (Fig. 17).

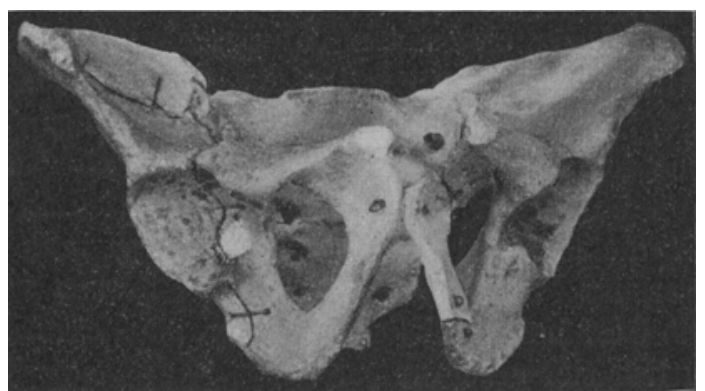

Fig. 17.

Asymmetrische Fraktur des vord. Beckenringes, rechts Pfannenbruch. Splitterung an der Symphysis pubis. Splitterbruch des rechten Os ilei.

Malgaigne sagt: „Ich werde unter dieser Bezeichnung einen vielfachen Bruch des Beckens beschreiben, welcher sich von allen anderen durch eine Art von RegelmäBigkeit unterscheidet, und welcher überdies unter der dreifachen Beziehung der Diagnose, Prognose und Behandlung ${ }^{1}$ ) eine besondere Aufmerksamkeit verdient. Es ist eine Vereinigung von zwei vertikalen Bruchen, die auf einer Seite des Beckens ein mittleres Fragment ausschneiden, welches das Hüftgelenk in sich schlieBt, und je nachdem dieses mittlere Fragment sich nach oben oder innen verfügt, folgt $\mathrm{ihm}$ das Femur in seinen Bewegungen, und von da Veränderungen in der Länge und Richtung des Gliedes, welche mehr als einmal die Praktiker zum Irrtum verleitet haben. Von diesen Bruchen nimmt der vordere fast immer den horizontalen und absteigenden Ast des Schambeins ein, indem er diesen Knochen vom Darm- und Sitzbein absondert; der hintere befindet sich immer hinter der Pfanne und meistens an dem Darmbein, einmal hat ihn indessen Richerand am Heiligbeine gesehen. Endlich kann anstatt des Bruches ein Auseinanderweichen der Symphysis sarcoiliaca statt haben. Gerdy hat ein Beispiel davon berichtet."

In dem vorliegenden Falle láuft die Bruchlinie durch den vorderen Beckenrahmen, durch den medianen Teil der rechten Hüftgelenkpfanne hin, nach unten durch den absteigenden Sitzbeinast, nach oben fast genau in der Synostosenlinie zwischen dem Ramus horizontalis ossis pubis und dem Os ilei, das ist durch die Incisura acetabuli zur Eminentia ileopectinea (Tuberculum ileopubicum). Rückwärts vom Acetabulum aber zieht zwar leicht zickzackförmig, aber im wesentlichen in der Vertikalen eine lange Bruchlinie von der Höhe des rechten Darmbeinkammes zum unteren Ende der Synchondrosis sacroiliaca, zuletzt ein Stück weit in dieser hinlaufend. Das das rechte Hufftgelenk umfassende Bruchstück aus dem Beckenringe lie $B$ sich an der Leiche bei einigem Kraftaufwande etwas

1) Malgaigne läßt also die Entstehungsweise unberücksichtigt. 
nach abwärts und aufwärts drücken, wurde aber durch die Muskeln und Bander in seiner normalen Lage erhalten, so daß von einer Verkürzung oder Verlängerung des Beines an der Leiche nichts zu bemerken war.

Auch am Schambein (Nähe der Symphysis pubis) und am Sitzbein der linken Seite fanden sich noch zwei Fissuren, und ein kleiner Sprung zog vom dritten linken Foramen sacrale zum freien Rande des Kreuzbeins.

Dem Verletzten war das Rad eines Lastwagens über die rechte Beckenhälfte und den Oberschenkel gegangen.

Vergleicht man das Bild der Bruchlinien dieses Falles, so wird man zugestehen müssen, daß es sich in keinem wesentlichen Punkte von demjenigen der übrigen Beckenringbiegungsbrüche unterscheidet, die man nach Malgaignes Auffassung fast alle als "doppelte Vertikalfrakturen" bezeichnen müßte. Denn immer läuft - die Fälle mit „gekreuzter Anordnung“ ausgenommen - die Bruchlinie einmal hinten vertikal durch Os ileum, bezw. Synchondrose, bezw. Kreuzbein, und gleichzeitig vorn vertikal durch Scham- und Sitzbein; es besteht also immer eine doppelte vertikale Bruchlinie, welche das Hüftgelenk zwischen sich faßt. Der Sitz der vertikalen Bruchlinie kann überaus mannigfaltig sein, das einheitliche Moment bei diesen Beckenbrüchen liegt in der Art ihres Zustandekommens, nämlich durch Zusammenpressung des ganzen Beckenringes. Es sind Beckenringbiegungsbrüche Nicht die Ausnahme bildet die doppelt vertikal verlaufende Fraktur, sondern durchaus die Regel, freilich kommt es nur verhältnismäßig selten zu so schwerer Dislokation, daß dies in einer Längenveränderung des Beines zum Ausdruck kommt. Aber gröbere Verschiebung der Fragmente ist bei den Beckenringbrüchen überhaupt verhältnismäßig selten.

Fig. 18 zeigt, was den Sitz der Bruchlinie anlangt, fast genau dieselben Verhältnisse wie Fig. 17, nur sind dieselben weniger ausgedehnt. Die Wiederkehr der durch die Incisura acetabuli und die Pfanne zum Tuberculum ileopubicum hinlaufenden Fissur läBt darauf schlieBen, daB diese Verbindungslinie (Knochennahtlinie) zwischen $0 \mathrm{~s}$ pubis und $O s$ ilei gute Vorbedingungen zum Zustandekommen eines Bruches darbietet.

Von vorn her sieht man auch eine Bruchlinie in der rechten Synchodrosis sacroiliaca, eine gewisse Lockerung bestand indeß auch an der linken. Endlich ist auch der rechte Schambeinschenkel (Ramus descend.) noch licht an der Symphysis pubis gebrochen; die Harnröhre war hier blutunterlaufen, nicht zerrissen.

Endlich gebe ich in Fig. 19 noch die Vorderansicht des oben schon geschilderten Präparates (Fig. 11) wieder, linkerseits ein typischer "doppelter Vertikalbruch" im Sinne von Malgaigne. 


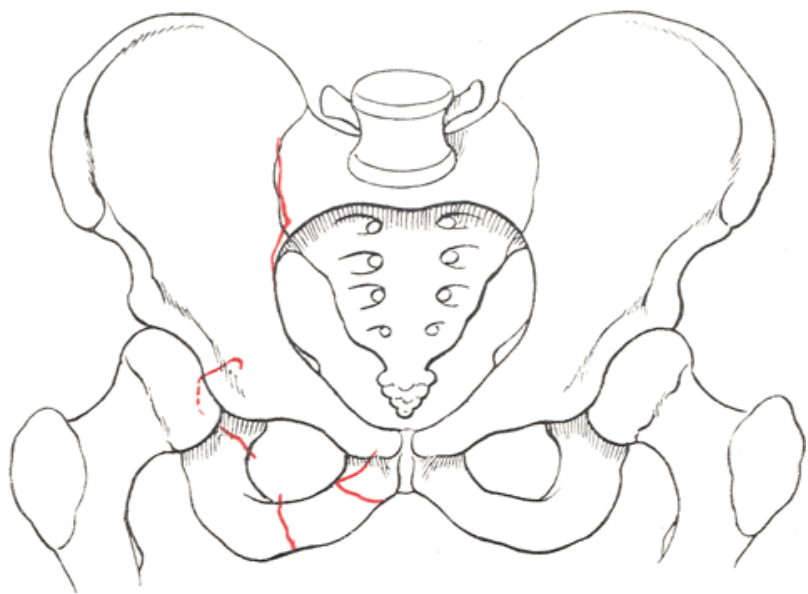

Fig 18.

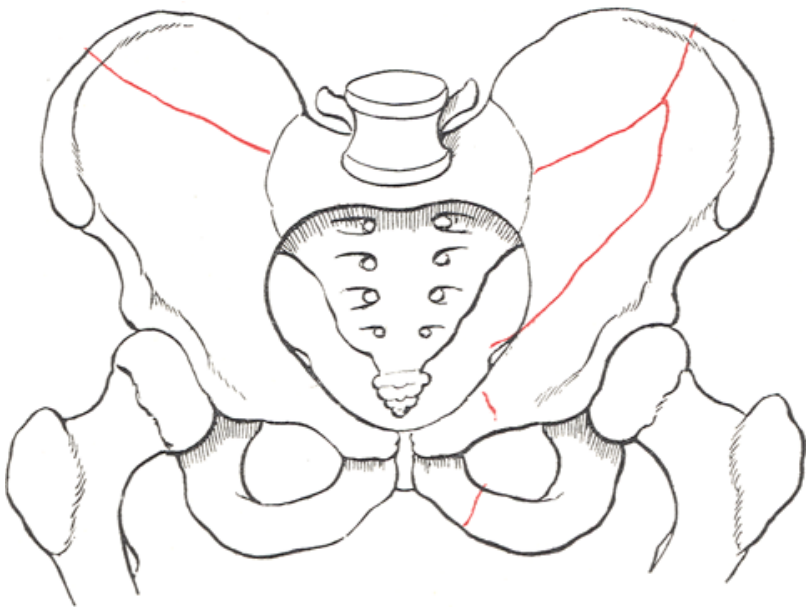

Fig. 19.

Die im Vorhergehenden gegebene summarische Schilderung der Haupttypen der Beckenbrüche ergab sich mir aus der Fülle der anatomischen Erscheinungsformen, die sich mir an dem selten reichen Material darbot. Zu den 33 macerierten Becken kommen aber noch eine Anzahl eigener Beobachtungen an Leichen, bei denen sich das Becken nicht entfernen und macerieren ließ. Die Maceration aber, bezw. die sorgfältige Präparation an dem vollständig herausgenommenen Becken ist nach meiner Erfahrung Vorbedingung, 
will man wirklich alle Läsionen der Beckenknochen, alle Sprünge Fissuren) übersehen.

Es können daher Protokolle über Obduktionen, welche diese Bedingung nicht erfüllen, meine Behauptung von der regelmäßigen Multiplizität der Läsionen bei Beckenringbrüchen nicht widerlegen. In dem Winkel, der hinter der Symphysis sacroiliaca beiderseits von der hinteren Ausladung der Darmbeinschaufel und dem Kreuzbein gebildet wird, in der Concavität des letzteren können Fissuren und Compressionseffekte leicht übersehen werden, da abnorme Beweglichkeit bei geringfügigerer Zerstörung natürlich oft fehlt. Für die Deutung zahlreicher vorübergehender klinischer Symptome, z. B. leichter Lumbal- bezw. Sacralwurzelläsionen ist eine sorgfältige Erforschung gerade dieser Gegend bei Beckenverletzungen sehr erwünscht. Dann steht die Aufklärung mancher bis jetzt noch nicht genügend aufgehellter Erscheinungen bei verhältnismäßig geringfügigen Beckenquetschungen zu erwarten.

Es ist unmöglich, von meiner gesamten Beckensammlung sorgfältig gezeichnete Abbildungen jedes einzelnen Präparates zu geben, da ein jedes mehrere Aufnahmen erfordern würde. Ich habe deshalb nur in Skizzen die hauptsächlichsten Typen wiedergegeben, indem ich die Bruchlinien annähernd naturgetreu in ein Schema eintrug. Wer sich nicht an unwesentliche Abweichungen vom Haupttypus ohne Not klammert, dem kann meines Erachtens die Gesetzmäßigkeit in Sitz und Form der Frakturlinien bei der Betrachtung dieser Bilder nicht entgehen.

Auf die für die Prognose der Beckenverletzungen und für die Diagnose, wie schon Malgaigne hervorhebt, so überaus wichtigen Verletzungen der Hüftgelenkpfanne muß ich noch mit einigen Worten eingehen. Bei den allerschwersten Zertrümmerungen des Beckenringes, bei denen so viel Frakturen vorliegen, daß man eine Gesetzmäßigkeit nicht wohl mehr verlangen kann, weil direkte und indirekte Gewalt in allzu großer Stärke durcheinander wirken und gleichzeitig an zu vielen Punkten einsetzen, wie dies bei Eisenbahnverletzungen, Sturz aus der Höhe mit vielfachem Aufschlagen der Fall ist. Hier finden wir die eine oder andere Hüftgelenkpfanne in der Regel mit geborsten, meist in einer sternförmigen Bruchlinie. Dann sieht man den Oberschenkelkopf in das Beckeninnere hineingetrieben. Nicht bloß die Blase ist von den Fragmenten des Schanıbeins angestochen, anch die Harnröhre ist zerrissen, auch der Darmkanal gelegentlich eröffnet oder durch die Bruckstücke vorgefallen, von ihnen eingeklemmt. Diese Fälle entbehren oft des chirurgischen 
Interesses, weil die Verletzten infolge dieser oder anderer Verletzung in der Regel sofort tot sind. Uns interessieren vielmehr die leichteren Verletzungen des Hüftgelenkes. Da wird man einen Unterschied machen müssen zwischen denjenigen, welche man nach der Art der Entstehung als Teilerscheinung eines Beckenringbiegungsbruches aufzufassen hat und zwischen den durch direkte Gewalteinwirkung entstandenen isolierten Hüftgelenkpfannenbrüchen. Freilich werden sich beide Arten gelegentlich auch kombinieren. Es kann nicht meine Aufgabe sein, im Rahmen dieser Arbeit auf die Pfannrandbrüche einzugehen, wie sie sich nicht selten zu Luxationen hinzugesellen, die Diagnose wie die Behandlung meist gleicherweise sehr erschwerend.

Dagegen ist hervorzuheben, daß bei Fall auf den Trochanter major, aber auch bei Fall aus der Höhe mit durchgedrückten Beinen auf die Füße Sprengungen der Hüftgelenkpfanne beobachtet sind.

Als Teilerscheinung des Beckenringbiegungsbruches ist die Pfannenverletzung bei mehreren meiner schon beschriebenen Präparate (Fig. 3, 15, 16) und bei zwei noch folgenden anzusehen. Was aus meinen Skizzen nicht ersichtlich sein kann, das lehren die Originale, nämlich, daß die Fissuren hier im Hüftgelenk gern der Linie der ursprünglichen Zusammenfügung der hier fest aneinander gefügten Knochen folgen. Es ist die auch am macerierten Becken des Erwachsenen in der Regel nicht mehr erkennbare Synostosenlinie zwischen Os ilei, Os pubis und Os ischii. Die Incisur des Beckenringes, welche gegen das Foramen obturatorium hinliegt, ist ja eine gegebene schwache Stelle für die das Foramen überspringende Bruchlinie, sie setzt sich in leichteren Fällen isoliert durch die Fossa acetabuli zum Tuberculum ileo-pectineum fort. Wir werden später einen Fall kennen lernen, welcher lehrt, daß diese Verletzung bei Harninfiltration einen verhängnisvollen Wanderpfad für Infektionsstoffe abgeben kann.

Fall 17 (Fig. 20). Beckenringbruch mit beiderseitiger Hüftgelenkverletzung. Typus der alten Malgaignefractur.

Das von einem Überfahrenen herstammende Präparat läßt trotz der Vielheit der Knochensprünge doch immer noch eine gewisse Symmetrie im Sitz der letzteren erkennen. Für besonders beachtenswert halte ich die Fissuren dicht am Hüftgelenk beiderseits an correspondierender Stelle des horizontalen Schambeinastes, an einer Stelle, die auch an zahlreichen anderen Präparaten eine Fissur, manchmal auch nur eine Infraktion, wie hier oberhalb der rechten Pfanne, zeigt. Daß von hier bei gröBerer Gewalteinwirkung Fissuren über den Pfannenrand in die Gelenkhöhle hineinlaufen, wie dies links der Fall, ist naheliegend. Die Verletzung des Pfannen- 
randes, die man klinisch bei alten Beckenverletzten recht oft aus Abductionsbeschränkung des Beines annehmén muB, erklärt sich daraus, daB eine Prädispositionsstelle für Bruch am Horizontalast so nahe an der Gelenkpfanne liegt, wie dies die Abbildung veranschaulicht.

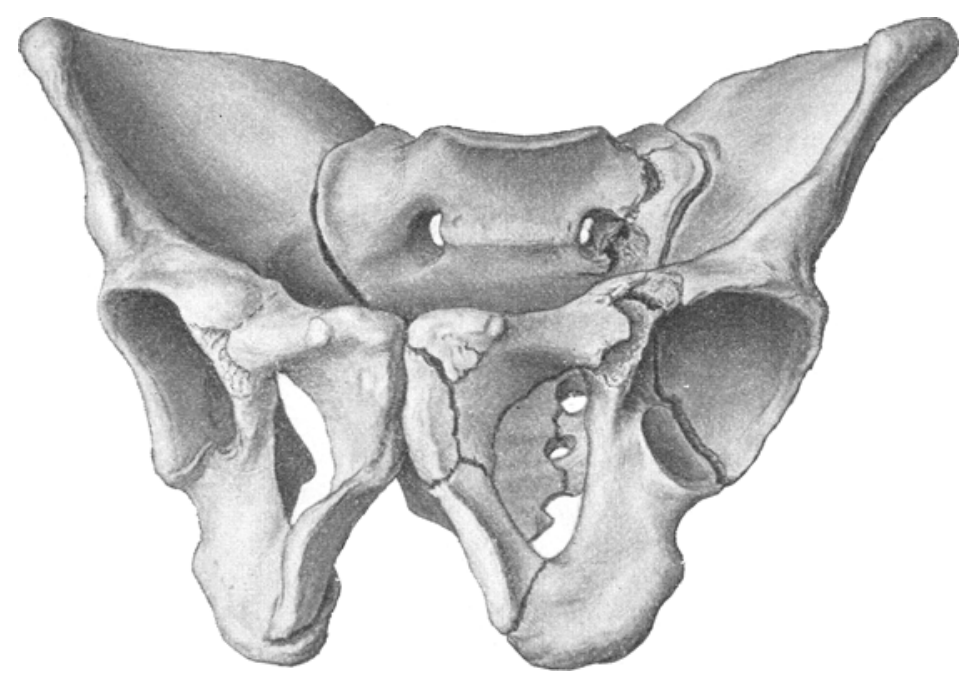

Fig. 20.

Zahlreiche Frakturen am vord. Becken, links Pfannenbruch, Linlssseitiger Bruch des Os sacrum durch sámtliche Foramina.

Die lange Fissur, welche durch die linken Foramina sacralia hinläuft, hat einen wiederholt an meinen Präparaten beobachteten Sitz.

Die Fissuren des Schambogens haben typischen Sitz. Und es ist aus der Abbildung erklärlich, daß sich solche Fragmente, wie sie linkerseits in diesem Falle vorbanden sind, bei Harninfiltration leicht sequestrieren.

Fall 18 (Fig. 21 und 22). Beckenringbruch mit Fissur durch lie rechte Huftgelenkpfanne. Typus Malgaigne rechts.

Über das aus dem pathologischen Institut zu Breslau stammende Präparat sind nähere Angaben über die Entstehung des Bruches nicht vorhanden. Es zeigt eine Abweichung von dem gewöhnlichen Typus, indem die Fissuren an der vorderen Beckenhälfte nicht ganz symmetrisch sitzen. Die Fissur rechterseits läuft durch das Sitzbein vom Tuber aus aufwarts durch die Hüftgelenkpfanne, ähnlich wie in Fig. 18. Linkerseits ist der Sitz der Fissuren nicht correspondierend, indem in der Nähe der Symphyse unregelmäBig verlaufende Sprünge liegen, die indes eine eigentliche Symphysentrennung nicht hervorrufen.

Die Kreuzbeinfissur, nur an der Rückseite (Fig. 22) in ganzer Ausdehnung erkennbar, läuft zwischen den Foramina sacralia durch die Mitte hin, den Wirbelkanal eröffnend. Vorn ist nur ein feiner Sprung im untersten Teil des Os sacrum zwischen 3. und 4. Foramen sacrale sichtbar, aber auch eine minimale Fissur an der rechten Synchondrose. 


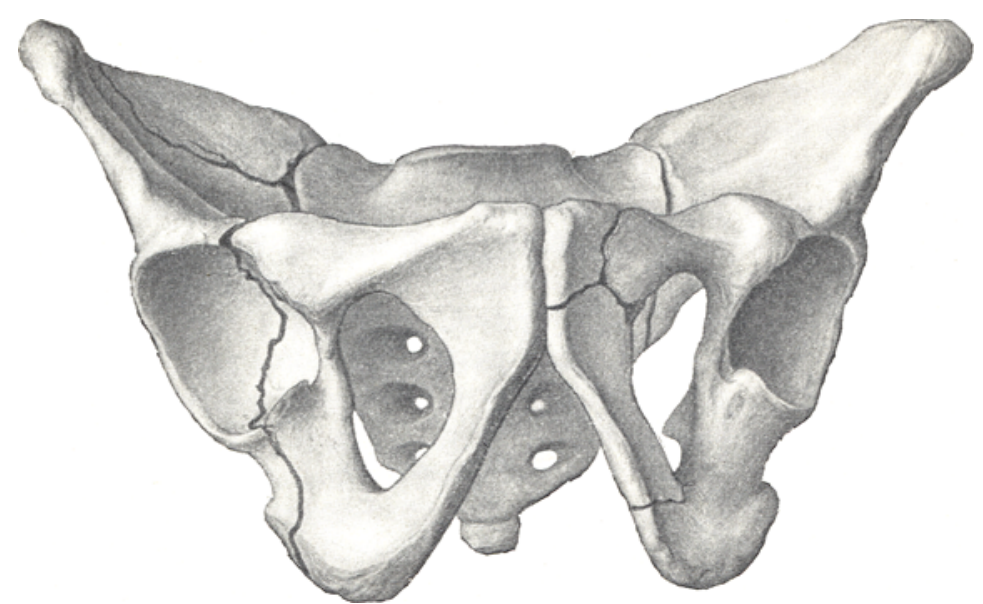

Fig. 21.

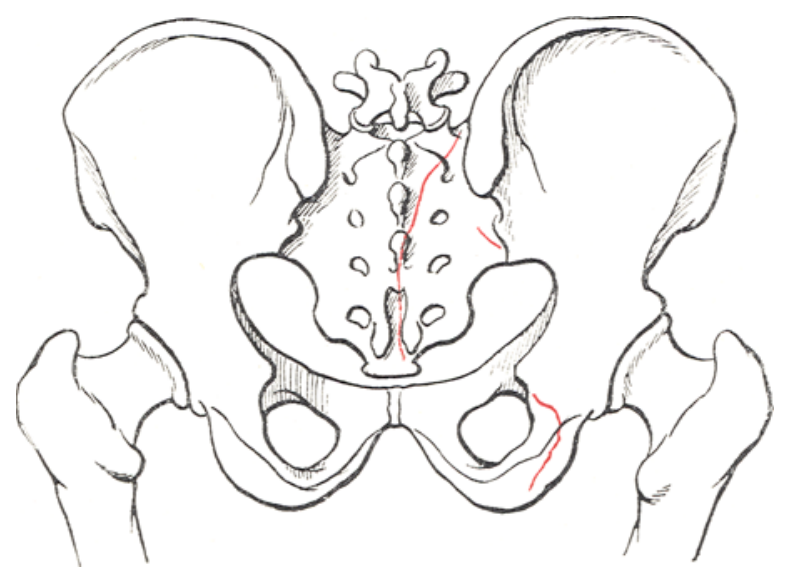

Fig. 22.

Wenn ich noch auf die Beschaffenheit der Frakturen kurz eingehen darf, so kann sich kein Beobachter einer größeren Anzahl von Beckenbrüchen dem Eindruck entziehen, daß auch die Art und das Aussehen der Bruchlinien auf die Entstehung durch Compression des Beckenringes hinweist. Das läßt sich schwer beschreiben, während beim Betrachten die Ringform in der Knochenanordnung mit der Splitterbildung zu diesem Eindruck zusammen wirkt. Ich habe einzelne Präparate, an denen man sieht, wie z. B. der horizontale Schambeinast in die laterale Knochenanschwellung am Hüftgelenksrande hineingetrieben erscheint, wie 
sich Spähne von der Linea innominata ablösen, mit einem freien, gelösten Ende ins Beckeninnere hineinfallend. Aber auch am Kreuzbein sind die Zeichen frontaler Zusammenpressung gegeben, indem der freie Rand, der die vordere Grenzlinie mit dem Darmbein bildet, eingebrochen erscheint, oder die Massae laterales bersten in der Richtung der Sacrallöcher.

Das möchte ich nochmals hervorheben, daß ich mit Ausnahme eines einzigen Falles, der später noch beschrieben und abgebildet werden soll, kein Becken gesehen habe, an dem man eine Luxation (Diastase) in einer der Symphysen fände. Eine wirkliche Diastase, eine lediglich auf die Symphyse beschränkte Zusammenhangstrennung kann bei äußeren Traumen allenfalls in der Schambeinfuge vorkommen, nicht aber in den Kreuzbeinfugen. Ich glaube daher, daß die noch von König (im Lehrbuch) angeführte Malgaignesche Einteilung der Symphysentrennungen des Beckens in solche 1. der S. pubis, 2. der Symphysis sacroiliaca, 3. dieser beiden mit einander (Luxation des Darmbeins), 4. der beiden Symphyses sacroiliacae (Luxation des Krenzbeins), 5. der 3 Symphysen fallen gelassen werdev muß, weil sie durch die praktische Erfahrung nicht begündet ist. Es gibt keine reine Lnxation des Kreuzbeins oder des Darmbeins in dem Sinne, daß genau in den Symphysenlinien eine Verschiebung des einen oder anderen Knochens vorkäme. Fällt einmal ausnahmsweise die Continuitätstrennung in eine der Symphysen, so greift die Fissur so gut wie immer auch darüber hinaus and kann als Fraktur und als Teilerscheinung des Beckenringbiegungsbruches angesehen werden. Man könnte nur, wie an der Wirbelsäule, von Luxationsfraktur sprechen.

Die später im klinischen Teil noch zu erörternde Lockerung in der Gegend der Kreuzdarmbeinfuge, von der man gelegentlich spricht, ist nicht blos als Bandzerrung sondern auch als Knochenverletzung aufzufassen; denn es wird in der Regel auch eine Fissur dahinterstecken.

Endlich möchte ich im Hinblick auf meine Präparate (Fig. 6, 8 , 14) noch betonen, daß Beckenrandbrüche durch direkte Gewalt und Beckenringbiegungsbrïche sich naturgemäß gelegentlich combinieren. Am häufigsten ist ein Randbruch der Darmbeinschaufel mit multiplen Effekten der akuten Biegung an typischen Stellen vereint zu beobachten. Der scharfe Rand des Wagenrades, welcher über die Beckenrundung hinläuft, bricht leicht am Darmbein ein Dreieck heraus, oder die ganze Ausladung der Beckenschaufel springt ab. Aber auch am Kreuzbein kam ein Bruch durch 
direkte Gewalt, also eine Querfraktur neben den Spuren des typischen Biegungsbruches zll meiner Beobachtung.

Fall 19 (Fig. 23 und 24). Beckenringfraktur mit atypischer Querfraktur des Kreuzbeins.

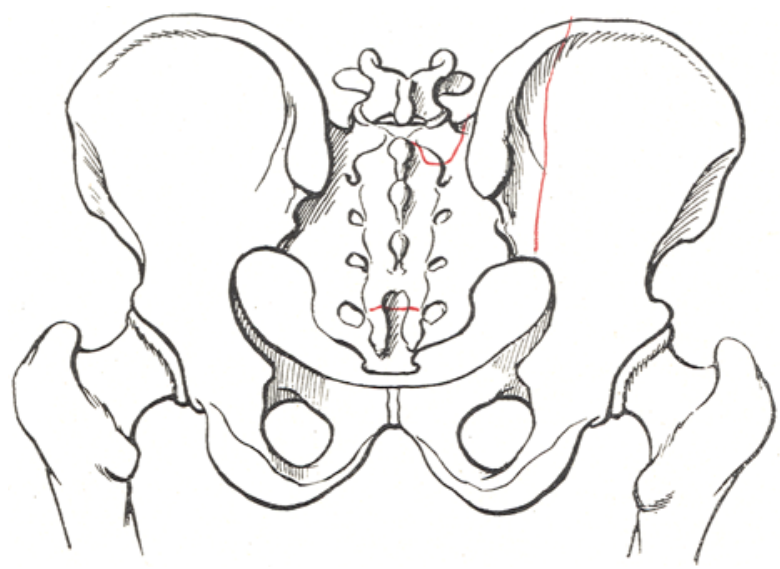

Fig. 23.

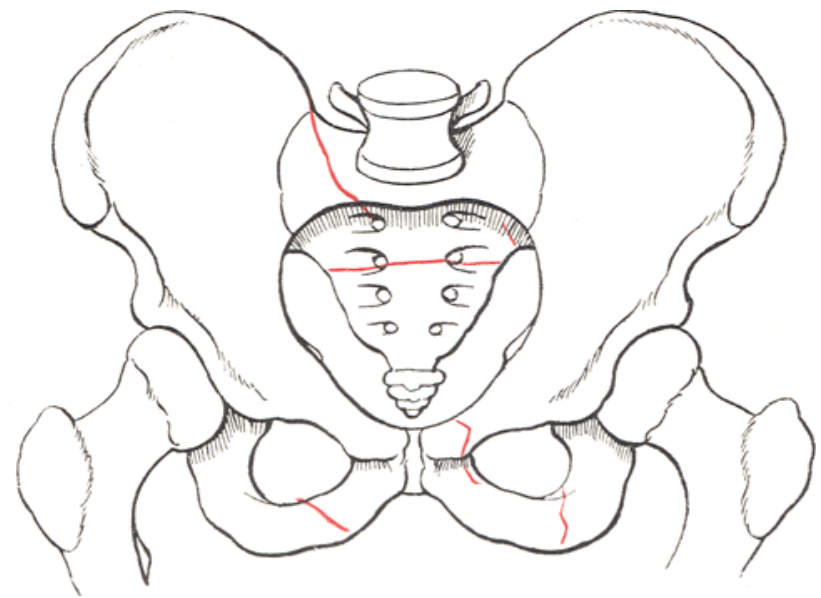

Fig. 24.

Das Präparat stammt von einem aus grosser Höhe abgestürzten, sofort verstorbenen (Commotio cerebri) Manne. Der Sitz und die Beschaffenheit der äußeren Verletzungen ließ darauf schließen, daß der Verunglückte mit der rechten Körperseite und dem Rücken aufgeschlagen war.

Es fand sich außer einem Schädelbasisbruch und Rippenbrüchen rechterseits eine Anzahl von Fissuren am Becken, die im Bereich des 
Sitz- und Schambeins annähernd typischen Sitz haben. Am Kreuzbein aber ist außer einer Fissur durch die rechte Massa lateralis, die an der Vorder- wie an der Rückfläche sichtbar ist, eine Querfraktur zu finden. Die Bruchlinie zieht vorn durch das zweite Paar der Foramira sacralia, über diese hinaus das ganze Kreuzbein durchsetzend; hinten dagegen sitzt sie tiefer, hier das 4. Paar der Kreuzbeinlöcher verbindend. Außerdem sieht man von hinten her noch eine Fissur in der rechten Darmbeinschaufel. Querfissuren des Kreuzbeins als Teilerscheinung von Beckenringbiegungsbrüchen scheinen selten. Ein Präparat (Fig. 25) scheint mir besonders beachtenswert.

Fall 20: Isolierte Kreuzbeinfraktur. Vermutlich Compressionsbruch im Sinne der Wirbelsäulencompressionsfrakturen. Hinten Querfissuren. Vorn Absprengung eines Stücks durch Längsfissur.

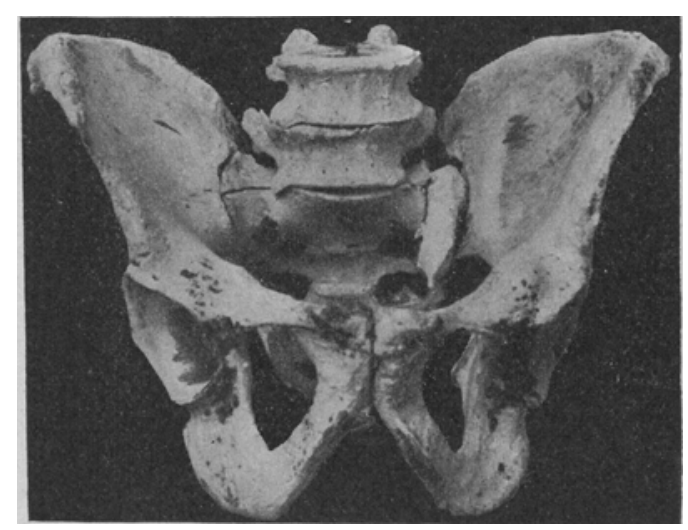

Fig. 25.

Isolierte Querfraktur des Kreuzbeins.

Der tötlich Verletzte war mit einem Gerüst durchgebrochen und 3 Stockwerk abgestürzt. Schädellochbruch, Compressionsbruch des 11. und 12. Brustwirbels, Bruch des rechten Oberarms. --

An der Vorderfläche (Fig. 25) sieht man von der Seite der linken Kreuzbeinhälfte ein Bruchstück, das in der Synchondrose ebenfalls gelockert war, etwa $3 \mathrm{~cm}$ nach vorn dislociert. Vom oberen Ende dieses offenbar herausgepreBten Fragments läuft eine Fissur durch die Zwischenwirbelspalte horizontal zur anderen Seite bis weiter zur Synchondrose, die ebenfalls am frischen Präparat gelockert war.

In der Rückseite läuft eine Fissur vom obersten Kreuzbeindornfortsatz schräg durch das zweite Foramen sacrale dext.

Die Weichteilquetschungen am GesäB und die Kreuzbein- und Wirbelfrakturen lassen annehmen, daB der Sturz auf das GesäB, vielleicht direkt auf das 0 s sacrum erfolgt ist. Wir hatten es also hier mit einer direkten Fraktur des Kreuzbeins zu tun. 
Überblicke ich die große Zahl meiner Präparate, so fällt vor allem auf, daß unter ihnen Luxationen oder besser reine Diastasen in den Synchondrosen des Beckenringes, wie sie von Malgaigne und nach ihm von vielen anderen theoretisch immer wieder angenommen werden, überhaupt nicht vorkommen. Es wäre vielleicht allzu kühn sie nun gegenüber einem, wenn auch großen, doch keineswegs alle Varietäten erschöpfenden Material ganz leugnen zu wollen. Aber da es an sich schon etwas Mißliches ist, am Becken von Luxationen zu sprechen, da doch keine einzige der knöchernen Aneinanderfügungen ein Gelenk im landläufigen Sinne darstellt, so halte ich es für zweckmäßig, den Begriff Beckenluxation gänzlich fallen zu lassen, selbst wenn einmal eine wirklich genau auf beide Synchondroses sacroiliacae fallende Parallelfissur beobachtet werden sollte oder zwei Bruchlinien, von denen eine genau in der einen Kreuzdarmbeinfuge, die andere genau in der Symphysis pubis verlief. Wer die Malgaigneschen Ausführungen im Original nachliest, wird heut keineswegs ganz überzeugt davon sein, daß jene Fälle, die er als Lnxationen beschreibt, in der Tat obige Anforderungen erfüllen. Alle Kasuistik der späteren Zeit aber steht zu sehr unter dem Einfluß von Malgaignes Autorität, als daß sie sich von der Einteilung in Frakturen und Luxationen freimachen konnte. Ich komme auf diesen Punkt noch zurück, wenn ich die Literatur der Beckenverletzungen berücksichtige.

Die spätere Erörterung der klinischen Symptomatologie erleichtert es vielleicht, wenn ich noch voranstelle meine eigenen pathologisch-anatomischen Erfahrungen sowohl über die Beschädigung der Weichteile der Beckenumgebung und des Beckeninnern (ausgenommen Harnröhre und Harnblase, deren Verletzungen zweckmäßig gesondert behandelt werden) als auch über die anatomische Heilung der Beckenbrüche.

\section{Weichteilverletzungen bei Beckenbrïchen.}

Die äußeren Beschädigungen der Haut nnd der Weichteile bei Beckenbrüchen geben vielfach eine Erklärung für die Art der Entstehung. Sie sind daher bei legalen Sektionen besonders zu beachten und am Lebenden manchmal Fingerzeige, wo man etwa Knochenverletzungen, die unter den starken Weichteilen nicht fühlbar, zu suchen oder zu vermuten hat. So führen Pferdehufschläge oft zu Beckenrandbrüchen, Fußtritte können auch ohne Beckenbruch zu Harnblasenzerreißung Anlaß geben, ohne daß auch äußer- 
lich an den Banchdecken Spuren des Traumas vorhanden sind. Beim "Puffern", das ist beim Zusammenquetschen des Beckens durch aufeinander stoßende Eisenbahnwagen, findet man auf zwei diametral entgegengesetzten Stellen des Beckenumfanges Blutergüsse in der Musknlatur, Hautabschürfungen. Aber das sind Quetschungseffekte, die sich in nichts von denjenigen irgend einer anderen Körperstelle unterscheiden.

Dagegen scheint mir die Beckenumgebung ein Lieblingssitz des Décollement traumatique zu sein; ich meine das von MorelLavallée und Gusserbauer als eigenartige Verletzungsfolge mit Recht herausgehobene traumatische Lymphextravasat. Fs kommt (vergl. meine Arbeit über die ihrer Natur nach gleichartige sogenannte Meningocele spuria traumatica), durch tangential einwirkende Gewalten zustande. Solche liegen besonders häufig bei Überfahrenen vor. Das sich drehende Rad, welches über den Beckenteil hinläuft, schält besonders gern an der Außenseite des Oberschenkels, in der Trochantergegend und an der Regio lumbosacralis Haut und Weichteile von der festen Unterlage ab. Es kommt so mit oder ohne äußere Wunde zu einer ausgedehnten Taschenbildung zwischen Haut und Muskelfascie oder zwischen einzelnen Muskelbäuchen oder zwischen diesen und dem darunter liegenden Periost. Aus den dabei zerreißenden Lymphgefäßen ergießt sich seröse Flüssigkeit, die in manchen Fällen noch nach Wochen nicht zum Stehen kommt. Je nachdem anch Blutgefäße mit zerrissen sind, ist dieses Lymphextravasat mehr oder weniger bluthaltig. Ein Beispiel:

Fall 21. Beckenrandbruch mit traumatischem, subkutanen Lymphextravasat der Kreuzbeingegend.

Am 17. Oktober 1901 machte ich mit Herrn Professor Dr. LesserBreslau die gerichtliche Obduktion der Leiche eines 9 jährigen Mädchens,

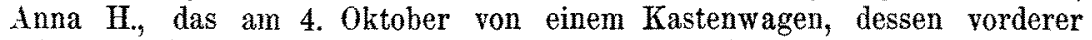
"Schieblich" herausfiel, herabstürzte und überfahren wurde. An der Leiche fand sich unterhalb der linken Spina ossis ilei anterior ein talergroßer Hautdefekt, der unter der Behandlung eines deswegen angeklagten Kurpfuschers zur Eingangspforte einer septischen Infektion geworden war. Am linken Darmbein war ein $12 \mathrm{~cm}$ langes, etwa $4 \mathrm{~cm}$ breites Randstück abgebrochen, von Periost entblößt, von Eiter umspült.

Hier nun fanden wir in der Regio lumbosacralis ein mächtiges Décollement traumatique, an einer Stelle, wo der zur ersten Hilfe gerufene Arzt bald nach der Verletzung nur Schmerzhaftigkeit, keinerlei Geschwulstbildung beobachtet hatte.

Bei der Sektion fühlte man äuBerlich eine grosse, undulierende Anschwellung, deren höchste Erhebung man durch Wegdrücken des Inhalts 
verschieben kann. Die leichteste Berührung löst Wellenbewegungen aus, welche vom Steißbein bis zu den oberen Lendenwirbeln hin reichen und sich seitlich beiderseits bis handbreit von den Dornfortsatzen hinweg bemerkbar machen. Beim Einschneiden durchtrennt man Haut, Unterhaut und eine Fascienlage, dann ergießt sich aus einer riesigen Tasche dünne, nirgends geronnene, blutig verfärbte Flüssigkeit, die indes für Blut zu dünn erscheint. In der Tiefe der Tasche liegen die Fascien der Lendenmuskeln frei, nur nach den Seiten hin hat die quetschende Gewalt die Muskulatur selbst eingerissen, aus der offenbar die Blutbeimengung des Tascheninhaltes stammt. Im Bereich des Kreuz- und Steißbeines ist die Haut direkt von diesen abgeschält. In den peripheren Teilen der Höhle ziehen sehnenfädenartige dünne Balken von der Unterlage zur Haut frei durch den mit Flüssigkeit erfüllten Hohlraum, dessen Begrenzung nach oben hin eine $5 \mathrm{~cm}$ breite Zone stark blutig durchtränkter, blauroter Muskulatur billet, über welcher wiederum ein stark wässrig durchtränktes Unterhautfett liegt. Die Höhle mochte im ganzen $75-100 \mathrm{ccm}$ Flüssigkeit enthalten; diese coagulierte im Glase nicht, setzte bald eine dunkelrote Schicht ab, während die Oberschicht das Aussehen gelber, wasserheller, seröser Flüssigkeit hat. Mikroskopisch wurde sie nicht untersucht.

Auch ausgeheilt sah ich ein solches durch Überfahren entstandenes Décollement, und zwar am Oberschenkel.

Fall 22. Décollement am Oberschenkel bei Beckenquetschung.

Ein Feldartillerist R. M., der in Peking von einem Fouragewagen überfahren worden war, stellte sich mir zur Untersnchung für seinen neuen Beruf. Er gab an, das Hinterrad eines leeren Lastwagens sei über seinen linken Oherschenkel an dessen Innenseite hingelaufen, vom Knie bis zur Leistenbeuge und dann weiter über den linken Darmbeinkamm. Danach sei eine schwappende Schwellung entstanden, die sich von der Mitte des Oberschenkels bis unter die Haut der Bauchdecken, handbreit über der Leistenbeuge hinzog. Drückte er unten mit der Hand darauf, so wurde die Geschwulst oben am Bauche größer. Herr Professor Perthes-Leipzig hat einen $5 \mathrm{~cm}$ langen Einschnitt on unterster Stelle gemacht, durch diesen angeblich 3 Liter mehr wässriger, als blutiger Flüssigkeit entleert. Danach wurde es alsbald so, wie es zur Zeit meiner Untersuchung war. Nur eine geringe Derbheit erinnerte an das Lymphextravasat; die Haut hatte sich überall glatt angelegt.

Von Verletzung der großen Schenkelgefäße oder des Mastdarms habe ich keinen Fall selbst beobachtet, in der später zu berücksichtigenden Literatur sind solche mitgeteilt. Dagegen sah ich bei schwerster, sofort tödlicher Zertrümmerung des Beckens, wobei der abgebrochene Schenkelhalskopf in den Binnenraum eingebrochen war, eine Einklemmung einer Dünndarmschlinge zwischen den Fragmenten der linken Seite.

An den Muskeln des Beckeninnern, am Psoas major, lliacus internus, Obturatorius internus sieht man vielfach Blutungen, welche auf eine darunter sitzende Fraktur hinweisen. Das Beckenbinde- 
gewebe ist bei Kreuzbeinbrüchen in dessen Excavation oft stark durchblutet; ich vermute, daß dies manchmal den Anlaß zu Blasenlähmung oder vielmehr zu Harnverhaltung geben mag ${ }^{1}$ ). Auf Blutungen in den Canalis sacralis ist meines Wissens noch nicht geachtet worden, und ich selbst habe auch verabsäumt, bei Frakturen des Kreuzbeins am frischen Präparat darauf zu fahnden. Paresen der Beinmuskeln, neuralgische Erscheinungen dürften auf Durchblutung und Zerrung der sacralen Nervenwurzeln ebenso häufig wie auf Zerreißung solcher zurückzuführen sein. Das Rückenmark selbst kann bei Beckenverletzungen nicht unmittelbar in Mitleidenschaft gezogen werden, da sein Stamm nicht bis in das Kreuzbein herabreicht. Es stehen mir nicht alle meine Obduktionsprotokolle über Beckenverletzte mehr zur Verfügung; ich würde auch ermüden durch die eingehende Wiedergabe aller Einzelheiten und aller Nebenverletzungen. Das möchte ich nur hervorheben, wenn der Tod sich nicht aus einer Organverletzung ohne weiteres erklären läßt, muß man daran denken, daß der Tod infolge von Fettembolie der Lungen eingetreten sein kann. Gerade bei Beckenbrüchen spielen schwere Gewebsquetschungen, daneben herlaufende Knochenbrüche mit Markzertrümmerung immer eine Rolle und so kommt es gerade bei ihnen gelegentlich zu weitgehender Überschwemmung des Lungenkreislaufs mit flüssigem. Fett. Man wird also den mikroskopischen Nachweis von Fett in den Lungenkapillaren in allen bezüglich der Todesursache unklaren Fällen, aber zweckmäßig auch sonst machen müssen und er ist bekanntlich ohne große Mühe ausführbar.

Fall 23 (Fig. 26). Beckenringbruch, Oberschenkelfraktur. Tod durch Fettembolie. (Abbildung s. nächste S.)

Das in der Fig. 26 skizzierte Becken stammt von einem 25jährigen Feuerwehrmann, der aus der Höhe abstürzte und auf die linke Beckenseite fiel. Er hatte außer den in der Skizze angedeuteten Bruchlinien durch beide Darmbeinschaufeln und den Fissuren am linken Scham- und Sitzbein einen Bruch des linken Oberschenkels erlitten und zeigte, nachdem er sich von einer leichten Hirnerschütterung erholt hatte, die allmảhlich stärker werdenden Zeichen von Lungenödem, dem er nach 3 mal 24 Stunden erlag; mikroskopisch ließ sich eine außerordentliche Überschwemmung der Lungen durch Fett nachweisen.

Fall 24. Beckenbruch, Tod durch Fettembolie.

Ebenfalls als alleinige Todesursache muBte Fettembolie der Lungen angesehen werden bei einer 44jährigen Frau, die aus dem Fenster des ersten Stocks sprang und auf Steinfliesen aufschlug: Bruch des r. Darmbeins und des r. Scham- und Sitzbeins, sonst keine ernsteren Verletzungen. sitzt.

1) L. R. Müller ist ja der Ansicht, daß die Blaseninnervation extraspinal 


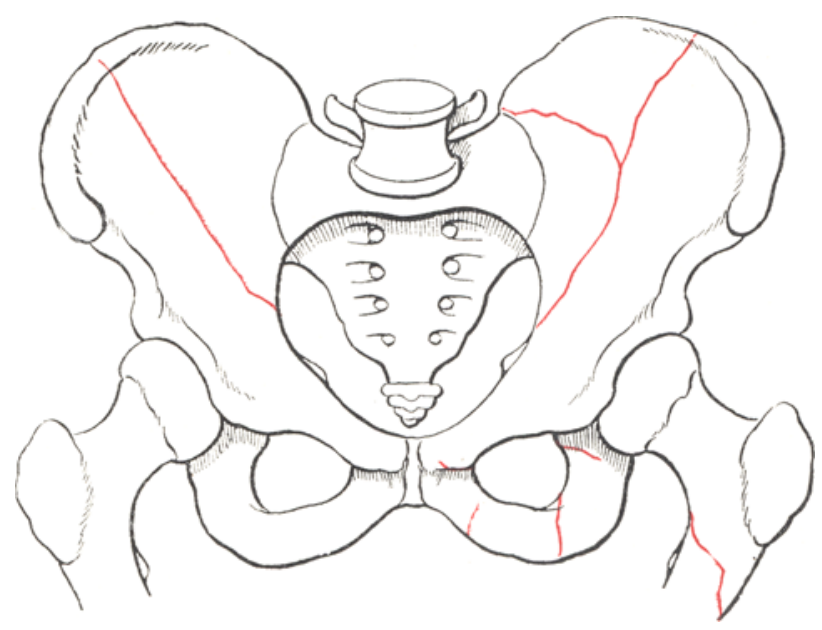

Fig. 26.

In zahlreichen anderen Fällen wurden so viele andere schwere Verletzungen neben dem Beckenbruch beobachtet, daB man die Fettembolien in ihrer Bedeutung als concurrierende Todesursache nicht abschätzen konnte.

Auf die häufigste sekundäre Todesursache, die septische Infektion im Gefolge von Harnröhrenzerreißung komme ich später zurück.

Endlich möchte ich noch bemerken, daß überall da, wo man das knöcherne Becken aus äußeren Gründen nicht zur Macerierung entnehmen kann, doch eine ziemlich vollständige Untersuchung desselben möglich wird, wenn man entweder nach Luxation der Oberschenkel diese in den Hüftgelenken auslöst oder im obersten Teil des Schaftes beiderseits durchsägt und dann die Weichteile auch an der Rückseite des Beckens vorsichtig im ganzen ablöst und genau besichtigt, event. nach Durchtrennung der Wirbelsäule im Lendenteil. Man kann so das ganze knöcherne Becken herauslösen und ohne Entstellung der Leiche wieder anstandslos einfügen.

So habe ich es beispielsweise in dem folgenden Falle ausgeführt, an dem mir, wie ich glaube, keinerlei Knochenläsion entgangen ist.

Fall 25. Beckenringbruch. Blutdurchtränkung der Beckenweichteile. Fettembolie der Lungen.

Der 28 jährige Arbeiter K. W. wollte am 11. 5. 02, wahrscheinlich in etwas angetrunkenem Zustande, den in voller Fahrt befindlichen ersten Wagen der elektrischen Straßenbahn besteigen, dem noch zwei AnhängeSommerwagen folgten. Er wurde von dem Trittbrett des ersten derselben erfaBt und auf dem Steinpflaster eine Strecke hingeschleift.' Er verstarb an den Folgen seiner Verletzung nach 3 Stunden. Bei der Obduktion fand 
man eine complicierte Fraktur in der Mitte des rechten Oberschenkels, eine Spiralfraktur der linken Tibia und eime Splitterfraktur der linken Fibula, Frakturen der 4.-8. Rippe linkerseits, zahlreiche Hautabquetschungen und Hautabschürfungen am rechten Unterschenkel, an beiden Händen und im Gesicht. Endlich wurten von mir folgende Verletzungsspuren am Becken festgestellt:

Die Weichteile zeigen zu beiden Seiten des Beckens über den Trochanteren ausgedehnte Hautabschürfungen, angetrockne Blutschorfe. Die Muskulatur an der linken Beckenschaufel, besonders um die Spina ossis ilei anterior ist stark blutig durchtränkt, rechts auch, doch in geringerem Grade. Die Beckenschaufeln wippen abnorm bei Druck von vorn her, die linke auch bei Druck von hinten her, doch ist Crepitation dabei nicht wahrnehmbar. Blutige Durchtränkung des linken Musc. psoas major läßt eine Zusammenhangstrennung in der Gegend der linken Synchondrosis sacroiliaca vermuten. Rechts ist der Musc. psoas major nicht durchblutet.

Der knöcherne Beckenring wird nach Durchsägung der beiden Femurschäfte handbreit unter dem Trochanter major und Durchtrennung der Lendenwirbelsäule frei gemacht von den Weichteilen. Man erkennt nun mehr Bruchlinien, beiderseits von der Synchondrosis sacroiliaca ausgehend, in die rechte wie in die linke Darmbeinschaufel hinein. Auf der rechten Seite ist eine Knochenlamelle von der Linea innominata in der Nảhe der Synchondrose von dem Rande des Os ilei ganz abgelöst. Auch linkerseits zieht eine Fissur von der Kreuzdarmbeinfuge bis in die Mitte der linken Darmbeinschaufel.

Am Horizontalast des rechten Schambeins ist eine flache ca. $10 \mathrm{~cm}$ lange Lamelle am inneren Beckenrande abgelöst, hängt aber lateral noch fest. Es läBt sich ohne weiteres erkennen, wie diese Lamelle mit ihrer medianen freien Spitze bei frontaler Zusammendrückung des Beckens für eine reichlich gefüllte Harnblase gefährlich werden kann, indem sie dann in diese hineinstieb. Eine nahe dem Hüftgelenk gelegene Fissur durchsetzt den horizontalen Schambeinast quer, diese Bruchlinie hat offenbar ihre Fortsetzung jenseits des Foramen obturatorium, indem hier eine Fissur quer den absteigenden Schambeinast durchsetzt. Auch am rechten absteigenden Schambeinast, näher der Symphyse als links, sitzt eine Knochenläsion, die aber nur als Infraktion zu bezeichnen ist, da die innerste Spange am Foramen obturatorium nicht durchgebrochen ist. Die äußere nach unten festhaftende Spange ist auf $3 \mathrm{~cm}$ weit abgespalten, klaffend.

Alle diese Frakturen erwecken den Eindruck, daß sie durch Zusammenpressung des Beckens entstanden sind; wie grob auch das Trauma, die typische Lokalisation der Fissuren ist unverkennbar.

Harnröhre und Harnblase waren intakt.

Auch in diesem Falle ließ sich Fettembolie der Lungen in erheblicherem Grade nachweisen.

\section{Heilung der Beckenbr üche.}

Die Heilung der Beckenfrakturen erfolgt, wie eine Reihe meiner Präparate lehren, mit oft recht stark entwickeltem Callus. 
Leider sind solche geheilte Beckenfrakturen meist zufällige Befunde bei der Obduktion, so daß man meist nicht zu sagen vermag, welche Symptome im Leben etwa als Folge der Callusbildungen vorhanden waren. Immerhin bestätigen meine derartigen Präparate die bisherigen Ausführungen über den Sitz der Fissuren. Auch lassen sie gewisse klinische Symptome verständlich erscheinen. Deshalb gebe ich gerade von ihnen einige genau gezeichnete Abbildungen wieder.

Fall 26. Callus, der das Foramen obturatorium sin. verhleinert und die Beweglichkeit im Hüftgelenk behindert.

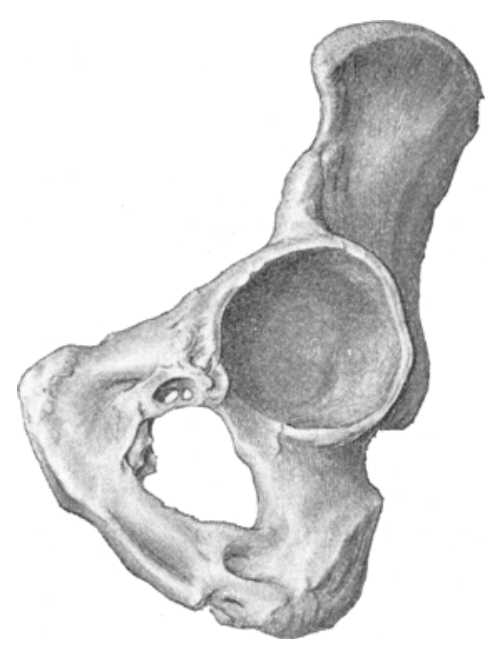

Fig. 27.

Fig. 27 stellt die linke Beckenhälfte dar, von einem Individuum, über dessen Verletzung nichts bekannt ist. Neben leichtem stalaktitenartigen Callus der linken Kreuzdarmbeinfuge fanden sich callöse Veränderungen im Bereich des Foramen obtur., das durch sie sichtlich verkleinert worden war. Die Verlötnng einer Fissur von typischem Sitz im horizontalen Schambeinast hat $\mathrm{zu}$ den durchlöcherten periostalen Knochenauftreibungen dicht an der Gelenkpfanne geführt, deren Rand infolge dessen gewisse Unebenheiten führt. Diese können intra vitam sehr wohl Störungen im Sinne einer Adduktionsbeschränkung bedingt haben. Auch der Callus dicht vor dem Sitzbeinhöcker entspricht einer typischen Fissurstelle. Er dürfte am Lebenden fühlbar gewesen sein oder wenigstens einen ungleichen Tastbefund gegenüber der normalen entsprechenden Stelle der anderen Seite ergeben haben.

Stärker fast als an der Außenseite ist die Callusproduktion in diesem Falle an der Innenseite, von der ein Höcker auf dem nach der Symphyse gerichteten Winkel des Foramens einengend in dieses bereinragt.

Recht interressant erscheint mir ein Präparat des pathologischen Instituts in Breslau, herrührend von einem 31 jährigen Manne, welcher am 21. Tage nach der Verletzung starb (Fig. 28). Es zeigt die Callusbildung in einem verhältnismäBig frühen Stadium.

Fall 27. Frische Callusbildung bei Beckenbruch.

Am Ramus horizontalis dicht neben der Hüftgelenkpfanne zieht eine sich mehrfach teilende Fissur aus dem Beckeninnern schräg nach vorn und auswärts in das Foramen obturatorium hinein. Während an macerierten Präparat an der Innenseite die Fissuren sich völlig glatt und unverheilt darstellen, liegt an der vorderen Fläche des Beckens, den Fissuren wie Mörtel aufgeworfen, eine poröse Knochenmasse aufgelagert. Dicht vor dem 
Die Beckenbrüche m. Bemerkgn. üb. Harnröhren- u. Harnblasenzerreißungen. 533

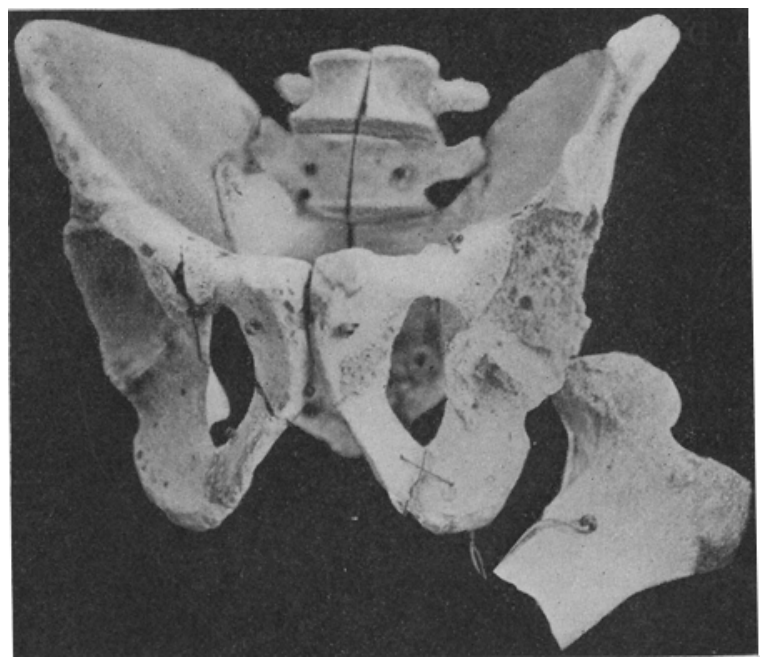

Fig. 28.

Tuber ischii besteht nur eine Infraktion des Ramus ascendens, die an der Außenfläche ebenfalls mit neugebildeter Knochenkittsubstanz bedeckt ist. An einer Querfraktur durch den Ramus descendens ossis pubis ist keine Callusbildung bis jetzt bemerkbar.

Am Kreuzbein zieht linkerseits eine Fissur durch die ganze Länge der Massa lateralis, sie läuft nicht eigentlich durch die Foramina sacralia hin, sendet aber jeweils zu ihnen Zweigfissuren. Auch hier ist an der Vorderseite des Kreuzbeins teils schwammige, teils stalaktitenbildende Callusmasse über die Fissur hingebreitet, sie schließend bezw. sie verdeckend. An der Rückseite ist an der viel feineren Längsfissur Callus nicht entwickelt.

Der Verletzte ging zugrunde, weil es im AnschluB an eine Zerreißung der Harnröhre zu Harninfiltration und zu eitrig-jauchiger Coxarthritis linkerseits und zu einer Infektion des Beckeninneren kam. An dem Präparat bemerkt man eine völlige Zerstörung des linken Hüftgelenks, dessen Pfanne wie der Femurkopf des Knorpelüberzuges ganzlich beraubt waren. Auch der Knochen ist im Bereich des Gelenkes zerfressen, schwammig aufgelockert. Auch an dem linken unteren Teil des Kreuzbeins besteht infolge des eitrigen Prozesses leichte Caries. An dem linken Schambogenschenkel besteht an einer Fissur in der Nähe der Symphysis pubis eine Spur von Callusentwicklung, eine Fissur dicht vor dem Tuber ischii ist unverheilt.

Die Heilung von Brüchen der Schambogenschenkel veranschaulichen drei Präparate, von denen eines im Bilde wiedergegeben sei. 
Fall 28. Fig. 29. Callus an beiden Schambogenschenkeln und am rechten Darmbein. Verschiebung des letzteren gegen das Kreuzbein.

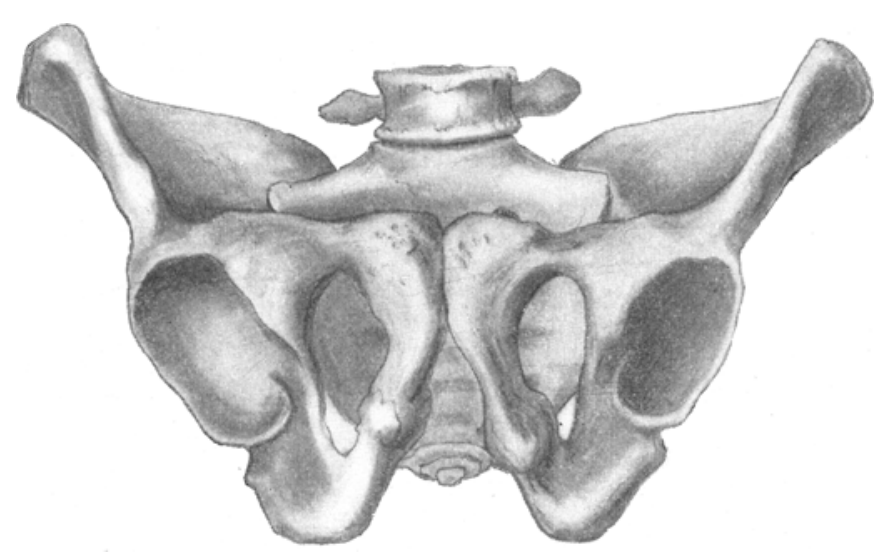

Fig. 39.

Fraktureallus an beiden sitzbeinaisten.

Fig. 29 läßt an beiden Rami ascend. ossis ischii zwingenförmige Callusverdickungen erkennen, dicht unterhalb der Synostose zwischen Os ischii und Os pubis. An der Rückseite sieht man am rechten Darmbein stalaktitenförmigen Callus. Die leichte Verschiebung in der rechten Kreuzdarmbeinfuge kommt in einem geringen Tieferstehen der rechten Kreuzbeinhälfte auch an diesem Bilde zum Ausdruck.

Fall 29. Direkte Fraktur beider Schambogenschenkel, mit Callus geheilt. Tod nach 8 Jahren.

Ganz àhnlich stellt sich die ausgeheilte Fraktur an einem Becken dar, das ich in Königshütte bei der Sektion eines alteren Mannes gewann, der an Lungenentzündung verstarb, und der 8 Jahre zuvor in der Grube einen Unfall der Art erlitten hatte, wie ich ihn oben schon gesthildert habe. Er ging auf dem Schienenstrang einer Grubenbahn hin, die uber hohe Böcke hinlief, glitt aus, fiel und kam so rittlings auf die Schienen zu sitzen; er zog sich so eine schwere Quetschung der Dammgegend zu. Die Harnröhre war nahezu völlig durchgequetscht, obne daß außerlich eine Wunde sichtbar war. Urethrotomia externa. Es blieb danach eine Striktur zurück, wegen der er wiederholt längere Zeit bougiert werden mußte.

Hier saß die Fraktur etwas höher als im vorigen Falle, die Rami descendentes ossis pubis waren beiderseits quer gebrochen. Das Bild des Callus ist das unregelmäBiger, höckriger kleiner Exostosen, sie wechseln mit grubigen Vertiefungen an der Vorderfläche ab, während an der Rückfläche nur leichte Unebenheiten erkennbar sind.

Fall 30. Fraktur beider Schambogenschenkel.

In dem dritten Falle endlich (Präparat des pathologischen Instituts Breslau) handelt es sich ebenfalls um eine geheilte Querfraktur des ab- 
steigenden Schambeinastes beiderseits mit verhältnismäßig geringfügiger Deformität durch den Callus. Über die Herkunft des Beckens, welches außerdem eine knollige supracartilaginäre Exostose zwischen 4 . and 5 . Lendenwirbelkörper zeigt, ist Näheres nicht bekannt.

Lehren diese Präparate schon, daß die Callusentwicklung bei der Heilung von Beckenfrakturen des öfteren eine so deutliche ist, daß wir lange nach der Verletzung oft die Diagnose Fraktur mit größerer Sicherheit stellen können, als am frischverletzten, so ist es nach meiner Erfahrung fast die Regel, daß man Callus dentlich fühlen kann, vorausgesetzt, daß man sorgfältig die Beckenknochen abtastet.

Ja, außergew öhnlich mächtige Callusentwicklung scheint gerade bei Beckenbrüchen nicht selten zu sein.

Fall 31. Excessire Callusentwicklung bei Beckenringbiegungsbruch.

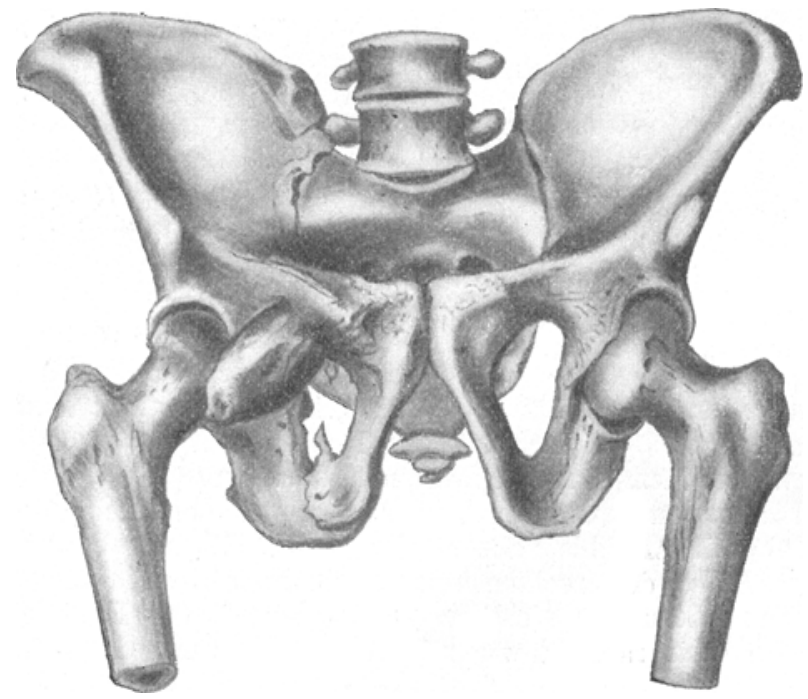

Fig. 30.

Geheilte mehrfache Fraktur der reehten Hälfte des vorderen Beekenrings. Machtige Exostose am Ramus horizont. ossis pubis dext.

Ein Beispiel 'excessiver Callusbildung stellt Fig. 30 und Fig. 31 dar, welche beide ein Präparat betreffen (Ansicht von vorn, bezw. von rechts hinten). Es handelt sich um eine alte Beckenringfraktur mit Bruchlinien nur der rechten Seite, und zwar vorn am horizontalen Schambeinast und am Sitzbein, hinten mit einer Fraktur von der Crista des rechten Darmbeins zur Incisura ischiadica, den hinteren Flügel abtrennend.

Der rechte horizontale Schambeinast ist (Fig. 30) nahe der Schambein- 
fuge gebrochen gewesen und etwas nach vorn dislociert. Eine dreidaumendicke compakte Exostose wächst wie ein mächtiger Knochentumor von der Vorderfläche des Ramus horiz. hervor, schräg nach abwärts und auswärts, so die Adduktion des rechten Femur behindernd. An der Bruch-

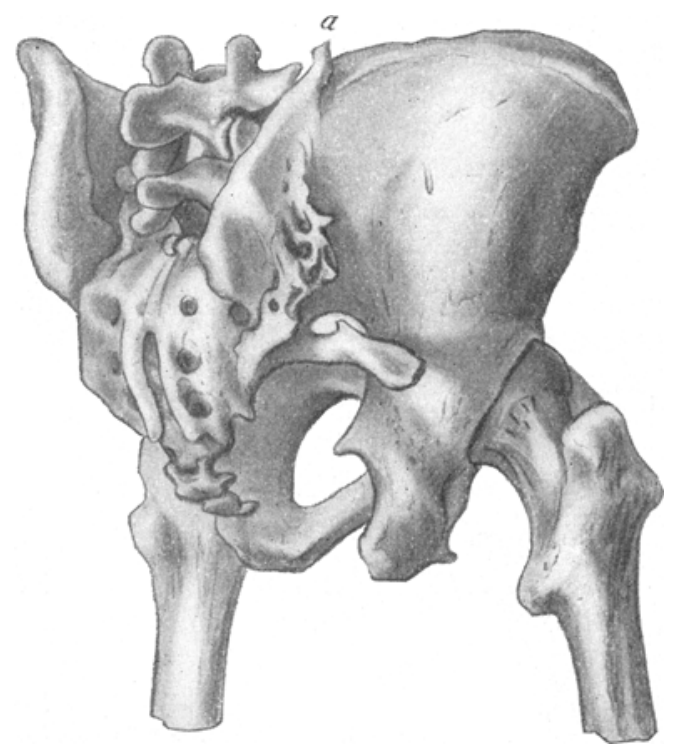

Fig. 31.

Abbrauh des hinteren Darmbeinfligels, geheilt mit Stalaktitenbildung. Vergl. Fig. 8, 10, 13.

linie selbst ist nur geringer Callus entwickelt, doch sind auch hier lieine Exostosen zahlreich rorhanden. Vom unteren Rande des Foramen obturatorium zieht eine Fissur durch den Ramus ascendens des rechten Sitzbeins, die mit erheblicher Dislokation geheilt ist. Das Foramen ist infolge dessen sichtlich eingeengt. Eine zackige lange Exostose ragt von dem Fragment nach oben in das Foramen hinein.

Nicht weniger grotesk ist die Callusbildung an der Rückseite des Beckens, an der rechten Darmbeinschaufel (Fig. 31). Die Bruchlinie läuft hier an recht typischer Stelle vertikal von dem hintersten Teil der Crista ilei zur Incisura ischiadica, eine spitze Exostose an der Crista (a) kennzeichnet das obere Ende, durchlöcherter Callus gibt die Richtung der Fissur nach unten an und eine nicht weniger als $7 \mathrm{~cm}$ lange, elfenbeinartige Spange zieht an dem Ausgange der Fissur von dem Kreuzbeinrande hinter der Xneisura ischiadica im Bogen her seitwärts bis nabe an das rechte Hüftgelenk heran. Auch an der Vorlerfläche der rechten Symphysis sacroiliaca sind stalaktitenförmige Calluswucherungen sichtbar, so daB sowohl das Foramen obturatorium wie die Incisura isch. wie mit Dornen umwachsen erscheinen.

Auch dieses Präparat von geheilter Fraktur zeigt die Vielheit der Bruchlinien bei Beckenringbrüchen; Malgaigne würde auch diesen Fall als doppelte Vertikalfraktur angesprochen haben.

Ich möchte noch hervorheben, daß, obwohl vorn und hinten die Continuität durch den ganzen Beckenring zweifellos aufgehoben war, es nicht zu einer wesentlichen Dislokation des aus dem Ringe ausgelösten Fragments, also auch nicht zu einer Verlängerung bezw. Verkürzung des rechten Beins gekommen ist. 
Fall 32. Beckenring- und-randbruch. Exostosen am Beckenrand. Callus an der Innenfläche des horizontalen Schambeinastes der anderen Seite.

Bei einem in Königshütte secierten Phthisiker fand ich große $2 \mathrm{~cm}$ lange breitbasige Exostosen an der rechten Crista, offenbar herrührend von der direkten Contusion. Als ich daraufhin das Becken auf weitere Läsionen absuchte, fand ich an den Kreuzdarmbeinfugen keinerlei Verletzungsspuren, dagegen zeigt das macerierte Präparat eine alte geheilte Fraktur am linken Ramus horiz. ossis pubis, mit besonders merkwürdigem Callus an der Innenfläche des Beckens. Das etwas eingedrückte Fragment ist mit dicken Spangen, die in lange Spitzen auslaufen, mit dem Beckenringe im Zusammenhange geblieben. An der Außenseite des Ramus ascend. ischii dicht über dem Tuber läßt die UnregelmäBigkeit der Oberfläche anf eine zweite Fissur schließen.

Fall 33. Callus luxurians an der Innenseite der Beckenschaufel und am Tuber ischii. Beckenring- und -randbruch.

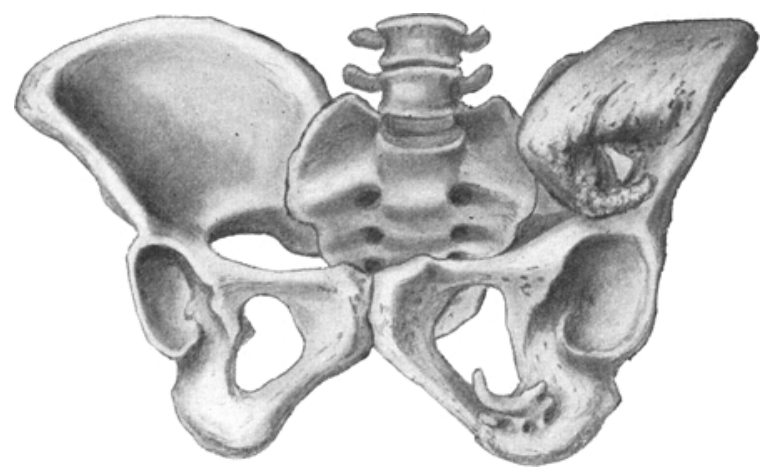

Fig. 32.

Laxuriierender Callus an der Innenseite der linken Darmbeinsehaufel und am linkē Śitzbein.

Endlich veranschaulicht die Fig. 32 die Abbildung des Beckens eines durch Überfahren verletzten und nach vielen Jahren verstorbenen Mannes (aus dem patholog. Institut zu Breslau) noch die Neigung der Knochenheilung am Becken zu luxuriierender Callusbildung. Das Becken zeigt eine im wesentlichen vertikal verlaufende Bruchlinie von der Höhe der linken Crista ilei zur Incisura ischiadica, eine Querfraktur des horizontalen Schambeinastes nahe der Symphyse und als deren Fortsetzung eine Querfraktur des Sitzbeins dicht vor dem Tuber ischii. Die Schambeinfissur hat nur geringfügige Spuren hinterlassen. Um so augenfälliger sind die Callusbildungen am linken Darmbein und am Sitzbein; am ersteren ist eine massige, schwammige Knochenneubildung an der Innenfläche $\mathrm{zu}$ sehen, die wie ein mächtiges Horn über dem Pfannenrande liegt. Oberhalb des Tuber ischii liegt eine halbmondförmige Callusbildung an der Vorderfläche, die mit mehreren kleineren Bogen die Bruchlinie verlötet. Es würde auch dieser Beckenringbiegungsbruch als Malgaigne sche Vertikalfraktur anzusprechen sein, wenn man nicht vorziehen müBte, diese Bezeichnung 
ganz fallen zu lassen. Intra vitam müssen diese Callusmassen natürlich sehr wohl tastbar gewesen sein. Auch die Verdickung des Sitzknorrens mag fühlbar gewesen sein.

Es ist ersprießlich, sich die eben beschriebenen Präparate mit geheilten Fissuren am vorderen Teile des Beckenringes mit Rücksicht auf die Diagnose intra vitam anzusehen. Da ergibt sich, daß einmal der Callus so kräftig entwickelt war, daß er auch durch die Haut bei sorgfältiger Abtastung deutlich fühlbar sein mußte. Er hätte in dem Fall der Fig. 29-32 anch im Röntgenbilde sicher erkennbar werden müssen. Freilich bleiben Fälle, bei denen weder die Palpation noch die Röntgenphotographie sicheren Aufschluß zugeben vermag. In solchen Fällen hilft uns, sofern sie nicht mehrere Jahre alt sind, klinisch noch die Probe anf Druckempfindlichkeit. Ohne einige Übung und sorgfältige Vergleichung beider Seiten des Verletzten sind callöse Verdickungen und kleinere Verschiebungen durch die dicken Weichteile natürlich nicht zu fühlen, aber wer die Configuration des Beckens oft abgetastet hat, vermag doch meist wertvolle Anhaltspunkte zu gewinnen.

Der überschießende Callus ist bei Beckenfrakturen nach meiner Erfahrung nicht selten. Das mag auf den ersten Blick wunder nehmen, zumal wenn man bedenkt, daß die den Callus anregende Beweglichkeit der Fragmente doch nicht vorhanden ist. Vielleicht muß man sich die starke Knochenwucherung so erklären, wie jene Myositis ossificans, die wir bei Brüchen am unteren Humerus auch gelegentlich sehen, nämlich durch Ablösung von Perioststïcken, die dann den Ausgangspunkt von Knochenneubildungen in den inserierenden Muskeln und Sehnen bilden.

Für die klinische Beurteilung mancher Funktionsstörungen gewinnen die Callusgewächse hohe Bedeutung. Beschränkungen der Beweglichkeit des Hüftgelenks, bei Framen Geburtsstörungen, sind beobachtet.

Die Verschiebung der Bruchstücke war an den Präparaten geheilter Beckenbrüche meist wenig augenfällig. Am Frischverletzten kann sie ebenso auch dem Geübten oft entgehen.

Fall 34. Heilung mit wesentlicher Dislokation an der Schamfuge.

Das männliche Becken (aus dem pathologischen Institut in Breslau) läßt in der einen Abbildung nicht alles erkennen, was es von zahlreichen interessanten Befunden darbietet. Die Fig. 33 zeigt nur die mit starker Dislokation verheilte Lösung in der Schamfuge. Der ganze rechte Schambogenschenkel ist um $1 \mathrm{~cm}$ tiefer getreten, das rechte Schambein hinter das linke dislociert und in dieser Stellung mit dem linken verwachsen. 
Hier ist infolge dessen auch das rechte Hüftgelenk leicht abwärts geschoben. Eine unregelmäBige callöse Verdickung spricht von einer aus der Symphysis pubis zum For. obturat. laufenden Querfraktur. Eine solche ist auch am linken Schambogenschenkel, aber tiefer sitzend durch Callusbildung angedeutet. Bei Retrachtung von vorn her bemerkt man noch stalaktitenartigen

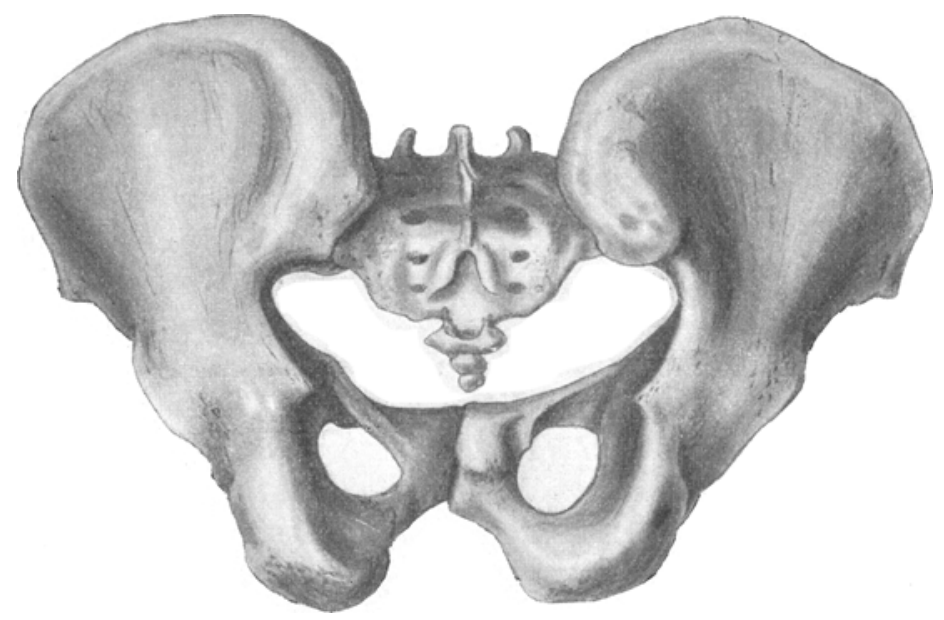

Fig. 33.

Zusammenschiebung des Beckenringes bei Lösung ler Schambeinfuge. (Blick von hinten her.)

unregelmäBigen Callus an der Grenze des linken Ram. desc. pubis und ascend. ischii, sowie eine minimale Knickung am Ramus horiz. Die Querfraktur rechts ist noch deutlicher als an der Pückseite an der Vorderfläche sichtbar an Callusmassen dicht oberhalb des Tuber.

An der linken Synchondrosis sacroiliaca deuten Hyperostosen am unteren Teil auf die hier stattgehabte Lockerung: also wiederum ein Beckenringbruel mit vielfachen Lisionsstellen.

Fall 35. Pseudarthrosenheilung.

Endlich möchte ich eines Präparates der Sammlung des Breslauer pathologischen Instituts Erwähnung tun, welches lehrt, daß auch am Becken gelegentlich Pseudarthrosenheilung vorkommen kann. Es ist ein Schambein dort verwahrt, welches eine Verschiebung der Fragmente mit locker fibröser Verbindung zeigt.

Fall 36. Pseudarthrosenheilung.

Ein abgebrochenes größeres Stück der Darmbeinschaufel fand ich einmal, ins Becken hinein disloziert, locker und verschieblich in den Weichteilen liegend gelegentlich der Untersuchung eines vor vielen Jahren Verletzten, dem es keinerlei Beschwerden machte.

Wenn ich diese meine eigenen Beobachtungen an Becken Verstorbener mit den in der Literatur niedergelegten Beschreibungen 
zusammenhalte, so stehe ich im großen ganzen keineswegs im Widerspruch zu ihr mit den tatsächlichen Befunden. Nur baben die älteren Autoren das Moment der Zusammenpressung des Beckenringes und die aus den Gesetzen der Biegungsspannung sich ergebende regelmäßige Wiederkehr der Multiplizität der Beckenfissuren nicht genug betont. Familton erläutert die Kntwickung des Beckens eingehend, weil er der Meinung ist, daß an den Stellen der knorpligen Fugen der Jugendjahre Fissuren besonders häufig vorkommen. Das trifft in der Tat am vorderen Beckenringe $\mathrm{zu}$; hier sahen wir die Fissuren an den Schambogenschenkeln und im horizontalen Ast des Schambeins, und zwar einerlei, ob die Gewalt das Becken in frontaler oder in sagittaler Richtung zusammenpreßte. Ja selbst bei Fall auf die Füße bersten diese schwächsten Strebepfeiler scheinbar zuerst (Richerand, citiert bei Malgaigne). Messerers dankenswerte Experimente stimmen nicht in allen Punkten mit den praktischen Erfahrungen überein (z. B. erzielte er bei frontaler Pressung - Crista ilei contra Crista ilei - nicht Fraktur, sondern Luxation in der Synchondrosis sacroiliaca), aber sie bestätigen doch einwandfrei, daß bei der Überwindung der Gewölbespannung des Beckenringes dieser stets zwei Fissuren zeigt, die ein Stück des Ringes herausschneiden.

Eine willkommene Ergänzung dazu bilden Kusmins Experimente an Becken Erwachsener, die er im Zusammenhang mit Wirbelsäule und Oberschenkeln ließ. Danach können durch leichtere Gewalten gegen die vordere Beckenpartie hier Frakturen wegen deren Gebrechlichkeit ohne Wirkung an entfernteren Stellen zustande kommen; stärkere aber rotieren unter Anspannung der Lig. sacroiliae. ant. die Darmbeine nach aulen, so dal es in der Nähe der Symphysen zu Läsionen kommt. Die Einwirkung auf die Spinae ant. sup. in sagittaler Richtung von vornher ergab Fissuren im Gebiet des Acetabulums, aber auch Rißfrakturen im Kreuzbein. Ein bei gleichgestellten Oberschenkeln gegen diese geführter Schlag trieb den Kopf in das Beckeninnere hinein; dasselbe erzielte man bei Schlag auf die stark abducierten Füße. Indes entstanden in letzterem Falle, ehe das Acetabulum barst, Frakturen an der Vorderwand des Beckenringes.

Im allgemeinen haben auch diese Experimente ergeben, daß zum Beckenringbruch „mindestens zwei der Beckenachse mehr oder weniger parallele Spalten gehören." Es bleibt die seltene Ausnahme, daß einmal nur eine einzige Fissur durch den Beckenring geht.

Aus der Kasuistik sei noch ergänzend erwähnt, daß Riedinger, 
Letenneur, Linhart, Steinthal Rißbrüche durch Muskelzug an der Crista ilei beobachtet haben; von einem solchen am horizontalen Schambeinast berichtet Maydl. Durch Fall auf die stark gespreizten Beine, ohne daß der Damm selbst getroffen, sah - nach mündlicher Mitteilung - Englisch eine Fraktur am Schambogenschenkel entstanden.

In einer Hinsicht erscheint mein Beobachtungsmaterial lückenhaft, insofern nämlich, als es keinen einzigen Fall von Beckenluxation beibringt. Nun will ich nicht bezweifeln, daß es Continuitätstrennungen des Beckenringes gibt, die so überwiegend in der idealen Gelenkspalte der Symphysis pubis und der Symphyses sacroiliacae verlaufen, daß man von Luxation zu sprechen Veranlassung hat. Aber derartige Beobachtungen sind überaus selten. Salleron hat 6 Fälle berichtet, d. h. aus der Literatur gesammelt, nicht selbst gesehen, wo das Kreuzbein in beiden Gelenken, einen Fall, wo es nur in einem ausgelöst war. Die Lösung aller drei Symphysen hat als eine totale Zertrümmerung des Beckens und seines Inhalts kein klinisches Interesse. Im besten Falle aber sind das doch wohl immer Luxationsfrakturen, denn ohne zahlreiche Abrißfragmente und Fissuren sind Luxationen nie beobachtet. Malgaigne zählte noch - und mit ihm Lossen - sechs Formen von Beckenluxation auf, Linser, der neuerdings zwei Fälle beschreibt, betont dagegen, daß man nur von 2 Arten reden könne, von der Verrenkung der einen Beckenhäfte (Lösung einer Kreuzdarmbein - und der Schoßfuge) hierher gehört auch der Fall von Hopkins - und von der Verrenkung des Kreuzbeins, d. h. einer Lösung in beiden Synchondr. sacroiliacae und zwar mit oder ohne Trennung der Symphysis pubis, auch von Wilhelm beschrieben. Aber auch diese Einteilung bleibt eine im wesentlichen theoretische. Denn, abgesehen davon, daß die meisten derartigen Beckenverletzungen sofort tötliche sind, die Symphysen des Beckens sind nun einmal, mögen sie auch entwicklungsgeschichtlich und streng anatomisch als echte Gelenke anzusehen sein, in mechanischer Hinsicht den Gliedmaßengelenken nicht gleichzustellen. Ich halte es deshalb für praktischer, von Beckenverrenkungen künftighin überhaupt nicht zu reden. Auch die Verrenkung des Steißbeins läßt sich ebenfalls als Fraktur ansprechen.

Von den Mitverletzungen der im Becken befindlichen Weichteile seien aus der Literatur noch erwähnt Zerreißungen von Beckenvenen, die gelegentlich zu langsamer Verblutung oder zu Venenthrombose führten. Bell und Fischer berichten von der tran- 
matischen Entstehung eines Aneurysmas der Art. glutaea, Bryant von Thrombose der Art. iliaca externa in 3 Fällen infolge Überdehnung der Gefäßwand (Zerreißung der Intima und Media) mit nachfolgender Extremitätengangrän. Feré und Perruchet beschreiben eine hartnäckige Neuralgie des Nervus obturatorius. Ka ufmann betont an der Hand eines Falles die nachteiligen Folgen, die eine Knochenverschiebung am Becken für den Fall künftiger Entbindung haben kann. Daß schwere Beckenverletzungen bei Graviden auch Abort mit all seinen Folgen hervorrufen können, ist selbstverständlich, aber, wie einzelne Antoren berichten, nicht unbedingt die Regel.

\section{B.}

Die Beckenbrüche kommen im allgemeinen nur durch verhältnismäßig große Gewalten zustande und sie mögen daher mit der von Jahrzehnt zu Jahrzehnt größeren Entwicklung der maschinellen Industrie auch häufiger geworden sein. ${ }^{1}$ ) Im Förderbetriebe der Bergwerke und Hütten werden die Arbeiter von den in schmalen Gängen auf Schienen laufenden Wagenzügen oft an die Wand gequetscht, an einem Pfeiler vorüber gerollt, zwischen zwei zusammenlaufenden Wagen am Becken zusammengedrückt (gepuffert.) Aber auch Verschüttungen, Quetschungen durch umfallende Lasten, Sturz von der Leiter sind dort noch häufigere zu Beckenverletzungen führende Ereignisse als die Unfälle im alltäglichen Leben der Großstädte und des flachen Landes. All diesen schweren Unfällen ist, wenn sie zu Beckenringbiegungsbrüchen führen, eines bezüglich des Nechanismus der Gewalt gemeinsam: wir finden immer Druck und Gegendruck. Der rollende Wagen greift an der einen Seite des Beckens an, der Pfeiler verhindert ein Entweichen. Und wenn jemand aus der Höhe abstürzt, wobei der Stoß scheinbar fehlt, da ist es die Eigenschwere des Körpers, welche die direkte Gewalteinwirkung ersetzt. So kommt es im Augenblick der Gewalteinwirkung zu einer momentanen Zusammenpressung des Beckenringes, die sich vermöge der Elasticität der Beckenknochen im nächsten Augenblick wieder völlig ausgleichen kann (Messerer). Je nachdem die Richtung von Druck und Gegendruck eine rein äquatoriale oder in einem kürzeren Durchmesser den Beckenring durchlaufende, je nachdem sie mehr frontal oder mehr sagittal ist, sind die Stellen verschieden, wo die höchste Biegungsspannung zum Ausdruck kommt,

1) Malgaigne sah im Hôtel-Dieu in 11 Jahren nur 10 Beckenbrüche. 
wo die Fissuren sitzen. Naturgemäß spricht in zweiter Linie auch die Festigkeit der unter Biegungsdruck gesetzten Knochen bei der Lokalisation der letzteren mit.

\section{Diagnose der Beckenringbiegungsbrïche.}

Wie äußert sich nun ein Beckenringbiegungsbruch sofort, wie stellen wir ihn am Krankenbett fest? - Die Verletzten haben im Augenblick die Empfindung eines großen Schmerzes und geben meist an, daß es im Beckeninnern gekracht habe.' Da der Beckenring ein so wesentlicher Faktor für die anfrechte Körperhaltung ist, so brechen die Verletzten in der Regel sofort zusammen und können sich nicht wieder erheben. Doch gibt es natürlich auch darin Ausnahmen und ich selber habe mehrfach Bergleute mit schwerer Zusammenquetschung noch gehen sehen. Der eine gab an, es krache bei jedem Schritt im Kreuz. Der Shok ist aber bei schweren Beckenringbrüchen mit Complikationen meist ein beträchtlicher, und dann ist die Erkennung der später zu erwähnenden Symptome auf den ersten Blick möglich.

Aber die leichteren Formen von Beckenringbruch machen oft auch gar keine Shokerscheinungen und werden eben deshalb wohl häufig als Beckenbruch zunächst oder überhaupt nicht erkannt. $\mathrm{Ja}_{\mathrm{a}}$ bei Personen mit anderweitjgen schmerzhaften Verletzungen kann es vorkommen, daß die Beckenfraktur erst nach vielen Wochen, beim Aufstehen oder bei der Wiederaufnahme der Arbeit bemerkt wird, indem jetzt bei der Belastung des Beckenringes erst Schmerzen an den Bruchstellen auftreten, die vordem in der Bettrückenlage dem Patienten selbst gar nicht zum Bewußtsein kamen. Das bestätigt auch wohl die Beobachtung ron F. Bähr, der die Schmerzen im Kreuz auf Zugbelastung das Erector trunci zurückführt. Es ist also ganz ähnlich wie bei leichten Graden von Compressionsfraktur eines Wirbelkörpers, wo der Umstand, daß sich an einer bis dahin schmerzlosen und äußerlich zweifellos unveränderten Stelle des Rückgrats verspätet, wohl gar erst bei der Aufnahme der Arbeit Schmerzen und zuweilen ein Gibbus ausbildeten, zu der Aufstellung eines viel erörterten, jetzt wieder zur Seite gelegten Krankheitsbildes, der Spondylitis traumatica $\mathrm{K} \ddot{\mathrm{mmm}}$ ells geführt hat.

Man wird eine leichte Beckenfraktur am ehesten nicht übersehen, wenn man in allen Fällen, in denen.nach Art des Unfalls die Möglichkeit einer solchen vorliegt, eine Prüfung der Bewegungsfähigkeit der Beine anch im Bett vornimmt und durch Druckprüfung am 
Beckenringe und sorgfältiges Abtasten der einzelnen Beckenknochen auf Bruchschmerz prüft.

Diese Druckprüfung, mit einiger Vorsicht und dann ohne jede Gefahr oder besondere Beschwerden für den Patienten geübt, geschieht in der Weise, daß man mit der flachen Hand von vorn her auf die vorderen Darmbeinstachel drückt. Dann klagen die Verletzten, wenn sie eine Fissur an einer der beiden Kreuzdarmbeinfugen oder in deren Nachbarschaft haben, ungefragt über Schmerzen in dieser Gegend, weil es dabei zu einem Klaffen bezw. einer Reibung an der Fissurstelle kommt, aber auch Bruchstellen am horizontalen Schambeinast, an der Schoßfuge, seltener solche am Schambogenschenkel werden bei dieser Gelegenheit snbjektiv wahrnehmbar gemacht.

In anderen Fällen löst! erst ein zweiter Handgriff Bruchschmerz an den genannten Stellen aus, nämlich Druck mit beiden flachen Händen gegen die hintere Fläche der Darmbeinschaufeln in der Richtung nach vorn. Hierbei kommt es ebenfalls oft zu einem Klaffen oder Reiben an Fissuren des vorderen oder hinteren Beckenringes. Läßt man sich vom Patienten genau die Stellen des Schmerzes bei diesen beiden Prüfungen durch indirekten D ruck lokalisieren, möglichst mit einem Finger zeigen, dann gewinnt auch die Angabe über Schmerz an der oder den angezeigten Stellen bei, direktem Druck durch den Finger des Arztes den Wert eines objektiven Symptoms.

Mehry ron Symptomen als diesen ungefragt angegebenen Schmerzäußerungen bei indirektem Druck kann man bei Fissuren, die an den tief verborgen liegenden Beckenknochen sitzen und die ohne Dislokation der Fragmente bestehen, selbstverständlich nicht verlangen. Sie müssen uns also, wenn die Art des Unfalls überhaupt geeignet erscheint, einen Beckenbruch hervorzurufen, zur Diagnose eines solchen genügen wie wir ja auch Rippenfrakturen lediglich daraufhin diagnostizieren.

Die Abtastung der Beckenknochen wird in allen leichten Fällen außer dem direkten Druckschmerz in der Regel nichts ergeben; denn das sind eben schon schwerere Fälle, bei denen ein Tieferstehen der einen Beckenschaufel infolge Verschiebung an der hinteren Fissur oder am vorderen Beckenring, oder ein Klaffen der Bruchstelle vorkommt. Ja selbst wo es vorhanden, ist es am Frischverletzten, den man im Bett nicht einmal aufrichten sollte, nicht zu kennen; die Dislokation einer Beckenhälfte kommt erst zur Beobachtung, wenn der Patient wieder aufrecht stehen kann, und wird selbst 
dann leicht übersehen, da es sich doch immer nur um einen Niveauunterschied von wenigen, allerhöchstens $3 \mathrm{~cm}$ handelt. Am ehesten fühlt man noch kleine Dislokationen der Fragmente am Frischverletzten an den Schambogenschenkeln und an der Scholfuge. Hier läßt sich auch Crepitation gelegentlich deutlich feststellen, wenn nicht die subcutane Blutergießung eine zuerhebliche ist. Bei Frakturen beiderseits von der Symphys pubis ist diese durch Umfassen manchmal verschieblich, oder gar schon von selber beckenbinnenwärts verschoben. (Über die Prüfung auf Harnröhren- und Harnblasenverletzungen siehe später.)

Die Tastung am horizontalen Schambeinast ergibt verhältnismäßig selten ein positives Resultat, es sei dem ein starkes Klaffen einer Bruchstelle vorhanden.

Über Sitz und Ausdehnung von Fissuren durch die Darmbeinschaufeln, durch das Kreuzbein ist mittelst Palpation selten etwas Sicheres zu erfahren, nur wenn die hinteren Darmbeinflügel abgebrochen sind - von Bähr als Contusionsfraktur beschrieben -, dann fïhlt man sie wacklig. Crepitation ist hier in der Kreuzbeinfuge nicht selten auch fühlbar, wenn man die oben erwähnte Druckprobe ron einem Assistenten machen läßt und selbst die Hand unter das Kreuz des liegenden Verletzten legt.

Die Sitzbeinhöcker, der aufsteigende Ast des Sitz- und der absteigende Ast des Schambeins lassen sich von außen her verhältnismälig leicht abtasten, ebenso das Kreuzsteilßbein. Die Palpation per raginam und per rectum wird selten etwas Neues, allenfalls bezüglich des Steiß- und Kreuzbeins ergeben; wo es die sonstigen Verhältnisse gestatten, ist sie indes auch am Frischverletzen erlanbt.

Die Röntgenphotographie wird praktisch bei Frischverletzten verhältnismäßig selten in Frage kommen. Gute Apparate werden schwere Dislokationen recht deutlich darstellen, aber bei leichten Fissuren an den versteckten Knochen doch auch nur unsichere Resultate ergeben. Dazu kommt, daß man den für den Patienten mühsamen Transport und die schwierige Lagerung gern vermeiden wird, besonders wenn die übrigen Untersuchungsmethoden ausreichen zn einer Diagnose. Bei Geheilten leistet sie großes für die Diagnose.

Endlich kommt die funktionelle Prïfung in Betracht, vor allem, wenn ich von der Blasenprüfung vorläufig absehe, die der Bewegungsfähigkeit der Beine. Die Fähigkeit, die Beine im Liegen von der Unterlage zu erheben, spricht keineswegs gegen einen Beckenbruch. Die Patienten aber empfinden auch dabei nicht selten an einer sonst nicht erkennbar geschädigten Stelle oft Schmerzen. 
Die Feststellung von Lähmungen durch traumatische Nervenläsion, häufiger an den Ausfallserscheinungen auf sensiblem als auf motorischem Gebiet erkennbar, ist schon deshalb notwendig, weil die Patienten sonst leicht irgend einer therapeutischen Maßnahme nachträglich die Schuld beimessen.

Für die Prognose und anch für die Therapie aber ist von besonderer Wichtigkeit die Erkennung der Art einer complicierenden Verletzung am Hüftgelenksapparat. Schon Malgaigne beschäftigt sich mit der Differentialdiagnose der hier in Frage kommenden Terletzungen. Es sind nach meiner Erfahrung tolgende Möglichkeiten zu erörtern:

1. Beckenringbruch Qhne Pfannenverletzung, aber mit Dislokation der einen Beckenhälfte nach oben oder nach unten.

2. Beckenringbruch mit Fissuren durch die Pfanne;

a) mit Dislokation einer Beckenhälfte,

b) ohne solche.

3. Isolierte Pfannenverletzung.

4. Luxation des Femurkopfes;

a) ohne,

b) mit Pfannenrandbruch.

5. Schenkelhalsbruch;

a) nahe am Kopf,

b) nahe an den Trochanteren.

6. Bei alten Fällen Coxa vara.

Ohne auf die diagnostischen Einzelheiten der sub 4 und 5 genannten Verletzungen näher einzugehen, sei nur betont, daß Verkürzung des einen Beins, Gebrauchsunfähigkeit (besonders bei Psoasdurchblutung und Läsion an der Symph. sacroil.) und auch Einwärtsrotation bei Beckenringbruch mit Dislokation nach oben, scheinbare Verlängerung des gebrauchsunfähigen Beins und starke Einwärtsrollung bei Beckenfraktur mit Abwärtsdislokation einer Beckenhälfte vorkommt. Wo man also überhaupt Veranlassung hat, einen Beckenbruch anzunehmen, da wird man die Diagnose Schenkelhalsbruch oder Luxatio femoris nicht prima vista stellen dürfen ${ }^{1}$ ). Steinthals differential-diagnostische Erörterungen über diese Frage im Handbuch der praktischen Chirurgie Bd. II, S. 853 befriedigen mich nicht.

Habe ich eindeutige Symptome einer Beckenverletzung, dann ist von vornherein eine Luxatio femoris oder eine Fractura colli

1) Auch Thiem erörtert diese Differentialdiagnose in seinem Handbuch. 
fem. wenig wahrscheinlich. Nun kann eine Beckenfissur durch die Pfanne laufen, auch mehrere (nämlich eine von oben her vom Ramus horizont. ossis pubis bezw. vom Darmbein, eine zweite vom Foramen obtur. her). Steht nun der Femurkopf in der geborstenen Pfanne, so wird dies die Palpation, die Stellung des Trochanter zur RoserNélatonschen Linie ergeben und der Patient wird bei Stoß gegen die Fußsohle des gestreckten Beines Schmerzen in die Pfanne und wohl auch an die Beckenfissuren lokalisieren. Bei Luxation empfindet der Patient den Stol an der Stelle des luxierten Kopfes mehr als dumpfen Druck wie als intensiven Gelenkschmerz, abgesehen davon, daß der luxierte Kopf an einer der typischen Stellen zu finden sein wird. Man begegnet bei den modernen Maschinenverletzungen den verwirrtesten Verhältnissen.

Fall 37. Beckenringbruch mit Luxatio femoris combiniert.

So sah ich in Königshütte einen 17jährigen Burschen, der vom Treibriemen erfalit und umher geschleudert worden war, der eine Luxatio femoris dextri, eine Fractura colli femoris sinistri, eine Dypuytrensche Malleolarfraktur am selben Bein und eine ganz multiple Beckenringfraktur hatte, nämlich Fissuren in beiden Kreuzdarmbeinfugen und am rechten horizontalen sowie am linken absteigenden Schambeinast. Gleichzeitig bestand mehrere Tage Harnverhaltung, ohne daß Blasen- oder Harnröhrenruptur nachweisbar war. Zum Überfluß fand sich im Urin der ersten Tage Blut, von dem es zweifelhaft blieb, ob Quetschung einer Niere oder Blasenwandläsion die Ursache war. Die Diagnose stellten wir hier erst in ihren Einzelheiten, als wir am 5. Tage nach Ablauf des schweren Shoks in Narkose die Luxatio femoris einrichteten, und ihre volle Bestätigung erfuhr sie, als der Patient wieder einigermagen gehen und stehen konnte durch den Nachweis von Callus an den Beckenknochen. Der jugendliche Patient blieb blog bezüglich seines linken Beins in mäBigem Grade invalide, da hier eine Verkürzung um $3 \frac{1}{2} \mathrm{~cm}$ und eine leichte Be. wegungsstörung im Fußgelenk dauernd zurückblieb.

Am schwierigsten dünkt mir die Diagnose bei Luxatio femoris mit Pfannenrandbruch und Beckenfraktur, eine Verletzung, die ich ebenfalls einmal und zwar mit wenig befriedigendem Resultat bezüglich der Funktion zur Ausheilung kommen sah. Die Krankengeschichte ist mir leider nicht zur Hand. Auch hier war die Diagnose erst bei der nach etwa acht Tagen vorgenommenen Narkose mit einiger Sicherheit zu stellen.

Kommt die Becken-, bezw. Hüftgelenksverletzung durch heftigen Sturz aus der Höhe auf den entsprechenden Trochanter zustande. dann wird gelegentlich der Kopf durch den Pfannenboden hindurch in das Beckeninnere hineingetrieben, wie auch François beobachtet hat, eine lokalisierte Beckenverletzung durch direkte Gewalt mit 
der indirekten Beckenbiegungsfraktur vergesellschaftet! Solcher Fälle, durch die Mitverletzung innerer Organe (z. B. Darmeinklemmung, Darmruptur, Blasenverletzung) meist tödlich, habe ich mehrere seziert, einen ebenfalls letalen Fall dieser Art hat Herr Dr. HeintzeBreslau beobachtet. Es mögen auch leichtere Fälle mit Pfannensprengung zuweilen auf ähnliche Weise durch direkte Gewalteinwirkung auf den Trochanter vorkommen. Auf die von Rose betonte Lokalisation von Ekchymosen oberhalb, des Poupartschen Bandes bei Pfannenbruch, unterhalb desselben bei Fractura colli femoris, möchte ich besonderen Wert nicht legen. Denn ist eine mit starker Dislokation verbundene Fraktur des horizontalen Schambeinastes dabei oder eines Schambogenschenkels, dann treten oft ausgedehnte blaue Verfärbung der ganzen Leistengegend und. des sehr imbibitionsfähigen Scrotums auf.

Diese complicierteren Verhältnisse: Brüche der Hüftgelenkpfanne, des Pfannenrandes, Verrenkung des Kopfes, Bruch des Schenkelhalses, wird man oft erst nach Ablauf einiger Tage, wenn der Hauptshok vorüber, völlig aufhellen können, meist erst in Narkose, die man dann gleich zu therapeutischen Maßnahmen verwendet. Und es kommt auch dann noch vollauf zurecht, da man ja auch sonst nicht nötig hat, eine etwa vorhandene Luxationseinrichtung zu übereilen.

Auch mit Coxa vara können ältere Beckenringbiegungsbrüche verwechselt werden (Peisker, Dissert. Breslau 1904). Hochstand des Trochanter major, Beinverkürzung, Adduktionsstellung, Auswärtsrotation, Behinderung der Innenrotation und Abduktion sowie Atrophie der Gesäß- und Oberschenkelmuskeln können jene vortäuschen. Hier wird Callus oder Dislokation des Sitzknorrens und das Nichthervortreten der Trochantergegend für Beckenfraktur entscheiden. Auch wird meist in der Kreuzdarmbeinfuge Callus zu fühlen sein, jedenfalls Belastungsempfindlichkeit bestehen.

Zur klinischen Diagnose der Beckenrandbrüche habe ich nur wenig hinzuzufügen. Die Lokalisation des Trauma, seine umschriebene Einwirkung, die auf eine einzelne Stelle begrenzten Schmerzen des Verletzten weisen auf den Sitz der Verletzung hin. Abgebrochene Stücke der Darmbeinschaufel ergeben ohne weiteres bei der Abtastung die Lageveränderung, den Bruchschmerz, Crepitation. Hufschlag, ein umfallender Stamm, der Druck eines über den Körper laufenden Rades das sind die gewöhnlichsten Ursachen. Die isolierten Frakturen am Schambogenschenkel (Os pubis und Os ischii), die durch Rittlingsfall auf eine frei dahinlaufende Eisenbahn- 
schiene, anf eine Stuhlikante (Fall 62), auf eine Zaunspitze, eine Wagenbrettkante (Fall 60 und 63), beim Reiten durch Aufschlagen auf den Sattelknopf zustande kommen, sind oft zunächst nilr an dem umschriebenen Druckschmerz erkennbar, später bestätigt dann der Callusring die Diagnose. Harnröhrenquetschung ist nicht selten eine Komplikation von größter Tragweite (s. u.). Heftiger Sturz auf das Gesäß, wobei die Sitzbeinhöcker auftreffen, mag gelegentlich auch zu Frakturen um das Foramen oburat. führen.

Eine einwandfreie Beobachtung isolierten Sitzbeinbruches dieser Genese ist bei Malgaigne erwähnt.

Die isolierten Querbrüche des Kreuzsteißbeins, auf die gleiche Art zustande kommend (siehe oben Fall 20), sind meist nur erkennbar an dem Bruchmerz, wenn man auf das distale Fragment von hinten oder per rectum von vorn her drückt. Bei völligem $\mathrm{Ab}$ bruch wird man dieses auch willkürlich dislocieren können oder stark dislociert finden. Doch möchte ich bezüglich des Steißbeins sehr warnen, aus Schmerz, Beweglichkeit und starker Einwärtsbiegung etwa immer auf Fraktur zu schließen, da empfindsame Personen immer Schmerz äußern und die Stellung und Beweglichkeit in sehr erheblichen Grenzen schwankt. Wir haben in unserem Institut mehrfach bei Fällen, die uns als Steißbeinfraktur zugingen, einen positiven Befund nicht erheben können.

Bei einem absolut glaubwürdigen Privatpatienten war dasselbe der Fall; doch bin ich geneigt, in diesem Fall mit Rücksicht auf die Art der Verletzung eine Querfissur im Steißbein bezw. an der Zusammenfügungstelle mit dem Kreuzbein anzunehmen.

Fall 38. Sturz auf das GesäB. Wahrscheinlich Kreuzsteißbeinfraktur.

Ein 38jähriger gesunder Offizier wollte demonstrieren, wie man als Dame reitet. In diesem Augenblick sprang das Pferd unter ihm weg und er fiel in Sitzstellung auf den unebenen Boden. Ein heftiger Schmerz brachte ihn einer Ohnmacht nahe. Er erholte sich bald, konnte aber von Stund an nicht reiten und auch auf dem Stuhl nur mit einer GesäBhälfte sitzen. Gehen und stehen war ihm möglich, bei hartem Stuhl groBe Beschwerden. Druck von hinten her auf das anscheinend nicht dislozierte Steißbein war ebenso wie bei Druck von vorn her per rectum sehr schmerzhaft. Als ich 14 Tage nach dem Unfall den Patienten sah, bestand keine abnorme Beweglichkeit. Bei Spreitzung der Beine Schmerz im Os coccygis, daher auch beim Schwimmen. Da ich von Massage nur eine Steigerung der Beschwerden sah, schickte ich den Patienten 6 Wochen in die Berge, wo sich ohne jede lokale Therapie die Beschwerden verloren, auch die Druckschmerzen. Der Patient konnte drei Monate später wieder ohne Störung das Manöver zu Pferde mitmachen. 
Steinthal sah nach Kreuzbeinfissur jahrelang heftige Beschwerden beim Bücken und Aufrichten bei einer sonst gesunden, nicht rentenberechtigten Frau. Und früher war ja viel von der Coccygodynie als einem charakteristischen Symptomenbilde nach Steißbeinverletzungen die Rede. Steinthal hat 2 solche Fälle erfolgreich mit Entfernung des Steißbeins behandelt. Auch mein Lehrer H. Fischer-Breslau berichtete in seinen Vorlesungen von hysterischen (?) Frauen mit Coccygodynie, die die Exstirpation des Os coccygis notwendig machte.

Eine Form direkter Fraktur, die Kaufmann beschreibt, habe ich selbst nicht beobachtet; es war eine mehrfache Fraktur beider Schambeine durch Stoß mit der Deichsel eines von der Höhe herabrollenden Wagens, kompliziert durch Harnröhrenzerreißung und Weichteilzertrümmerung am Scrotum, Penis und der Leiste.

Vielleicht ist der im Kapitel Harnröhrenzerreißung beschriebene Fall von Beckenfraktur eine solche direkte Fraktur. Hier war sicher nachweisbar nur ein Bruch des aufsteigenden linken Schambeinastes. Dem Verletzten war ein entgleisender Kippwagen gegen den Leib gefallen.

Endlich sei noch erwähnt, daß auch ohne direkten Stoß gegen das Becken Frakturen an diesem entstehen. So sind Muskelzugfrakturen an den Darmbeinschaufeln, an den Schambeinen beschrieben. Aber auch bei reinem Fall auf die Füße kann das Becken brechen.

Fall 39. Fahrstuhlverletzung. Läsion der linken Kreuzdarmbeinfuge.

Der 29jährige Haushälter S. ging mit einem Fahrstuhl $5 \mathrm{~m}$ in die Tiefe und stand überwiegend auf dem linken Bein, als dieser aufschlug. $\mathrm{Er}$ konnte alsbald nicht aufstehen oder gehen, mußte mit Wagen ins Krankenhaus gebracht werden. Als wir ihn nach 8 Monaten sahen, klagte er noch über Schmerzen in der linken Kreuzdarmbeinfuge und in dem linken Hüftgelenk. Er hatte ein Versteifungsgefühl im Kreuz. Objektiv war eine Verdickung der linken Kreuzdarmbeinfuge und eine erhebliche Behinderung in der Abduktion des linken Oberschenkels, der nicht atrophisch, nachweisbar. Für Coxa vara sprach das Röntgenbild nicht, das allerdings auch an den Beckenknochen nichts von Frakturcallus oder Dislokation erkennen ließ.

Druckempfindlichkeit und anscheinend Verdickungen im Bereich beider Synchondroses sacroiliacae fanden wir bei einem anderen Patienten, der aus großer Höhe herab auf die FüBe gesprungen war.

Die Behandlung der Beckenverletzten beginne wie die der Rückgratsverletzten mit einem verständig geleiteten Transport. Jede Zusammendrückung des Beckenringes von hinten und den Seiten her ist zu vermeiden; die breite feste Unterstützung der Kreuzlenden- 
gegend und der Beine ist den Kranken das angenehmste. Seitenlage ist meist sehr schmerzhaft. Bei gerader Rückenlage auf einer harten Matratze sind Kranke mit selbst schweren Beckenverletzungen manchmal völlig schmerzfrei; Decubitus ist bei ihnen nicht so zu fürchten wie bei Rückgratsverletzten mit spinaler Lähmung, deshalb sind Wasserkissen, Ringe und dergleichen Unterlagen nicht unbedingt erforderlich. Sie sind oft sogar unzweckmäßig, weil das öftere Unterschieben wie Anheben des Beckens Fragmentverschiebungen und damit jedesmal Schmerzen für den Patienten bedingt.

Bei starkem Collaps gilt es zunächst diesen zu bekämpfen; sobald er vorüber, wird die ärztliche Fürsorge in den bei weitem meisten Fällen von Beckenringbiegungsbruch (von Harncomplikationen zunächst abgesehen) sich auf die Anordnung absulut ruhiger Rückenanlage beschränken können. Denn von den Fällen mit stärkerer Dislokation einer Beckenhälfte überstehen eine ganze Anzahl den ersten Shok nicht; andere gehen an gleichzeitigen anderen Verletzungen zugrunde. So bleiben uns verhältnismäßig wenig Fälle ubrig, wo man eine Correktur in der Stellung der Fragmente vorzunehmen hat. Dislokationen des Kreuzsteißbeins lassen sich - ich habe selbst nie Gelegenheit dazu gehabt - wohl leicht vom Mastdarm aus beseitigen. Bei absoluter Rückenlage müßte m. E. die corrigierte Stellung auch ohne die von mehreren Seiten empfohlene Tamponade des Mastdarms zu erhalten möglich sein; wo dies nicht der Fall, da widerrät die Möglichkeit der Drucknekrose im Mastdarm doch auch die Tamponade. Die operative Entfernung des Steißbeinsfragments ist gelegentlich nötig geworden (Steinthal).

Auch die Reposition dislocierter Fragmente des Scham- oder Sitzbeins wird in der Regel ein überflüssiges Bemühen sein, wenn keine offene Wunde und keine Harnröhrenverletzung dabei ist. In letzterem Falle ist man gelegentlich genötigt, Splitter alsbald bei der Urethrotomie zu entfernen, da sie sich sonst doch durch die offene Stelle abstoßen. Schon Malgaigne erwähnt ältere Beobachtungen von Geburtsstörungen durch fehlerhaft geheilte Schambeinbrüche. $\mathrm{Ob}$ sich indes bei planmäßiger Behandlung solche fehlerhafte Heilungen immer vermeiden lassen, möchte ich dahingestellt sein lassen. Denn es scheint, als ob excessiver Callus mehr als die Fragmente selbst zur Beckenverengerung Anlaß gebe.

Von isolierten Brüchen der Beckenknochen wäre endlich noch der Abbruch des Darmbeinkamms bezüglich der Therapie zu behandeln. Da hat schon Malgaigue alle Repositionsversuche abfällig kritisiert: „Die Ruhe im Bett, die Lage auf dem Rücken, wenn der 
Kranke nicht eine andere vorzieht, das ist alles, was der Bruch fordert; das Übrige ist nutzlos oder schädlich." Eine völlige Correktur ist, wenn überhaupt eine stärkere Dislokation besteht, in der Regel unmöglich. Und auch so sind die Folgen keine ernsten. Ist die ganze Darmbeinschaufel abgebrochen - von Thiem als Duverney scher Bruch beschrieben - dann soll eine Quetschung des Musc. ileopsoas gelegentlich die Beweglichkeit des Beins erheblich beeinträchtigen. Auch in diesem Falle dürfte absolute Ruhelage das geeignetste Heilverfahren sein.

Wir kommen endlich zu der Form der Beckenringbiegungsbrüche, die mit Verschiebung einer Beckenhälfte, also mit scheinbarer Verkürzung, bezw. Verlängerung eines Beines einhergeht. In diesen Fällen wird man nach Ablauf des Shoks zunächst durch manuellen Zug eine Gleichstellung der Beckenhälften zu erzielen suchen. Das ist nach meiner Erfahrung an zwei in Heilung ausgegangenen Fällen und an mehreren als Leichen eingelieferten Fällen von Beckenbruch eine ziemlich einfache Maßnahme. Ja man kann auf die Dislokation schon bei der ersten Lagerung im Bett durch einen kräftigen Zug, bezw. Druck mit vollem Erfolg einwirken; dann bleibt auch die Stellung ohne weiteres erhalten. Es ist dieses Redressement meist so einfach gewesen, daß man von einer besonderen Methode eigentlich nicht zu reden braucht. Es ist so wie bei dem Redressement eines traumatischen Gibbus der Wirbelsäule, von dem man als von einem besonderem Eingriff gesprochen hat; es liegt schon in einer verständnisvollen Lagerung der Verletzten darin.

$\mathrm{Da}$ in verschiedenen Lehrbüchern zur Erhaltung der corrigierten Stellung die Extension und Contraextension empfohlen wird, so muß man annehmen, daß manchmal Neigung zur Dislocation bestehen bleibt. Wo dies der Fall, wird man gewiß durch Zug und Gegenzug Nützliches leisten. Ob man indes geringe Verkürzungen immer in solchen Fällen vermeiden wird, bleibt mir zweifelhaft, da man die Stellung der Fragmente doch nicht so minutiös controllieren kann, wie etwa bei Femurfrakturen. Die Contraextension kann selten oder nie am Becken vorgenommen werden. Wo Hochstellung des Bettfußendes nicht genügt, wird man den Gegenzug unter den Achselhöhlen anbringen müssen. Durch Abtastung der Bruchlinien wird sich ergeben, ob etwa durch Druck auf die Fragmente eine Verbesserung der Stellung erreicht werden kann. Ich betone indes noch einmal, daß die Mehrzahl der heilungsmöglichen Beckenbrüche nach meiner Erfahrung komplizierter therapeutischer Maßnahmen nicht bedarf. Abgesehen von den häufigen Complikationen durch Verlet- 
zung der Harnorgane bilden Wundinfektionen die Hauptstörungen im Heilverlauf. Ausgedehnte Hautabschürfungen, Quetschwunden disponieren zur Infektion. Ich habe oben (Fall 21) eine Eigenbeobachtung mitgeteilt, wo ein freilich arg vernachlässigter Fall von leichter Beckenfraktur (Abbruch des Darmbeinkammes) durch Infektion einer Quetschwunde an der Spina zum Tode durch Sepsis führte. Daß es bei der Nähe des Mastdarms und infolge der zahlreichen subkutanen Gewebszertrümmerungen auch gelegentlich zu Vereiterungen dieser, zur Sequestration von Fragmenten kommen kann, ist zu naheliegend, um eingehender erörtert zu werden.

Ein Décollement am Oberschenkel, in der Regios acralis kann vereitern. Man wird zunächst immer die Punktionsentleerung dieser subkutanen Taschen versuchen. Die Schnittoperation kommt nach Consolidation der Frakturen immer noch zurecht.

Von einer ebenso seltenen wie schwer verlaufenen Complikation berichtet Robinson: Ein 10jähriges Mädchen wird überfahren; circulärer Vaginalriß hinter dem Hymen, der bis ins Rectum geht. Eine Beckenfraktur wurde nicht festgestellt(!). Naht der Wunde, Heilung in 4 Wochen. Drei Jahr später über der Schamfuge ein Tumor; aus dem sich in die Vagina ein langer Sequester vom Ramus descend. ossis pubis abstieß. Durch Eröffnung des Cavum Retzii von oben entleerte man aus dem Abszeß noch 3 kleine Sequester. Rasche Heilung. Übrigens berichtet schon Malgaigne, daß Nélaton eine überfahrene Frau sah, bei der - frisch! - ein Fragment die Blase und Vagina durchbohrte. Es wurde extrahiert. "Und trotz der Urinergießung und der Eiterung, welche die Folge davon war, gelang es Nélaton' die Frau zu retten."

Eine eigene Beobachtung in Königshütte lehrte mich, daß solche Sequester in die Blase wandern und hier zu Steinbildung Veranlassung geben können.

Prognose und Diagnose.

Bezüglich der Prognose der Beckenbrüche kann man zahlenmäßige Angaben nicht machen; das aber läßt sich aus meinem Material sagen, daß eine ganze Reihe von Fällen, insbesondere von den leichteren Beckenrandbrüchen ohne nachteilige, erwerbsbeschränkende Folgen in einigen Wochen oder Monaten zur Ausheilung kommen. Von den Beckenringbrüchen kommen ebenfalls sehr viele zur völligen Ausheilung, besonders solche, die zunächst nicht als Brüche, sondern als einfache Quetschungen angesprochen worden sind. Aber es ist begreiflich, daß an den Callusstellen beim 
Gehen und besonders beim Tragen von Lasten noch lange Zeit nach der anatomischen Heilung Beschwerden wie an jedem Beinbruch auftreten. Das ist nach dem Sitz der geheilten Fraktur, aber auch nach der individuellen Empfindlichkeit sehr verschieden. Es lassen sich daher Rentennormalsätze für Versicherte überhaupt nicht angeben. Man kann nur von Fall zu Fall den Grad der Erwerbsfähigkeitsminderung und naturgemäß auch nur mit annähernder Sicherheit schätzen. Robuste, arbeitsfrohe Menschen machen von kleinen Beschwerden trotz groben objektiven Befundes wenig her, andere werden über kleineren Beschwerden hysterisch oder neurasthenisch resp. hypochondrisch, und die Gruppe der Arbeitscheuen hält sich leicht an die Diagnose "Beckenbruch", der natürlich niemals heilen könne; bei ihnen ist es oft recht schwer das Maß von Übertreibung richtig zu erkennen.

Ich habe den Eindruck, daß man im allgemeinen viel mehr positive Anhaltspunkte bei geheilten Beckenbrüchen findet, als gemeinhin angenommen wird. Nur muß man eben recht sorgfältig die Beckenknochen abtasten und auf Callus, kleine Dislokation und Druckempindlichkeit gerade an den Stellen fahnden, die erfahrungsgemäß die Lieblingsstellen der Fissuren sind. Dann wird man auch viel weniger isolierte Beckenfrakturen und viel mehr multiple, mehr typische Beckenringbiegungsbrüche festzustellen in der Lage sein. Wo man an der vorderen Beckenringhälfte Callus fühlt, da wird zwar nicht immer ein deutlicher Callus oder eine Dislokation an einer der Kreuzdarmbeinfugen sicher feststellbar sein, aber es wird vielleicht die subjektive Angabe des Verletzten, daß er Schmerzen an dieser Stelle empfindet, auf die Läsion daselbst hinweisen. Herr Kollege Löwe von unserem Breslauer Institut hat so bei der Aufnahme mancher "Beckenquetschung" die Diagnose in Beckenbruch rectificiert, deren Tatsächlichkeit wir alle bestätigen konnten. Es wird auch hier wie bei der Kümmellschen Krankheit, der sogenannten Spondylitis traumatica gehen, daß man bei besserem Verständnis der Beckenverletzungen überhaupt für die scheinbar übertriebenen Beschwerden mancher Unfallverletzter durch sorgfältige Untersuchung doch Anhaltspunkte findet, die ihre Klagen begründet erscheinen lassen.

Steinthal bericht von 4 Rentenfällen, darunter von zweien mit Hüftgelenksverletzung. Ich werde im Nachfolgenden von einigen begutachteten Fällen berichten, zu denen noch diejenigen später zu erwähnenden kommen, bei denen Verletzungen der Harnorgane im Vordergrunde stehen. Wenn man von den subjektiven Be- 
Die Beckenbrüche m. Bemerkgn. üb. Harnröhren- n. Harnblasenzerreißungen. 555

schwerden der Patienten absieht, so sind es hauptsächlich folgende objektiven Befunde, die man häufiger feststellen kann an geheilten Beckenverletzten.

1. Asymmetrie der beiden Beckenhälften, erkennbar an dem Niveauunterschiede beider Darmbeinkämme und der beiden Gesäßfalten am stehenden Patienten, manchmal mit secundärer Wirbelsäulenverbiegung.

2. Scheinbare Verlängerung bezw. Verkürzung eines Beines.

3. Muskelatrophie des Oberschenkels auf der lädierten Seite.

4. Leichte Kontourunterschiede zwischen beiden Symphyses sacaeroiliacae.

5. Behinderung in der Abduktion oder Adduktion des einen oder beider Oberschenkel.

6. Störungen in der Beweglichkeit eines Hüftgelenks und Empfindlichkeit des letzteren bei Stoß gegen die Fußsohle des gestreckten Beins, sowie Reibegeräusche im Hüftgelenk. Differentialdiagnostisch kommt oft das Malım coxae bei älteren Personen in Frage, das sich vielleicht manchmal direkt unabhängig, aber indirekt infolge der Ruhigstellung entwickelt; führt doch auch Ischias mit der damit verbundenen Inaktivität eines Beines sekuudär zuweilen zll Coxalgie und chronischer Coxarthritis.

Aus unserer Gutachtertätigkeit am Institut für Unfallverletzte in Breslau seien zur Illustration des Gesagten folgende Fälle unter Weglassung des für die Frage der Beckenbrüche nicht Interessierenden kurz angeführt:

Fall 40. Beckenringbruch mit Beckenrandbruch (rechter Darmbeinkamm) durch Zusammenquetschung des Beckens in frontaler Richtung. Vorübergehende Harnverhaltung ohne direkte Verletzung der Harnorgane.

Der 23 jährige Arbeiter 0. wurde beim Fortbewegen eines Eisenbahnwagens zwischen die Kopfwand desselben und die Ausschüttvorrichtung der Steinbruchanlage gequetscht. Er hatte einen Abbruch des rechten Darmbeinkammes erlitten und hier eine Hautwunde, in der sich ein AbszeB entwickelte. Auch mußte er in den ersten Tagen wegen Harnverhaltung katheterisiert werden. Als er nach 6 Wochen unserem Institut überwiesen wurde, konnte er wegen Schmerzen und Schwäche im rechten Bein noch sehr schlecht gehen, die Beugefähigkeit des Beines im Hüftgelenk war erheblich, die Abführung und Rollung in mäBigem Grade beschränkt.

Nachdem 0 . zwei Monate lang mediko-mechanisch und mit Massage und Bädern behandelt war, gab er bei der Entlassung an, dass er schwere Arbeit noch nicht werde verrichten können, weil er beim Bücken und Heben schwerer Gegenstände noch Schmerzen in der rechten Schambeingegend habe. Um diese Zeit, $3 \frac{1}{1} / 2$ Monate nach dem Unfall, war der Gang nicht 
mehr lahmend; in gerader Rückenlage war das linke Bein 1-11/2 cm anscheinend länger als das rechte bei gleichgestellten Darmbeinstacheln, obwohl die Entfernung vom Trochanter zum äußeren Malleolus auf beiden Seiten die gleiche.

Entlang laufend der rechten Darmbeinkante zieht eine $1 \mathrm{~cm}$ breite, anf der Unterlage gut verschiebliche, an einer Stelle noch schmerzhafte Hautnarbe von $12 \mathrm{~cm}$ Länge, in deren Umgebung noch 2 kleinere, nicht Aruckempfindliche Narben - herrührend von der Spaltung des Abszesses. Die Gegend der rechten Darmbeinschaufel ist stark misstaltet, verdickt; die ganze Crista ist verschoben, das an der AuBenseite des Darmsbeins festgewachsene Fragment ist deutlich prominent, etwas druckempfindlich. Am aufsteigenden Schambeinast rechts ist etwa in dessen Mitte ein druckempfindlicher Knochenvorsprung zu fühlen. Der ganze Sitzbeinknorren ist verdickt, tiefer stehend als der linke und anscheinend etwas nach außen verschoben. - Auch am horizontalen Schambeinast fühlt man eine druckempfindliche Verdickung. - Über der rechten GesäBbacke besteht noch eine Druckempfindlichkeit, an der Kreuzdarmbeinfuge beiderseits weder UnregelmäBigkeit noch Schmerzhaftigkeit. - Im Hüftgelenk besteht jetzt fast ganz normale Beweglichkeit; kein Muskelschwund am Bein nachweisbar.

Die Röntgenphotographie ließ die Darmbeinfraktur, aber auch den Callus am Sitzbein und am aufsteigenden Schambeinast recht deutlich erkennen.

Wir empfahlen unter Berücksichtigung der geklagten Beschwerden bei Belastung des Beckens für das erste Jahr eine Rente von $331 / 3$ Proz. und gaben der Erwartung Ausdruck, daß bei der Jugendlichkeit des Verletzten eine völlige Wiederherstellung eintreten würde. -

Fall 41. Beckenringbiegungsbruch durch Fall aus der Höhe auf die linke Seite. Leichte Verschiebung der linken Beckenhälfte.

Der $33 j$ ährige Arbeiter F. stürzte $31 / 2 \mathrm{~m}$ hoch herab von einer Leiter auf die linke Huftgegend. (Diagnose in den Akten Contusion des Beckens, insbesondere der linken Gesäßgegend). Zu Hause behandelt, versuchte er nach genau einem Vierteljahr die Arbeit wieder aufzunehmen, doch setzte er sie nach wenigen Tagen wieder aus wegen Schmerzen im Kreuz. Erst nach weiteren 2 Monaten kam er in unser Institut. Um diese Zeit ging F. noch sehr lahm, seine Bewegungen, besonders aber das Bücken, waren erheblich erschwert. Es wurde alsbald der später angeführte Befund festgestellt. - Bei der Entlassung aus unserer Behandlung gab F. an, daß es ihm erheblich besser gehe, daB er in der Ruhe keinerlei Beschwerden habe. Wohl aber träten noch Schmerzen in der linken Gesäßgegend auf bei längerem Gehen und solche im Kreuz beim Wiederaufrichten aus gebückter Stellung., Beim Gehen schont F. das linke Bein noch etwas. Der linke Darmbeinkamm steht etwas tiefer als der rechte. In der linken Leistenbeuge fühlt man am horizontalen Ast des Schambeines eine kleine druckempfindliche Knochenwucherung. Der linke Sitzbeinhöcker ist dicker als der rechte, die Abduktion des sonst gut beweglichen linken Beines ist eine Spur behindert; es mißt in der Gesäßfalte und handbreit über dem 
Knie $1 \mathrm{~cm}$ weniger im Umfange als das rechte. - Hier deuten auf eine Läsion in der hinteren Beckenringhälfte nur die anfänglichen Kreuzschmerzen und der leichte Niveaunterschied der Cristae ilei. - F. wurde mit einer Gewöhnungsrente von 20 Proz. entlassen. -

Fall 42. Beckenringbiegungsbruch mit Läsion der linken Kreuzbeinfuge und Doppelbruch am linken Scham-, bezw. Sitzbein durch Verschüttung.

Der 45jährige Arbeiter $K$. wurde am ganzen Körper bis an die Schultern von Lehm verschüttet, zum Teil von großen harten Stücken, in seine Wohnung mittelst Wagen transportiert, wo er acht Wochen bettlägerig war. Als er 4 Monate später in unser Institut kam, ging er noch mühsam an einem Stock und klagte über Schmerzen im Kreuz; er konnte das linke Bein nicht spreizen. Auch bei der Entlassung nach 6 Wochen hatte er noch Schmerzen im Kreuz und Druckschmerz beim Sitzen in der linken Gesäßgegend. Beim Treppen- und Leiternsteigen bekam er Zittern im linken Bein.

Seine Hauptbeschwerden verlegt der sonst gesunde und glaubwürdige Patient in die Kreuzgegend. Hier besteht eine Druckempfindlichkeit am Kreuzbein und dem untersten Lendenwirbeldornfortsatz. Eine UnregelmäBigkeit in der Form dieser Gegend ist nicht feststellbar. Am meisten schmerzhaft aber ist Druck auf die Gegend der linken Symphysis sacroiliaca; schmerzlos ist die Lendenmuskulatur beiderseits. Der beim Sitzen besonders empfindliche linke Sitzbeinknorren steht etwas tiefer als der rechte und ist deutlich verdickt. Die Abspreizung des linken Oberschenkels macht dem K. Schmerzen, hauptsächlich in der Gegend des linken aufsteigenden Schambeinastes, an dem ebenfalls eine daumenkuppengroße knöcherne Verdickung fühlbar. Bei Druck auf die Darmbeinstachel von vorn oder von hinten her wird ein besonderer Schmerz, wie dies früher der Fall war, nicht mehr ausgelöst. Das Hüftgelenk ist, von der Abduktionsbehinderung abgesehen, frei beweglich. Über dem Kreuzbein besteht ein handtellergroßer hypalgetischer Bezirk. Der linke Patellarreflex ist leicht gesteigert, der linke Bauchdeckenreflex nicht auslösbar. Links fehlt auch der Fußsohlenstichreflex. Wir empfahlen $\mathbf{K}$. vorläufig für eine Rente von $33^{1 / 3}$ Proz.

Fall 43. Beckenringbruch mit linksseitiger Fissur und Dislokation in der Symphysis sacroiliaca und am Schambein, Atrophie und scheinbare Verkürzung des linken Beines durch Fall auf den linken $F u B$.

Der Maurer $\mathrm{S}$. fiel in einen Fahrstuhl $4-5 \mathrm{~m}$ hinab und schlug mit dem Fuße des durchgedrückten linken Beines auf. Er konnte sich alsbald nicht mehr erheben, so dab er mittelst Wagens in das Krankenhaus gebracht werden mußte, wo er 22 Wochen verblieb. Dann in unserem Institut 5 Wochen behandelt, klagte er bei der Entlassung, also etwa 7 Monate nach dem Unfall, noch über Schmerzen in der linken Kreuzdarmbeinfuge und beim Gehen über Schmerzen im linken Hüftgelenk, die bis zum Knie ausstrahlten. Auch beim längeren Sitzen auf einem Stuhl sei er wie versteift im Kreuz und im linken Bein. 
Beim Gehen schont er das linke Bein, welches in gerader Rückenlage und bei gleichgestellten Darmbeinstacheln $1-1^{1 / 2} \mathrm{~cm}$ verkürzt erscheint. Die linke Darmbeinkante und auch die Gesäßfalte ist am stehenden Patienten eine Spur höher als die rechte. Das linke Fuß- und Kniegelenk, der FuB selbst und die Zehen funktionieren normal. Stoß gegen die Fußsohle wird im Hüftgelenk schmerzhaft empfunden. Hier besteht eine gewisse Bewegungsbehinderung, sowohl bei der Rollung des Oberschenkels nach auswärts, wie beim Spreizen der im Knie gebeugten Beine. Reiben im Hüftgelenk ist indes nicht wahrnehmbar, auch fehlt eine tastbare Formveränderung und Verdickung. Der Umfang des linken Beines ist an der Wade $3 / 4 \mathrm{~cm}$, handbreit über dem Knie $1 \mathrm{~cm}$, in der Gesäßfalte $3 \mathrm{~cm}(!)$ geringer als an den entsprechenden Stellen des rechten. Die Haut- und Sehnenreflexe zeigen keine deutliche Differenz.

Der seinem ganzen Wesen nach durchaus glaubhafte S. klagt über eine umschriebene Schmerzhaftigkeit bei Druck gegen den aufsteigenden linken Schambeinast und besonders bei Druck gegen die Gegend der linken Kreuzdarmbeinfuge. Hier springt der Rand des hintersten Teiles der Beckenschaufel etwas stärker hervor als auf der anderen Seite. Die Druckempfindlichkeit reicht nach der Mitte zu bis an die Dornfortsatzreihe, nach unten bis an die Spinae und die Gegend des Trochanter major. Eine Störung der Empfindlichkeit für Berührungen und Nadelstiche ist in diesem Bezirk nicht nachweisbar. -

$\mathrm{Ob}$ es sich nur um eine Erschütterung, bezw. Zerrung des Hüftgelenkapparates oder um eine Pfannenfissur gehandelt, ließen wir dahingestellt. Wir empfahlen eine Rente von zunächst 40 Proz.

Fall 44. Beckenringbruch, Läsion an der linken Kreuzbeinfuge und am linken Schambein. Retentio urinae.

Der 54 Jahre alte Werkmeister $\mathrm{S}$. kam in unser Institut 9 Wochen nach seinem Unfall, den er, wie folgt, schildert. Er sei von einem umfallenden Schleifapparat (mehrere Zentner im Gewicht) zu Boden geworfen und dabei am Becken seitlings zusammengedrückt worden. Sofort gehunfähig, sei er in einem Tuch in die nahe Wohnung getragen worden, wo er 6 Wochen zu Bett lag, ohne sich rühren zu können. In den ersten 5 Tagen sei der Urin nur tropfenweise abgeflossen, auch der Stuhl 8 Tage lang angehalten gewesen. Zuerst habe er sich nur an 2 Krücken fortbewegen können. Bei uns ging er auch noch sehr mühsam an einer Krücke. Bei der Entlassung nach 8 wöchiger Behandlung konnte S. zwar ohne Stütze gehen, klagte über Müdigkeit im Kreuz und in beiden Hüftgelenken, und über zeitweiliges „Drücken“ über der Harnblase.

Objektiver Befund: Die Wirbelsäule zeigte eine geringe Verbiegung im Brustteil convex nach rechts, im Lendenteil convex nach links. Der Oberkörper wird beim Stehen mehr nach links hinübergeschoben, so daß der rechte Darmbeinkamm und Trochanter mehr als auf der anderen Seite vorspringen. Bei gleichgestellten FüßBen steht die linke Hüfte etwas höher als die rechte. An der Verbindungsstelle zwischen linkem Kreuz- und Darmbein bemerkt man eine knöcherne Auftreibung, die besonders in die Erscheinung tritt, wenn S. den Oberkörper im Stehen nach vorn beugt. Der hintere Abschnitt des rechten Darmbeinkammes ist auf Druck em- 
pfindlich, desgleichen der absteigende Ast des rechten Schambeines dicht unter der Schamfuge; hier fühlt man auch eine kleinere knöcherne Auftreibung. Keine Störung in der Bewegungsfähigkeit der Beine, ja diese ist sogar auffallend ausgiebig, wohl infolge einer gewissen Schlaffheit der Muskulatur. In der GesäBfalte ist der Umfang des linken Beines $\left.2^{1}\right|_{2} \mathrm{~cm}$ geringer als der des rechten. Wir empfahlen eine Gewöhnungsrente von 30 Proz.

Fall 45. Beckenringbruch durch Sturz aus der Höhe, Callus am linken absteigenden Schambeinast, Schmerz in der linken Kreuzheinfuge. Blut im Urin.

Der 58jährige Dachdeckermeister $G$. stürzte ca. $5 \mathrm{~m}$ hoch herab auf Grasboden; gehunfähig. Anfänglich Blut im Urin. Nach $\left.5^{1}\right|_{2}$ Monaten unserem Institut überwiesen, war sein Gang noch sehr mühsam am Stock möglich. Sein Gehvermögen besserte sich hier in 8 wöchiger medikomechanischer Übung; doch blieb er zu Dachdeckerarbeit ungeeignet. Man fühlte eine Auftreibung am linken aufsteigenden Schambeinast dicht unter dem Schambogen, die recht druckempfindlich und auch bei flottem Ausschreiten schmerzhaft. Auch kann G. die Kniebeuge nicht ausführen, weil die Spreizung schmerzhaft ist. Der sonst gut bewegliche linke Oberschenkel zeigt eine Atrophie von $1 \mathrm{~cm}$. 40 Proz. Rente. - Ein Jahr nach der Entlassung klagt er hauptsächlich über Schmerzen in der linken Kreuzdarmbeinfuge, im übrigen derselbe Befund, nur ist der Gang erheblich besser geworden. 25 Proz. Rente.

Fall 46. Beckenrandbruch - Abbruch der Crista ilei.

Der 47jährige Arbeiter B. wurde von einer ins Rollen kommenden Winde gegen die rechte Körperhälfte geschlagen. Noch nach einem halben Jahr klagt er glaubhaft über Schmerzen an der rechten Darmbeinschaufel beim Gehen und besonders beim Spreizen des rechten Beines. Man füblte über der Leistenbeuge am Darmbein eine runde, harte Auftreibung, die bei Druck empfindlich. Die Rente, die B. zugesprochen erhielt, berücksichtigte besonders eine Mitverletzung des rechten Unterams.

Es besteht bei Nichtbeachtung geringer Residuen am verletzten Becken die Gefahr, daß man die Patienten für Simulanten hält. So waren die Residuen eines Beckenbruches über anderweitigen Verletzungen übersehen, zwar auch recht geringfügig, aber doch nicht bedentungslos für die Erwerbsfähigkeit im folgenden Falle.

Fall 47. Überfahren. Bruch des linken Oberarmes. Nieht erkannte Beckenverletzung.

Der 30 jährige Verletzte klagt uber Schmerz in der linken Leistenbeuge bei längerem Gehen, Es erwies sich das rechte Bein ein Spur verkürzt, am absteigenden rechten Schambeinast fühlte man eine geringe Verdickung. Das linke Bein war um $20^{\circ}$ in der Abduktion im Hüftgelenk eingeschränkt.

Fall 48. Bruch des Beckenringes rechts vorn am Schambein, rechts hinten in der Kreuzdarmbeinfuge. Nach 5 Monaten 
minimale scheinbare Verkürzung des rechten Beins. Schwierigkeit der Erkennung im Spätstadium.

Der 27jährige Klempner L. stürzte am 30. 1. 1903 mit einem Kameraden aus der Höhe von fünf Stockwerken von einem Gerüst. Der Kameral war sofort tot, er selbst blieb eine Stunde lang besinnungslos. In der Klinik stellte man autler der Gehirnerschütterung einen Gelenkbruch im rechten Ellenbogen and cinen Beckenbruch fest. Beztaglich der letztgenannten Verletzung gibt er an, er habe weder stehen, noch gchen, noch sitzen können. Er habe groke Schmerzen in beiden ]3einen und beiden Hüften gehabt. Er blieb ca. 4 Wochen in der Klinik und wurde dann ca. 9 Wochen mediko-mechanisch behandelt. Nach dieser Zeit stellte Herr Dr. Ludloff fest:

„Beim Gehen leichtes Hinken rechts, beim Bücken wird Schmerz an der rechten Vereinigungsstelle zwischen Kreuz- und Darmbein geäuRert, die auf Druck sich steigert. Bei der Betastung ist nichts Abnormes, auch bei Vergleichung mit der anderen Seite, wahrnehmbar.

In Rückenlage erschcint das rechte Bein etwas kürzer $($ ca. $1 \mathrm{~cm})$. Der rechte Rollhügel steht ungefähr $1 \mathrm{~cm}$ oberhalb der Roser-Nólatonschen Linie.

Bewegungen im Hüftgelenk sind auf beiden Seiten frei bei größerer Beugung Schmerz in der Schamgegend rechts neben dem Hodensack geäußiert.

Bei Betastung fühlt man hier am Sitzknorren am absteigenden Ast des Sitzbeins einc harte Resistenz, die dem Knochen angehört.

Die Röntgen-Photographie zeigt am Becken einen Bruch des absteigenden und wagrechten Schambeinastes ohne grobe Verschicbung bei maliger Callusbildung."

Da U. wegen Schmerzen im Becken und im Arm die Arbeit noch nicht aufnehunen konnte, blicb er noch 8 weitere Wochen in medikomechanischer Behandlung in unserem Institute für Unfallverletate. Bei der Entlassung zur Arbeit, etwa $5_{2}^{1:}$ Monate nach der Verletzung, klagte I., daß er noch Schmerzen im Kreuz babe bei langerem Stehen und Gehen. Er habe das Gefühl, als ob das rechte Bein kürzer sei.

Was die Verhältnisse am Jeeken des im ganzen wenig kräftigen IIannes betrifft, so wurde bei der Entlassung Folgendes notiert:

Am aufrecht stehenden Patienten fällt ein leichtes Hervorspringen des rechten Lendenmuskelwulstes auf. Der rechte Darmbeinkamm stebt ebenso wie der rechte Sitzhöcker eine Spur tiefer, als die entsprechenden Punlite linkerseits. Eine Druckmpfindlichkeit in der Kreuzlendengegend, bezw. in der rechten Kreuzdarmbeinfuge besteht nicht, dagegen ist der aufsteigende und horizontale Ist des rechten Schambeins an einem in der Röntgen-Photograpinic als Bruchstelle wohlerkennbaren Punkte druckempfindlich, ohne daß man hier Verdjckungen mit Sicherheit fúhlen könnte. Beide Beine können im Hüftgelenk ausgiebig gebeugt, gestreckt, gespreizt und herangeführt werden. Ein Umfangsunterschied besteht an den beiden Beinen nicht. Der Gang des U. ist nicht lahmend; er kann gut in die Ḱniebeuge gehen. Ein Stoß gegen die Fubsohlen lost im Becken Schmerzgefühl nicht. aus. Die Kniesehnen-, Fußsohlenkitzel- und -stichreflexe sowie das Hautgefühl am ganzen Körper erwiesen sich normal. 
Es was anzunehmen, daß U. nicht allzuschwere Arbeit wieder dauernd würde verrichten können. Die durch die Beckenverletzung bedingte Erwerbsfähigkeitsminderung würde man auf etwa 25 Proz. für sich haben schätzen müssen. Wir empfahlen ihn für eine Rente von 40 Proz. unter Rücksichtnahme auf die Ellenbogenverletzung und des consumierenden Krankenlagers.

Als beachtenswert möchte ich bei dem Falle hervorheben, daß auf eine Fissur in der hinteren Beckenhälfte (Kreuzdarmbeinfuge), die man bei der Beinverkürzung m. E. unzweifelhaft annehmen muß, nur in den ersten 8 Wochen die Druckempfindlichkeit hinwies, die aber bei der Entlassung nicht mehr vorhanden war, und daß man, vom Röntgenbilde und von der Druckempfindlichkeit abgesehen, auch die Fraktur am Schambeinast aus den gewöhnlichen Frak. tursymptomen (Dislokation, Crepitation) nicht diagnosticieren konnte. Die Beinverkürzung, die indes für weniger Geübte leicht übersehbar, war also nach Ablauf 1/2 Jahres nur unter Berücksichtigung der Schwere des Unfalles und der Frühsymptome zu erklären. Man kann sich demgemäß denken, daß solche Fälle leicht falsch beurteilt, die Klagen der Verletzten gelegentlich für unbegründet angesehen werden, besonders wenn die erste Behandlung nicht in den Händen besonders Erfahrener wie in vorliegenden Falle, ruht oder anderweitige schwerere Verletzungen die Aufmerksamkeit von der Beckenverletzung ablenken.

Ich halte es nicht für ausgeschlossen, daß gelegentlich auch Beckenringbrüche vorkommen bei akuter Belastung des Rumpfes, ohne daß die Gewalt am Becken selbst ansetzt, sondern fern ab davon, z. B. bei jäher Schulterbelastung. Wenigstens sprechen manche Beobachtungen dafür. Der folgende Patient behauptete bestimmt, daß weder sein Oberschenkel noch sein Becken direkt betroffen worden. Dann müßte man die beiden Oberschenkelköpfe als die Vermittler des Gegenstoßes ansehen.

Fall 49. Jähe Belastung der rechten Schulter des sich entgegenstemmenden Verletzten. Bruch in beiden Schambeinen und der rechten Kreuzdarmbeinfuge. Heilung mit leichter Verschiebung.

Der 40 Jahre alte, kräftige Arbeiter H. wollte am 13. August 1903 eine beladene Lowry heben. Diese fiel zurück und belastete plötzlich seine rechte Schulter, so den Mann zusammendrückend, ohne doch die Becken-, bezw. Oberschenkelgegend direkt zu berühren. Trotzdem wurde im Krankenhaus die Diagnose Oberschenkelquetschung gestellt, weil sich ein großer BluterguB in der Gegend des rechten Oberschenkels, des Hodens und Dammes mit starker Anschwellung entwickelt hatte. H. konnte nicht mehr aufstehen und muBte ins Hospital gefahren werden. Er hat zwar 
immer selbst Urin gelassen, aber er hatte in den ersten drei Wochen große Schwierigkeiten damit.

Nach 13 Wochen wurde $\mathbf{H}$. entlassen, weil die Krankenkassenfürsorge ablief und der inzwischen bankerott gewordene Arbeitgeber den Unfall nicht gemeldet hatte.

Auf der Wanderschaft zu Verwandten versagten die Beine den Dienst und so kam er in mein Krankenhaus in Göttingen.

Er klagte am 7. Dezember 1903 bei der Aufnahme über heftige Schmerzen im Becken, im Unterbauch, im Kreuz und in den Beinen und sah sehr elend aus. Er konnte sich nur ein wenig bücken, gar nicht in Kniebeuge gehen. Der rechte Oberschenkel war nur wenig abducierbar. Nach mehrwöchiger Bettruhe gingen die Beschwerden zurück und ich konnte mit Übungen beginnen.

Bei der Entlassung am 28. Februar gibt $\mathrm{H}$. an, daß es ihm viel besser gehe, daB sich sein Ernährungszustand gehoben habe, daß er aber noch Schmerzen im Kreuz verspüre und etwas rechts davon. Er wolle die Arbeit wieder aufnehmen.

Die Untersuchung ergibt rechts vom Penis nach der Leiste zu eine Vorwölbung, einer Bruchbildung ähnlich. Sie wird, wie man beim Tasten feststellen kann, durch verschobenen Knochen gebildet. Die Vorschiebung der rechten Schamfugenpartie ist ermöglicht durch eine Fraktur, etwa in der Mitte des horizontalen Schambeinastes und anscheinend auch durch eine Continuitätstrennung in der Schamfuge. Das rechte Tuber ischii steht deutlich tiefer als das linke. Am aufsteigenden Schambeinast ist Callus nicht zu fühlen.

Links vom Scrotum füblt man einen wohl $6 \mathrm{~cm}$ langen Knochenvorsprung in der Adductorenmuskulatur mit der Spitze durch die angespannte Haut prominierend. Er ist vergleichbar in der GröBe einem Zungenbeinhorn, beweglich wie dieses. Es ist offenbar ein vom Schambein abgesprengter und eingeheilter Knochenspahn.

In den Kreuzdarmbeinfugen ist etwas Abnormes nicht fühlbar, doch besteht noch leichte Druckempfindlichkeit rechts vom Kreuzbein.

Die Beine sind gleich lang; das rechte Bein ist ein wenig (um ca. 15 $5^{9}$ ) in der Abduktion beschränkt. Ausgiebige Abduktion beider Beine ist sehr schmerzhaft. H. kann bis zur Hälfte in Kniebeuge gehen, sein Gang ist nicht lahmend. Ich empfahl ihm eine Rente von $33 \frac{1}{1} 3$ Proz. zuzubilligen.

Bei Fällen, die sich unmittelbar nach der Verletzung als Beckenbrüche charakterisieren, findet sich nach Verlauf von Monaten und Jahren, auch bei sorgfältigster Untersuchung, oft objektiv nichts am Beckenringe von Frakturresiduen. Dann darf man aber sonst glaubhaft vorgebrachte Beschwerden keineswegs ganz ableugnen. Leichte Veränderungen findet der Geübte oft nur, während sie dem Ungeübten entgehen. Einige solche Befunde nach einwandfrei festgestelltem Beckenbruch seien hier kurz noch berichtet.

Fall 50. 52jähriger Mann, überfahren. Beide Beine können wenig gespreizt werden, linkes Bein $1 / 2 \mathrm{~cm}$ verkürzt, linkes 0 s pubis und 0 s ischii 
an der Synostosenstelle eine Spur verdickt und stark druckempfindlich. Er war obne subjektive Beschwerden und nahm seine Arbeit in rollem Umfange wieder auf.

Fall 51. 34jähriger Mann, überfahren, hatte eine vom Vorgutachter nicht wahrgenommene Verdickung an der hinteren Partie des rechten Darmbeinkamms und eine ebensolche am linken Schambein dicht unterhalb des Schamwinkels. Auch das rechte Schambein war, wie das linke, leicht druekempfindlich, die Abduktion des rechten Beins eine Spur gegen die des linken eingeschränkt. 20 Proz. für ein Jahr, dann 0 Proz.

Fall 52. 27jähriger Zimmergesell, 4 Stockwerk hoch abgestürzt: Commotio cerebri, Fract. radii dext; Fract. pelvis multipl., Contusio thoracis. - Rechte GesäBbacke weniger dick, in der GesäBfalte 1/2 cm dünner, rechtes Bein eine Spur verkürzt, seine Abduktion etwas eingeschränkt. Am rechten horizontalen, sowie am descendierenden os pubis dext. eine druckempfindliche Knochenverdickung.

Fall 53. Kalkträger, Sturz aus der Höhe, Bruch beider Fersenbeine und durch Fall auf das GesäB deutliche Lockerung des Steißbeins. Später an diesem nichts objektiv nachweisbar, aber subjektive Beschwerden beim Bücken und bei Stuhl.

Fall 54. 38jähriger Maurer, Sturz $4 \mathrm{~m}$ hoch vom Gerüst. Commotio cerebri. Fract. brach. dext. Am linken absteigenden Schambeinast deutliche Verdickung. Hier keine Beschwerden.

Fall 55. 40jähriger Dachdecker G. $5 \mathrm{~m}$ hoch abgestürzt auf die rechte Seite. Verdickung am linken absteigenden Schambeinast, der linke Oberschenkel $1 \mathrm{~cm}$ dünner, Abduktion beider Beine behindert. 30 Proz.

Fall 56. 49jähriger Arbeiter zwischen Wagen gequetscht; lag an den Folgen des Beckenbruchs 11 Wochen zu Bett. Klagt nach $3 / 4$ Jahr über Schmerzen im Kreuz und längs der Leistengegend, sowie in der rechten Synchond. sacroiliaca beim Vorwärtsbücken, in der linken Darmbeinschaufel beim Neigen nach links. Objektiv: Verdickung und Druckempfindlichkeit am rechten descend. Os pubis dext. Kniescheibenbandreflex rechts gesteigert, rechte Wade $2 \mathrm{~cm}$, Oberschenkel in der Gesälfalte $1 \frac{1}{2} \mathrm{~cm}$ dünner. Rechtes Bein etwas verkürzt, in der Abduktion beschränkt. $33^{1 / 3}$ Proz. wahrscheinlich dauernd.

Fall 57. 42jähriger Arbeiter, überfahren, am Tage danach Urethrotomia externa wegen Harnröhrenruptur. Klagt 3/4 Jahr später über Schwäche und Schmerzen im Kreuz beim Heben bei Kniebenge. AuBer der traumatischen Harnröhrenstriktur war am Beckenring nichts nachweisbar, obwohl ein früher aufgenommenes Röntgenbild mehrfache Fissuren an dem Schambein zeigte. Vorläufig 60 Proz.

\section{C.}

\section{Harnröhren- und Harnblasenverletzungen. \\ I. Harnröhrenverletzungen.}

Kaufmann hat Contusion der Harnröhre und Harnröhrenwandverletzung unterschieden. Da es sich bei beiden um Quetschungen handelt, so ist es vielleicht besser, zu sprechen von penetrierenden 
und nicht penetrierenden Verletzungen des Urethralrohrs. Das Kriterium der ersteren, wenigstens das für die Praxis und die Art der Behandlung ausschlaggebende, bleibt die Blutung aus dem Orificium externum, sei es, daß sie mit dem Urinstrahl oder ohne diesen tropfenweise erfolgt.

Wie oben schon erwähnt, ist der Rittlingsfall (chute à califourchon) recht häufig Veranlassung zur Harnröhrenläsion, nach Ka ufmann unter 59 nicht weniger. als 43 mal, nach Martens unter 24 Fällen 15 mal. Die Contusion kann mit einfacher Durchblutung des periurethraten Gewebes, z. B. der Corpora cavernosa abgehen, es kann selbst die Muscularis einreißen, die Mucosa aber noch erhalten bleiben. Erst wenn letzere auch birst, und hierbei spielen Quetschung und Zerrung naturgemäß ineinander, ist die penetrierende Verletzung mit Blutung ex orificio gegeben. Da sich die Stoßwirkung an den knöchernen Schenkeln des beim Manne wenigstens engen Schamwinkels erschöpft, noch ehe die vordere, bezw. obere Hälfte des Harnrohrs ganz zertrümmert ist, so bleibt die Durchtrennung der Circumferenz des Urethralrohrs oft eine teilweise. Ich habe 4 mal wegen dieser Verletzung selbst operiert und da jedesmal einen mehr oder weniger breiten, undurchtrennt gebliebenen, die Führung des Katheters in die Harnblase beeinflussenden Rest von Urethralwand gefunden.

Die Gefahr der Harninfiltration, das ist der springende Punkt, besteht bei kleinsten penetrierenden Läsionen so gut wie bei totalen Abreißungen.

Diese Erwägung läßt nur eine Therapie für alle penetrierenden, d. h. sich durch Blutung aus der Harnröhre äußernden Läsionen za, die Incision am Damm. Jeder Katheterismus zu diagnostischen Zwecken muß künftighin als gefahrbringend unbedingt verworfen werden, so gut wie heute jedes Sondieren, z. B. einer Schulswunde, zu diagnostischen Zwecken als Fehler angesehen wird.

Für den Mechanismus der Harnröhrenzertrümmerung durch spitze Fragmente gebe ich noch eine Bleistiftzeichnung eines Beckens von einem tot eingelieferten verschütteten Bergmann mit Durchreißung der Harnröhre dicht am Blaseneingang, Prostatazerreißung. und starker perirectaler Durchblutung.

Fall 58 (Fig. 34). Fraktur des horizontalen rechten Schambeinastes, des rechten Sitzbeins, Fissuren in der Nachbarschatt der rechten Kreuzdarmbeinfuge, Infraction des linken horizon- 
talen Schambeinastes, Berstung in der Schamfuge. Sofortiger Tod. Harniöhrenruptur dicht am Blaseneingang.

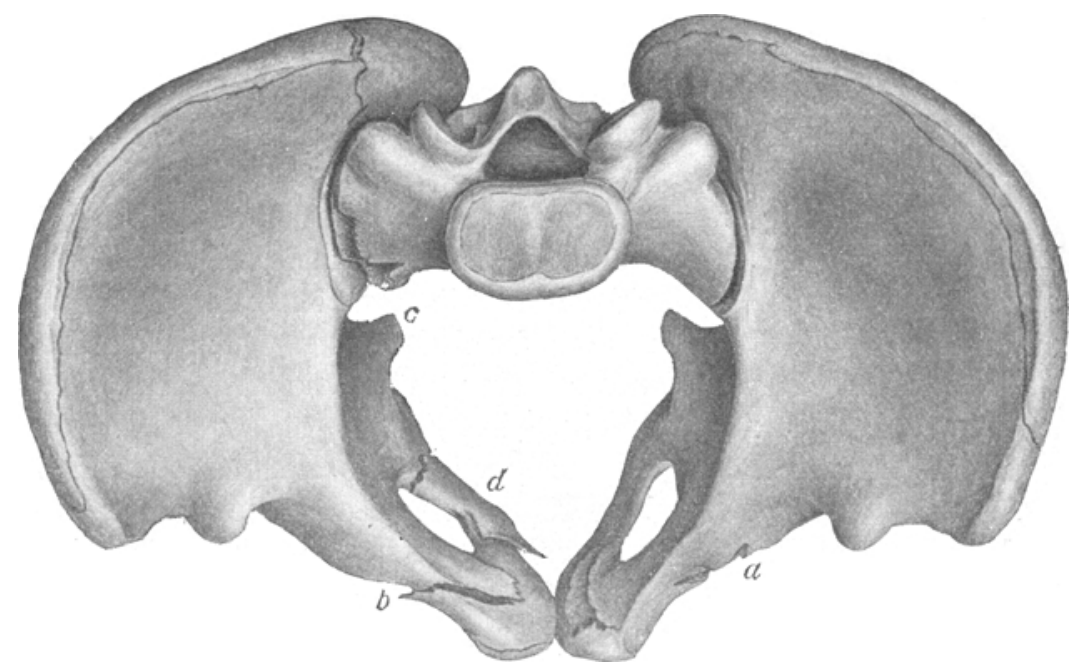

Fig. 34.

Harnröhrenanspiessung.

Das Präparat zeigt in seltener Weise in allen Läsionsstellen die Compression des Beckenringes. Am linken horizontalen Schambein sitzt eine Infraction (a) an der Vorder- bezw. oberen Contour, genau correspondierend mit den Anfange der Fissur an der anderen Seite (b). Die Pressung aber ist auch an den Continuitätstrennungen im Bereich der rechten Kreuzdarmbeinfuge (bei c) erkennbar. Hier ist der Kreuzbeinflügel splitternd geborsten an der Vorderfläche, die Fissur hält sich nicht an die Fuge, sondern läuft über diese hinweg in den Darmbeinflügel. Auch das nach innen sich abspaltende Fragment (d) am Sitzbein weist auf die Biegungsspannung hin. Sein spitzer Stachel wie der des Schambeinfragments — beide richten sich drohend gegen die Harnröhre, die im Augenblick stärkster Zusammenpressung des Beckens durchstochen wurde. Es redet eine deutliche Sprache dies Präparat! Vergl. Fig. 1.

In den Arbeiten von Terrillon, Oberst, König, Riedel, Kaufmann und neuestens von Martens sind alle hierfür in $\mathrm{Be}$ tracht kommenden, praktisch wichtigen Fragen bereits erörtert, auch die meisten chirurgischen Lehrbücher betonen die Wichtigkeit der Harnröhrenläsion und die Notwendigkeit eines aktiven Vorgehens bei denselben, aber Gemeingut aller Ärzte sind die dort niedergelegten Erfahrungen doch noch nicht geworden. Es kommt meines Erachtens für den Praktiker nicht wesentlich darauf an, ob die Pars membranacea oder die Pars bulbosa gequetscht, das Wesent- 
liche ist, sich bei einer Contusion der Dammgegend darüber zu vergewissern: Ist die Harnröhrenwand wirklich durchgequetscht bezw. gerissen oder nicht. Dafür aber bleibt, aber nur in ganz frischen Fällen, als einziger Anhalt die Beobachtung, ob sich von der Quetschungsstelle Blut entleert, nach außen bezw. in die Harnblase, aus der dann das Blut oft mit dem Urin vermischt oder in Gerinnseln entleert wird.

Die Bougierung vermag selbst bei völliger Durchreißung der Urethra diese nicht immer mit Sicherheit festzustellen. Das Bougie kann dann in der Regel nicht bis in die Harnröhre eingeführt werden, seine Spitze fällt in den durchblutenden Quetschungsherd.

Doch es ist ein, wenn auch seltener Zufall, daß die Spitze gerade das Lumen des proximalen Teils trifft.

Bei teilweiser Läsion läuft die Spitze des Bougies oder Katheters, geleitet von den erhalten gebliebenen Teilen der Harnröhrenwand, meist glatt bis in die Harnblase. Aber die führenden Fäden können schon nach wenig Tagen nekrotisch geworden sein, so daß dann, wie schon Kaufmann (1886) betont, der Katheter nicht mehr bis in die Blase gebracht werden kann. Auf einseitige Schmerzlokalisation darf man bei der allgemeinen Quetschung der Gewebe am Damm gar nicht rechnen.

Die Harnentleerung ist fast immer eine ungehinderte bei leichteren Zertrümmerungen der Harnröhrenwand.

Läßt also Bougierung oder Katheterisierung für die Diagnose von vornherein nichts erwarten, so wird man sie geradezu verwerfen müssen im Hinblick auf die Gefahr, falsche Wege zu bahnen und vor allem wegen der Gefahr der Infektion der Wundstelle.

Der Katheter oder das Bougie darf in solchen Fällen frühestens zur Anwendung kommen, wenn man im Begriff steht, die Urethrotomie zu machen, die in allen Fällen von Hararöhrenruptur sofort in Frage kommen muß.

In einer kleinen Arbeit, "Zur Diagnose der subkutanen Harnröhrenruptur" (1903), habe ich an Hand von 2 Fällen bereits berichtet, daß sowohl bei Harnröhrenruptur ohne, wie auch mit Knochenfraktur ein Nélaton glatt bis in die Harnblase gelangen kann, selbst bei vollständiger Durchtrennung der Urethra, wie auch Kaufmann berichtet. Das ist aber ein Zufall, mit dem man für gewöhnlich nicht rechnen darf.

Über den einen dieser Fälle möchte ich noch eingehend berichten. 
Fall 59. Beckenringbiegungsbruch mit zahlreichen Fissuren. HarnröhrenzerreiBung. Exitus am 5. Tage infolge Pneumonie.

Der 46jährige Fördermann $\mathrm{S}$. wurde etwa 2 Stunden nach seinem Unfall abends in das Königshütter Lazarett eingeliefert. Er war von zwei Förderwagen am Becken in frontaler Richtung zusammengequetscht worden und sofort zusammengebrochen. Er gab an, daß er im Becken ein lautes Krachen verspürt habe. Auf dem Transport habe er noch Urin in groBer Menge abfließen gefühlt. Bei der Aufnahme sah der an sich wenig kräftige Manl fahl im Gesicht aus. Über dem rechten Trochanter starke blaue Anschwellung, über dem linken Darmbeinrand leichte Hautabschürfungen.

Die Beine konnte S. in Rückanlage unter Schmerzen ein wenig erheben, die Patellarreflexe waren nicht auslösbar. Das rechte Bein hatte weniger motorische Kraft als das linke, es lag einwärts rotiert, etwas abduciert, war nicht verkürzt. An der Symphyse ließ ein scharfer Absatz erkennen, daß hier rechts neben der Mittellinie eine Fissur saß, in der die rechte Beckenhälfte leicht nach rückwärts dislociert war.

Druck auf die Spinae ilei ant. nach hinten, die von hinten her nach vorn machte auffallenderweise nirgends Schmerzen. Dagegen war Druck auf die Symphyse abwärts schmerzhaft und ergab an dem genannten "Absatz" Crepitation und Verschiebung. Aber man konnte die Symphyse für sich bewegen, ein Beweis, daB auch auf der anderen Seite eine Fissur, daßs die Symphyse gewissermaBen aus dem Ringe herausgebrochen war.

Harnblasendämpfung reicht bis 3 Finger unterhalb des Nabels. Scrotum und Damm blauschwarz von Blutunterlaufungen.

Urinentleerung unmöglich, auch nicht bei seitlicher Lagerung und im Bade. Es tropft andauernd Blut aus der Harnröhre.

Vom Mastdarm aus waren die Bruchstellen an beiden Schambeinen tühlbar, die Prostata schien nach oben gerückt, leicht verschieblich.

Mit einem Metallkatheter gelang es mir unbehindert bis in die Harnblase zu kommen, aus der sich Urin entleerte, bis ich den Abfluß verhinderte. In Morphium-Äther-Narkose wird die Urethrotomie gemacht, man kommt in eine mächtige bluterfüllte Höhle. Ein starkes Metallbougie vom Orificium externum eingeführt, fällt in diesen Hohlraum und stöBt beiderseits auf rauhe Fragmentflächen. Es blutet zunächst stark, erst nach mehrere Minuten langer Tamponade vermag man sich zu orientieren. Die Prostata ist als derb-weiche Resistenz tastbar. Aus diesem für das Gefühl charakteristischen Gewebe laufen einzelne lange Fäden mit Schleimhautepithel heraus, Fetzen der völlig durchrissenen Urethra. Es gelingt an diesen die zentralen Teile der Harnröhre hervorzuziehen und mit zwei Seidenfäden zu fassen.

Expression der Harnblase durch Druck auf den Bauch gelang nicht, auch nicht bei Lockerlassen der Seidenschlingen. Ein weiblicher Katheter, der ca. 3/4 Liter stark blutigen Urins entleert, zeigt, daß die Abrißstelle etwa $4 \mathrm{~cm}$ vor dem Blasenhalse sitzt.

Das periphere stark retrahierte Ende der Harnröhre zeigte keine rein quere DurchreiBung, ein sehr langer, spitz auslaufender Schleimhautfetzen war zunächst erreichbar, er mochte etwa $2 \mathrm{~cm}$ lang sein. Die andere Seite der Urethralwand fehlte hier in der gleichen Entfernung, ein correspondierender Fetzen des centralen Endes war mehrfach eingerissen. 
An ein direktes Zusammennähen der beiden Haruröhrenstücke war unter diesen Umständen gar nicht zu denken. Das periphere Stück war ja weithin beweglich und heranholbar. Aber das centrale war es nicht, auch nicht genug isolierbar. Überdies hätte man große Stücke der Harnröhrenwand resecieren müssen und damit für die künftige Harnröhre viel Epithelmaterial entfernt. Ich fixierte infolge dessen nur das centrale Stück mit den Seidenzügeln so, das die Katheterfuhrung gesichert blieb und holte auch das periphere nach Möglichkeit heran. Ausspülung der Höhle mit sterilem Wasser. Nélaton in die Harnblase mit Sicherheitsnadel an den Seidenzügeln fixiert, Jodoformgazetamponade.

Am folgenden Tage Befinden subjektiv gat, fieberfrei, aus dem sonst zugepfropften Nélaton wird 2 mal auf Wunsch Urin im Strahl entleert. Am 4. Tage abends Temperaturanstieg, rechts hinten unten Dämpfung, scharfes Bronchialatmen. Am 5. Tage abends Unruhe, plötzlich bewuBtlos, pulslos - unerwartet Exitus.

Die Obduktion ergab gutes Aussehen der Dammwunde, bezüglich der Harnröhre außer den schon geschilderten Verhältnissen noch folgende näher feststellbare Verhältnisse.

Die Harnröhrenruptur sab $3 \frac{1}{2} \mathrm{~cm}$ vor dem Blaseneingang; auch im centralen Stück waren noch über die gefransten QuerriBrander hinaus bis $1 \frac{1}{2} \mathrm{~cm}$ lange Längsrisse erkennbar. Am peripheren Ende war der lange Fetzen inzwischen nekrotisch geworden; der daneben bestehende Defekt reichte mit seiner Spitze etwa $2 \mathrm{~cm}$ hinauf. Das cavernöse Gewebe war weithin thrombosiert. Die Beckenverletzungen lassen sich kurz so zusammenfassen: Die Symphyse ist ganz herausgebrochen, indem sowohl die beiden horizontalen Schambeinäste wie auch die absteigenden durchgebrochen sind. Im linken hinteren Darmbeinflügel eine typische Fissur (siebe Fig. 3). In der rechten Kreuzdarmbeinfuge besteht eine deutliche Lockerung und Durchblutung des Gewebes dieser Gegend.

Der Tod war eingetreten infolge von Aspirationspneumonie beider Unterlappen, besonders des rechten. Myodegeneratio cordis, chronischer Magenkatarrh vermutlich infolge früheren Potatoriums.

$\mathrm{Zu}$ der sofortigen Operation vermögen sich die praktischen Ärzte begreiflicherweise nicht immer alsbald zu entschließen, besonders dann nicht, wenn zwar Blutungen aus der Harnröhre, aber keine Harnverhaltung beobachtet werden. Die unausbleibliche Folge ist dann so gut wie immer die Harninfiltration und weiterhin die septische Infektion, die unausbleiblich ist, wenn der Katheter zu diagnostischen Zwecken oder zwecks Harnentleerung angewendet wurde, aber meist auch ohne dies.

Wohl mag auch ohne Urethrotomie einmal eine kleine wirkliche Harnröhrenwandwunde primär, d. h. ohne die genannten Complikationen ausheilen, aber das ist doch ungemein selten und jedenfalls bei ernsten Dammquetschungen nur ganz ausnahmsweise zu erwarten. Die hohe Lebensgefahr, die man bei Unterlassung der operativen Therapie riskiert, rechtfertigt es, auch trotz dieser Möglichkeit der 
Spontanheilung das sofortige operative Vorgehen ein für allemal zu empfehlen. Denn ist erst Harninfiltration eingetreten, dann beherrscht man die Entwicklung der Folgen nicht.mehr, während die Boutonnière in frischen Fällen stets ohne nachteilige ernste Folgen für das Leben und die Gesundheit verläuft.

Kanfmann hat anf Grund großer Literaturzusammenstellung alles dies schon hervorgehoben, aber doch der abwartenden Behandlung immer noch Raum gelassen. Heute muß man sie gañz verwerfen. Mein Lehrer Wagner stand auf diesem Standpunkt und seine Auffassung gründete sich auf eine große Erfahrung. Bei ihm hatte ich also keine Gelegenheit, die schlimmen Folgen der Unterlassung der Frühoperation zu sehen. Aber die nachfolgenden Fälle mögen sie ins rechte Licht setzen.

Fall 60. 33 Jahre alte traumatische Harnröhrenstriktur. Unterlassung der primären Urethrotomie.

Ein 64 Jahre alter Briefträger $\mathrm{K}$. stand in Breslau lange in meiner Behandlung wegen einer hochsitzenden traumatischen Harnröhrenstriktur. Er war 1869 im Manöver, im Begriff einen Koffer vom Wagen zu reichen, beim Anheben desselben mit einem $\mathrm{FuB}$ abgleitend, rittlings auf die scharfe Kante des Wandbrettes des Kastenwagens zu sitzen gekommen. Es entleerte sich sofort Blut aus der Harnröhre und er hatte einen starken Bluterguß am Damm ohne äußere Wunde. Er konnte anfänglich nur tropfenweise unter Schmerzen Harn lassen, wurde deshalb katheterisiert und auch im Lazarett zunächst durch Katheterisieren behandelt. Nach etwa einer Woche, nachdem sich bereits Spontanentleerung des Urins eingestellt, erkrankte er aufs schwerste unter hohem Fieber, mit Anschwellung und Misfärbung der Damm- und Scrotalgegend. Jetzt erst wurde die Urethrotomie gemacht, an die sich eine mächtige AbstoBung motifizierten Gewebes anschloß. Nach mehrmonatigem Krankenlager trat Heilung ein.

Ich fand bei dem Patienten einen schmerzlosen großen harten Knoten am Perineum unter einer derben Narbenhaut. Die Harnröhre war im hintersten Teil auf eine Länge von etwa $4 \mathrm{~cm}$ stark verengt, für Mercier Nr. 8 noch eben durchgängig. K. hatte zeit seines Lebens mit einem in seiner Intensität schwankenden chronischen Blasenkatarrh zu kämpfen.

Fall 61. Quetschung der Schambogengegend. Harnröhrenschnitt erst am 3. Tage. Harninfiltration. Heilung mit großer Striktur. Tod nach 5 Jahren.

Der 32jährige Arbeiter S. fiel beim Einebnen eines rübenbeladenen Eisenbahnwagens am 25. November 98 von der Rückwand des Wagens herab und kam rittlings auf einen der beiden Puffer zu sitzen. Das Mittelfleisch war stark blutunterlaufen, doch ohne äußere Wunde. Starker Ausfluß von Blut aus der Harnröhre wies auf eine Zerreißung der Harnröhrenwand hin. Urin konnte ohne wesentlichen Schmerz gelassen werden. Der Patient wurde ins Krankenhaus aufgenommen, konnte aber hier stehen und gehen, auch die Blutung aus der Harnröhre hörte am 2. Tage auf. Erst 
als am 3. Tage die Harnentleerung wieder cessierte, Fieber einsetzte und die Dammgegend stärker anschwoll, machte der Arzt den Harnröhrenschnitt. Auch hier stieß sich im weiteren Verlauf ein faustgroBes Stück des infiltriert gewesenen Gewebes ab. Der SchluB der Harnröhrenfistel erfolgte erst nach mehreren Monaten.

Ein Jahr nach dem Unfall konnten wir eine in der Pars pendula penis beginnende Striktur feststellen, die sich nach der äuBeren I3etastung etwa $5 \mathrm{~cm}$ weit nach hinten erstreckte und überaus druckempfindlich war. Auch mit feinsten Bougies gelang es nicht sie zu überwinden. Bei Erektionen stand das Glied nach einer Seite geknickt. Beim Coitus latte der Patient beobachtet, daß sich kein Samen nach außen entleert, trotz Ejaculation, sondern nach der Blase zu. DemgemäB bestanden auch alle Anzeichen eines schweren Blasenkatarrhs: alkalische Reaktion, trübes Aussehen, Beimengung von Flocken, welche sich mikroskopisch als Gemisch von Zellen und Kristallmassen erwiesen. Der Urin lief dauernd in kleinen Mengen ab. Es bestanden heftige Schmerzen, die von der Dammgegend zu den Oberschenkeln ausstrahlten.

Der durch das lange Krankenlager mürbe gewordene Patient lehnte jede Therapie ab, sowohl eine blutige Operation, Excision der Narbe, wie auch eine Bougiebehandlung.

$1 \frac{1}{2}$ Jahre später sah ich ihn wieder, diesmal in erbeblich verschlimmertem Zustande. In bezug auf die Striktur hatte sich nichts geändert, aher der Urin war aashaft stinkend. Patient litt an abendlichen Temperatursteigerungen, allgemeinem Übelbefinden und sah schlecht aus. Er lehnte trotz aller Vorstellungen jede energische Behandlung und auch Untersuchung $a b$ und ist, wie ich aus den mir freundlichst zur Verfügung gestellten Akten der Zuckerberufsgenossenschaft sehe, am 19. Dezember 1903, also 5 Jahre nach dem Unfall verstorben. Sein Blasenleiden hatte sich, da er nicht Vernunft annehmen wollte, auch dem Schnapse sehr ergeben war, fortdauernd verschlechtert und vermutlich Nierenabszesse zur Folge gehabt. Schüttelfröste und erysipelatöse Erkrankungen der Beine verzehrten seine Kräfte, bis er schließlich unter den Erscheinungen eines apoplektischen Insults (septische Embolie?) zugrunde ging.

Im folgenden Fall kam es nach einer nicht beachteten Harnröhrenverletzung zu spontaner Fistelbildung am Damm, eine Bestätigung der freilich seltenen Beobachtung das die Urininfiltration auch ohne Operation in Heilung mit Fistelbildung ausgehen kaun, freilich nicht ohne recht unerfreuliche Begleiterscheinungen. fistel.

Fall 62. Dammquetschung. Dammnekrose. Dauernde Harn-

Ein 63jähriger Arbeiter D. kam zu unserer Beurteilung auf Veranlassung des Schiedsgerichts für Arbeiter-Versicherung, weil die Ansichten der Vorgutachter über den Grad der Erwerbsbeschränkung erheblich differierten. Nach den Akten und den eignen Mitteilungen des Mannes hatte er 6 Jahre zuvor eine Quetschung der Dammgegend dadurch erlitten, daßs er sich auf die Sitzbrettecke eines umkippenden Holzstuhls mit Wucht aufsetzte. Erst einige Tage später nahm D. ärztliche Hilfe in Anspruch, als 
völlige Urinverhaltung und Zeichen des Gewebsbrandes am Damm auftraten. Hier stießen sich ausgiebige Partien ab, während D. eine schwere Allgemeinkrankheit durchmachte. Seit jeiner Zeit besteht hinter dem Hodensack eine Fistel, durch die aller Harn nach Art der Frauen entleert wird. Es war ein spontaner Durchbruch des retinierten Urins durch das mortifizierte Gewebe seinerzeit erfolgt, freilich nicht ohne schwere septische (oder urämische?') Allgemeinerkrankung.

Mit Rücksicht auf die zuweilen bestehende Incontinenz, sowie auf das das dadurch bedingte Ekzem der Beine und das Bedrückende seines Zustands erhielt D. eine Rente von 40 Proz., obwohl er eigentlich allen seinen Arbeiten nachgehen konnte. Die operative Beseitigung der Fistel lehnte er ab mit Hinweis auf sein Alter.

Es ist mir gar nicht zweifelhaft, daß eine große Zahl derart Verletzter nach längerem oder kürzerem Krankenlager ad exitum kommt, durch Sepsis oder Urämie, die freilich durch die Literatur nicht zu unserer Kenntnis kommen, weil es eben Fälle sind, deren man sich begreiflicherweise nicht berühmen kann. Die Spontanheilung muß man doch als große Ausnahme ansehen. Noch zwei andere Fälle möchte ich anführen, an denen ich selbst erfahren habe, daß es auch Heilungen sicher festgestellter Harnröhrenwandläsionen ohne Operation gibt. Trotzdem halte ich bei Dammquetschungen mit Harnröhrenblutung die Frühoperation für angezeigt, denn es sind ohne Zweifel ebenfalls seltene Ausnahmen, die wir von vornherein nicht zu erkennen vermögen.

Fall 63. Harnröhrenwandverletzung. Spontanheilung mit Striktur.

Ein 37jähriger Kesselheizer S. fiel rittlings auf ein sich aufkantendes Brett und verspürte am Damm alsbald heftigen Schmerz. Als er nach einer Stunde Urin lassen wollten, ging dies nicht, es flob aber Blut aus dem Orificium externum. Er ging am folgenden Tage zum Kassenarzt, der ihn katheterisierte. Nach 8 Tagen ließ er sich, da die Harnserhaltung nicht nachließ, in ein Krankenhaus aufnehmen, wo er mit Bäderbehandlung und regelmäßigem Katheterisieren so weit gebracht wurde, daß er Harn regelmäBig lassen und die Arbeit wieder aufnehmen konnte. 8 Wochen nach der Verletzung aber trat wieder Harnverhaltung ein und nun wurde er unserem Institut überwiesen. Hier erzielte methodische Bougierung Beseitigung der subjektiven Beschwerden bis auf die Neigung, öfter Wasser zu lassen. Auch starke Bougies gingen schließlich glatt durch. Aber im Residualharn fand ich auch bei der Entlassung, obwohl der Harn im allgemeinen zellfrei war, noch kleine Fetzen, die sich mikroskopisch als Granulationsgewebe erwiesen, offenbar herrührend von einer ulcerierenden Stelle der Striktur. Er wurde angewiesen, sich unter allen Cautelen selbst zu bougieren.

Fall 64. Harnröhenläsion dicht hinter der Corona plandis durch HundebiB. Geringe Struktur.

Ein 8jähriger Knabe S. kam zu mir, blutend aus der Harnröhre des 
blau verfärbten, etwas geschwollenen Penis. Er war kurz vorher von einem Hunde durch die Hose gebissen worden, zwei Zahnabdrücke waren als leichte blauverfärbte Hauterosionen erkennbar. Ich unterlieb jede innere Untersuchung der Urethra und empfahl nur Bleiwasserumschläge und Hochlagerung des äußerlich von mir gereinigten Gliedes. Die Harnentleerung ging dauernd glatt vor sich. Die 8 Jahre zurückliegende Verletzung hat niemals sich irgendwie seit dem bemerkbar gemacht. Man fühlt aber jetzt noch ein schmerzloses Knötchen dicht hinter der Corona glandis. Vor einem Jahre hatte ich Gelegenheit, an dieser Stelle mit der Sonde eine kurze, faltenförmige, aber auf ein kleines Stück der Circumferenz beschränkte Striktur festzustellen. - Der so periphere Sitz der Quetschung rechtfertigte gewiß das exspectative Verfahren.

Die Harnröhrenzerreißungen mit Fraktur durch direkte Gewalt gegen die Schambogenschenkel bringen die Gefahr der Periostitis und ausgedehnter Knochensequestration mit sich. Dasselbe gilt auch von den Brüchen durch indirekte Gewalt, also den Beckenringbiegungsbrüchen. Wir sind sonst geneigt, subcutane Knochenbrüche um jeden Preis subcutan zu lassen und verzichten auch bei Durchstechungsfrakturen möglichst auf jeden percutanen Eingriff. Die einen Beckenbruch complicierende Harnröhrenruptur verpflichtet indes, von diesen allgemeinen Grundsätzen abzugehen. Ein Beckenbruch mit Harnröhrenruptur ist eben eine complicierte Fraktur. Wir haben in erster Linie die Harnröhre zu behandeln, von der bei abwartendem Verhalten die nächstliegende Gefahr ausgeht. Man wird kleine Fragmente vielleicht dabei enfernen können, Reposition anderer von der Dammwunde aus versuchen dürfen, aber im allgemeinen werden die Fragmente schon dadurch außer Gefahr gesetzt, daß wir eben durch die Dammincision die Urininfiltration vermeiden.

Die Frage, ob die einfache Urethrotomia externa bei frischen Harnröhrenrupturen genügt, oder ob man in jedem Falle sofort die Naht der Harnröhre anschließen soll, ist in der chirurgischen Literatur noch nicht entschieden. Es gibt Chirurgen, welche behaupten, daß es ihnen nach dem Torschlage Birketts in jedem Falle gelänge, die beiden Harnröhrenstücke zusammenzunähen, weil auch bei völliger Durchquetschung die Urethralwand hinreichend von beiden Seiten heranziehbar, auch hinreichend isolierbar sei, um die Zusammenziehung und Naht zu ermöglichen. Ich will mir nicht anmaßen, diese Frage nach der einen oder anderen Richtung zu entscheiden. Nur das möchte ich sagen, daß meine eigenen Erfahrungen am Lebenden, die freilich nur 7 Fälle betreffen, es mir unwahrscheinlich erscheinen lassen, daß die Naht immer möglich ist. 
An der Leiche gelang es mir freilich, einen dichten Nahtverschluß immer zu erzielen noch voraufgesetzter Resektion oder Ruptur durch stumpfe Gewalt. Aber am Lebenden fand ich die Beschaffenheit der Läsion doch meist recht verschieden von den Cadaververletzungen. Bei den vitalen Rupturen findet man meist weithin reichende Längssprengungen der Urethra, Risse, die zur Achse der Harnröhre parallel laufen und deren Ausdehnung man zunächst gar nicht übersehen kann. Resecieren wird man doch nur die sichtbar zertrümmerte nächste Nachbarschaft der Querläsion. Diese durch ungleiche Zerrung bedingten Längsrisse aber können sehr wohl auch eine Harninfiltration ermöglichen, die man doch eben durch den operativen Eingriff vermeiden will. Dazu kommt, daß bei totaler Durchreißung es nach meiner Erfahrung oft rechte Schwierigkeiten macht, den proximalen Teil der Harnröhre aus dem Gewebe soweit hervorzuholen und zu isolieren, daß man an ihm wirklich im nicht Gequetschten die Nähte anlegen kann. Ich sehe bei Martens, daß es in seinen Fällen zweimal überhaupt nicht gelang, das centrale Stück der Harnröhre zu finden. Das halte ich für sehr' begreiflich und ich kann mir sehr wohl Fälle denken, in denen man zur Behebung der Harnverhaltung die Sectio alta hinzufügen muß. (Die Blasenpunktion zum Zweck des retrograden Katheterismus bleibt m. E. als nicht absolut erfolgversprechend außer Betracht.)

Zugegeben nun, es lassen sich in gewissen Fällen die Enden der Harnröhre an der Rilstelle durch Naht vereinigen, so ist damit gewiß sehr viel genommen, man verringert die Strecke des künftigen Rohres, die zu epithelisieren bleibt. Dem Bougie ist für künftige Tage ein wohl abgesteckter Weg vorgezeichnet.

Aber; eine völlige Circulärnaht mit völlig dichtem Abschluß des Kanals, wie etwa bei der circulären Darmnaht, halte ich doch meist für praktisch undurchführbar. Dafür ist das Lumen der Urethra zu klein, das Haftgewebe für die Nähte zu gering, die Gewähr für gute Durchgängigkeit des geflickten Rohres recht klein.

Dazu bleibt immer die Möglichkeit weit reichender Längsriße der Schleimhaut und Muscularis zu befürchten.

So wird man sich darauf beschränken müssen, die Naht nur im oberen (bezw. vorderen) Teil der Harnröhrenwand anzulegen, nachdem man die Enden genügend freigelegt und herausgeholt hat, sie unten aber offen zu lassen, ebenso wie die Dammwunde, wie dies König auch für die Resektion von Strikturen empfohlen hat. 
Unter Verzicht auf eine kritische Betrachtung der umfangreichen Literatur (Birkett, Hägler, Kaufmann, Lennander, Wasiliev, Martens u. a.) sei es gestattet, meiner Stellung zu den aktuellen Fragen der Behandlung der Harnröhrenzerreißung in folgenden Sätzen Ausdruck zu geben:

1. Bei Quetschung der Dammgegend durch Fall auf diese, zumal beim Rittlingssturz sind Harnröhrenquetschungen ohne Knochenbruch etwas sehr Häufiges. Die gegen die Knochen des Schamwinkels gedrückte Harnröhre wird direkt teilweise oder ganz durchgequetscht, aber auch oft so gezerrt, daß auch Längsriße der Rohrwand neben der Querläsion zu berücksichtigen sind. Die Zerreissung durch Fragmente bei Beckenringbiegungsbrüchen ist meist eine totale Querläsion.

2. Am Frischverletzten hat man auf Blutentleerung in das Harnröhrenlumen zu achten. Bleibt diese aus, so läßt sich eine Wandläsion ausschließen. Erfolgt eine solche, dann ist sicher Harnröhrenwandberstung anzunehmen und damit Harninfiltration mit allen ihren gefährlichen Folgezuständen ziemlich sicher zu befürchten.

3. Jeder weitere diagnostische Versuch mit Katheter oder Bougies ist überflüssig, unzuverlässig, aber auch sehr gefährlich (falsche Wege, Wundinfektion.) Der Katheterismus gelingt bei partiellen Querläsionen oft anstandslos, dann gelingt aber auch meist die manuelle Ausdrückung der Blase. Der Katheterismus ist zunächst nicht nötig, wohl aber gefährlich, weil er die einzig rationelle Maßnahme, den Harnröhrenschnitt, zum Schaden des Patienten hiauszuschieben pflegt. Für den Harnröhrenschnitt bleibt eine gewisse Füllung der Blase sogar erwünscht.

4. Es ist deshalb ganz allgemein zu verlangen, daß bei Blutung aus der Harnröhre nach Dammquetsehung die Anwendung des Katheters oder Bougies unbedingt unterbleibt, erst als Hilfsmittel bei der Urethrotomie ist sie zulässig.

5. An die Incision des durchbluteten Damms schließe sich eine sorgfältige Freilegung der Wundstelle der Harnröhrenwand; kleine Läsionen werden sich nur mit Hilfe des Bougies, event. mit Einlauf steriler Kochsalzlösung per Katheter feststellen lassen. Kleine Einrisse, besonders Längsläsionen dürften sich alsbald durch Naht verschließen lassen bei größeren, aber nach partiellen Querrißen wird man die Rißstelle verkleinern können.

6. Bei totaler Querläsion kann die Auffindung bezw. Hervorholung des proximalen Stückes große Schwierigkeiten machen, ja unmöglich sein. Manchmal gibt der Strahl des ausgepreßten Urins einen Fingerzeig, den centralen Teil zu finden. Gelingt es nicht, 
so wird man abwarten, da Expression des Urins meist auch später möglich. Anderenfalls kann die Sectio alta nötig werden (KönigMartens). Findet man aber den centralen Stumpf, so nehme man ihn an Seidenzügel, die bei späterem Verbandwechsel gute Dienste leisten können, die aber auch bei der etwa möglichen Nahtvereinigung der Harnröhre in Bereich ihrer vorderen Cireumferenz gute Dienste leisten.

7. Über die Zweckmäßigkeit eines Verweilkatheters sind die Meinungen geteilt. Ich empfehle die Einlegung eines Néatoll, der aus der Dammwunde herausliegt mitten in den Wundtampon. Er wird an den obengenannten Seidenzügel befestigt. Seine Entfernung erfolgt am 3. Tage beim ersten Verbandwechsel. Mit diesem verbindet man den ersten Tersuch einen Nélaton durch die vordere Harnröhre hindurch, zur Wunde heraus und von da zwischen den Seidenzügeln in die hintere Harnröhre und Blase einzufülnren und einige Stunden liegen zu lassen. Dieses Manöver wird damn, verbunden mit antiseptischen Blasenspülungen, zunächst jeden Tag wiederholt, bis es gelingt, die Durchführung von oben her glatt zu erzielen. Während die Dammfistel sich schlielit und nach deren Schlußs sind methodische Bougierung und je nach der Beschaffenheit des Urins Blasenspülnngen lange Wochen und Monate hindurch erforderlich.

8. Bei schon bestehender Harninfiltration geniigt in Notfällen fürs erste die einfache Dammincision und lockere Tamponade des infiltrierten Gewebes, ein Eingriff, den jeder Arzt auch im Privathause machen kann und nötigen Falls machen muls. Die Incision wird dann zweckmäßig Knopflochgröße überschreiten.

II. Bezüglich der Harnblasenverletzungen, welche bei Beckenverletzungen vorkommen, möchte ich mir nur einige differential-diagnostische Bemerkungen und die versicherungsrechtlichen Gesichtspunkte hervorzuheben gestatten. Einige diagnostische Fragen habe ich bereits früher "Zux Diagnose der subcutanen Harnblasenrupturen" - ohne Beckenbruch (Vortrag in der mediz. Sektion der Schles. Gesellschaft für vaterl. Kultur, 30. 1. 1903 und Ärztl. Sachverständ.-Zeitung 1903, Nr. 6) erörtert.

Wir haben oben schon kennen gelernt, wie Fragmentspitzen und insbesondere an der inneren Circumferenz des vorderen Beckenringes sich abspaltende Knochenspangen die Harnblase, besonders wenn sie stark gefüllt ist, beim Biegungsbruch anstechen, im Moment der stärksten Zusammenpressung des Ringes die Blasenwand zerreißen können. Nach Wegfall des Druckes wird die Fragmentspitze in der Regel wieder zurückweichen und sich in die alte Form weiter einpassen, aber das Unglück der Blasenwandverletzung ist 
geschehen. Ich gebe die Zeichnung Fig. 1 noch einmal wieder im photographischen Bilde (Fig. 35), welches noch besser als die Zeich-

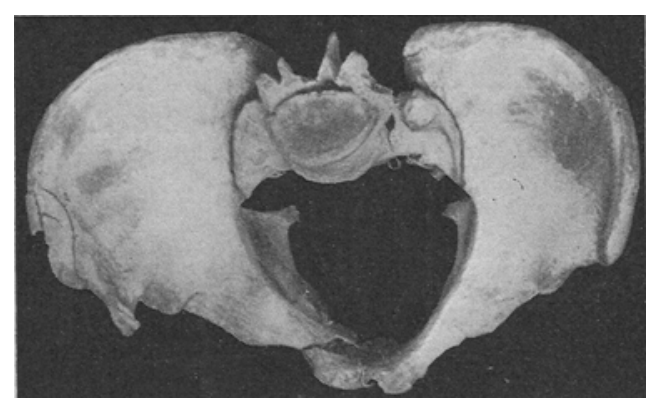

Fig. 35.

nung die Einbiegung der ganzen rechten Beckenhälfte veranschaulicht, die an dem oberen Darmbeinrande (Spina anterior) die Spuren der direkten Gewalt (mehrfache Fissuren) erkennen läßt und welche das stachelförmige, spitze Fragment des horizontalen Schambeinastes gerade gegen die Blasengegend gerichtet zeigt. (Auch auf die Fissur, die längs durch die linke Hälfte des Kreuzbeins hinläuft, sei noch anfmerksam gemacht!) Das Bild demonstriert recht augenfällig den Mechanismus der Harnblasenzerreißung.

Aber wir dürfen nicht vergessen, daß es auch ohne die Mitwirkung solcher Knochenfragmente zur Blasenwandverletzung kommen kann, nämlich durch dieselbe Gewalt, die die Beckenknochen zum Bersten brachte. Das sind die Blasenberstungen bei stark gefüllter Harnblase, die auch ohne jede Fraktur an dem vorderen Beckenringe durch jähe Zusammendrückung der Blase zustande kommen, z. B. durch Überfahren, wenn das Rad oberhalb der Symphysis pubis über die Blasengegend länft, oder beim Fußtritt oder Hufschlag gegen diese.

Fragmentdurchstechungen werden häufiger extraperitoneale Blasenrupturen machen, während die intraperitonealen häufiger durch Berstung infolge direkter Gewalteinwirkung zustande kommen. Die Literatur, insbesondere Bartels Arbeit, bestätigt diese Vermutung. Weiß der Verletzte über die Art seines Unfalls genaue Auskunft zu geben und ist der Beckenbruch derart erkennbar, daß die Vermutung einer Fragmentverletzung der Blasenwand nahe liegt, so wird, wenn auch sonst noch die klinischen Symptome einer Blasenruptur vorliegen, die Diagnose meist nicht schwer sein. Aber die beiden erstgenannten Voraussetzungen treffen oft nicht zu und die letztere dann auch manchmal nicht. 
Solche Unfälle passieren oft Betrunkenen, die dann bewußtlos auf der Straße liegend gefunden werden und so gut wie nichts über den Hergang wissen. Große Blutergüsse verhindern eine sorgfältige Abtastung der Beckenknochen und die subjektiven Angaben der Potatoren uber Bruchschmerz sind oft wenig prägnant, Wenn nun gar Ausnahmen von dem landläufigen Symptomenkomplex sich dazugesellen, so kann man leicht im Zweifel bleiben, ob wirklich eine Blasenruptur vorliegt oder nicht. Aber langes Zuwarten kann verderblich werden. Wir stehen hier vor einer ähnlich dringlichen und doch schwierigen Situation wie bei den Bauchcontusionen mit der Frage: Darmzerreißung oder nicht?

Dürfen wir doch nicht vergessen, daß keineswegs jede Urinverhaltung bei Beckenbruch durch eine Blasenzerreißung bedingt sein muß (siehe Fall 40). Ausgedehnte Blutungen im Beckeninnern, besonders in das prävesicale Gewebe, in die verschiedenen Strata des Beckenbodens, in die Kreuzbeinaushöhlung mit den für die Innervation der Blase wichtigen Plexus lumbosacrales können die Unmöglichkeit der Blasenentleerung bedingen. Aber auch eine Gehirnerschütterung, eine Rückenmarksquetschung bei den complicierten Unfällen dieser Art (Absturz aus der Höhe, Verschüttuug, Überfahren) sind als Ursachen der Harnretention zunächst auszuschließen.

Druck auf die Harnblase ist unbedingt zu vermeiden, da er deren Inhalt in das Beckengewebe oder in die Bauchhöhle auch durch eine nur ganz geringe Wandläsion pressen könnte.

Und bringt uns der Katheterismus über die Frage ins Klare? Keineswegs. Dennoch ist er hier unbedenklich. Denn liegt eine Blasenruptur nicht vor, dann schadet er nichts, wenn er mit allen Cantelen, insbesondere aseptisch, ausgeführt wird. Schaden stiften kann er nur, wenn er brüsk geschieht und etwa bei einem mehrere 'Tage alten Fall eine bereits in Heilung begriffene sehr geringe, durch Verklebung mit Darmschlingen inzwischen abgeschlossene Wandläsion wieder aufrisse. Man wird also hier den Katheter nur zur Harnentleerung in Anwendung bringen, die insoferm auch ein diagnostisches Hilfsmittel ist, als sie die Beschaffenheit des bis dahin zurückgehaltenen Urins zu unserer Kenntnis bringt (Blutgehalt). Eine Austastung der Blase mit dem Metallkatheter ist also dringend zu widerraten. Es wird immer nur der weiche Nélaton in Frage kommen Er gibt uns auch genügenden Aufschluß und jedenfalls am ungefährlichsten, ungefährlicher als der Metallkatheter in dem Falle, daß eine hochsitzende Harnröhrenzerquetschung oder Abreißung vor- 
liegt, dicht am Blaseneingang. Dann wird die Einführung bis in die Blase eben nicht gelingen. Heftiger Schmerz fällt mit dem Erreichen des Hindernisses zusammen, weil die Spitze in eine große Wunde eintritt. Aus dieser Wundhöhle entleert sich dann auch wohl, wie wir es einmal gesehen, stark blutiger Urin und das kann vielleicht zu der Täuschung Anlaß geben, daß man wirklich in der Harnblase sei. Man muß sich da vergegenwärtigen, daß sich eben Urin aus der Blase in dieser blutenden Wundhöhle angesammelt hat, den nun der Katheter erst entleert.

Es sind das Erlebnisse, mit denen sich der erfahrene Chirurg abzufinden, die er sich zu erklären vermag, aber wer kritiklos derartige therapeutische oder diagnostische Eingriffe vornimmt, wie dies leider manchmal geschieht, der gelangt leicht zu verhängnisvollen Entscheidungen.

Einen eigenartigen, leicht irreführenden Harnbefund, der nach meiner Kenntnis der Literatur bislang ${ }^{1}$ ) sonst noch niemals gemacht ist, habe ich in meinem bereits angezogenen Vortrag mitgeteilt, Gehalt an Eiweiß und Leukocyten bei einer 3 bezw. 4 Tage zurückliegenden Verletzung. Der Patient, ein Kutscher, welcher zuvor auswärts behandelt war, gab an, daß er seit längerer Zeit an Kopfschmerzen und Nasenbluten leide, und daß er in einem Ohnmachtsanfall von seinem Wagen gefallen und überfahren worden sei. Kein Beckenbruch. Er war wegen Harnverhaltung katheterisiert, wobei Blut von ihm nicht bemerkt wurde - der Arat berichtete später, daß er Spuren bemerkt habe. 52 Stunden nach dem Unfall entleerte der keineswegs collabierte, fieberfreie Patient im Stehen $1 / 2$ Liter Urin, der sehr trübe, aber nicht blutig. Die Untersuchung ergab: viele weiße Blutkörperchen, Cylinder, hyaline und gekörnte, ganz vereinzelte rote Blutkörperchen. Der filtrierte Urin enthielt 10 pro mille Eiweißs, am 4. Tage 6 pro mille. - Die Obduktion ergab einen $2 \mathrm{~cm}$ langen $\mathrm{Ri} \beta$ an der Hinterwand der Harnblase nahe dem Scheitel, der durch fibrinbelegte Darmschlingen größtenteils abgeschlossen war. Dabei ist der Eiweißgehalt bei dem nierengesunden Manne ohne weiteres erklärt, ebenso der Lenkocytenbefund, nicht freilich ohne weiteres die gefundenen Cylinder. Diese waren offenbar keine Harnkanälchencylinder, sondern vermutlich in den Blasenfalten ähnlich geformte Fibrin-, bezw. Blutbestandteile.

Hier möchte ich noch hinzufügen, daß man auch bei Rückmarkstotalläsion im Urin der Frischverletzten sofortige Trübung und

1) Nobe erwähnt bei einem auch von mir untersuchten Patienten Jobke Leukocytenbefund am 2. Tage. (Diss. Leipzig 1903.) 
zwar nicht durch Leukozythen, sondern durch Blasen- und Nierenepithelien bezw. -Cylinder findet, wie ich andernorts mitgeteilt habe. Auch diese Möglichkeit bliebe bei Schwerverletzten gelegentlich zu berücksichtigen.

Bei der Diskussion meines Vortrages wurde von einem Blasenspezialisten der Einwand gemacht, daß für die Harnblasenrupturen die Cystoskopie als diagnostisches Hilfsmittel herangezogen werden müßte. Ich glaube, daß man diesen Vorschlag unbedingt ablehnen muß, da diese Untersuchungsmethode nicht nur alle Fährnisse des brüsken Katheterismus mit sich bringt, sondern wegen der Blutbeimengung zum Urin völlig resultatlos bleiben müßte.

Meine eigenen Erfahrungen haben mich also gelehrt, daß die Diagnose der Harnblasenruptur gelegentlich unmöglich, jedenfalls schwieriger sein kann, als dies aus der bisherigen Literatur erhellt. Darum gehören alle verdächtigen Fälle und zwar sofort in ein chirurgisches Krankenhaus. Hier wird in ganz verschleierten Fällen der Probeschnitt mit derselben Berechtigung gemacht werden dürfen, wie die Probelaparotomie wegen Verletzungen des Darmes und in, wenn auch seltenen, Fällen wirklich notwendig werden. Freilich dürfte manchmal mit dem Widerstande der Pat. zu rechnen sein, aber dann ist hier auch ein verschleppter Fall noch eher rettbar als im Privathaus oder wenn nachträglich erst die Überführung erfolgt.

Die Heilerfolge, die von Jenckel, Dohrn, Alsberg, Berndt, Nobe (aus v. Mikuliczs Klinik), Degen, Braun, Walsham, Seldowitsch u. a. veröffentlicht sind - es sind ihrer schon etwa $50-$, empfehlen ein operatives Vorgehen aufs wärmste.

Zum Schluß möchte ich noch auf die versicherungsrechtliche Seite der Harnröhren- und Harnblasenverletzungen eingehen. Die erwerbsbeschränkenden Unfallsfolgen sind naturgemäß immer zusammen mit den etwa durch Beckenbruch bedingten Beschwerden abzuwägen. Deshalb ist, stets von Fall zu Fall zu entscheiden, es ist auch nicht annähernd ein Einheitssatz möglich.

Immer mache man die Berufsgenossenschaft auf die Möglichkeit der Verschlimmerung des Zustandes aufmerksam. Beim Zurückbleiben einer traumatischen Harnröhrenstriktur ist dies selbstverständlich, aber auch nach dem Blasenschnitt bleiben doch so gut wie stets Zeichen von Cystitis zurück. Diese nimmt recht oft gerade bei Arbeitern einen wenig günstigen Verlauf, weil sie bei körperlicher Arbeit in Wind und Wetter oft Erkältungen erfahren und auch bezüglich ihrer Getränke Fehler begehen. 
580 XXIII. Stolper, Die Beckenbrüche m. Bemerkgn. üb. Harnröhren- etc.

Bei der Rentenabschätzung ist das in Betracht zu ziehen, vor allem sind Leuten, die noch der ärztlichen Controlle bezüglich einer Striktur unterstehen, höhere Renten, 50-60 Proz. mindestens zu gewähren, damit sie in der Lage sind, den Ausfall eines Tagelohnes zwecks ärztlicher Consultation zu verschmerzen. Das muß man den Berufsgenossenschaften auseinandersetzen, dann werden sie gern die höheren Sätze bewilligen. Ja man hat als Arzt die Verletzten selbst damit in schärferer Controlle, man kann sie zwingen sich regelmäßig zur Bongierung zu stellen, was ja leider recht oft nötig wird, nur von den Ärzten nicht immer geschieht. Für die Strikturbehandlung muß man die Patienten der Arbeiterunfallversicherungspraxis fest an die Leine nehmen, wer es nicht tut, macht sich für Verschlimmerungen verantwortlich. Erst wenn ein Dauerzustand gewährleistet ist, meist ist dies nicht vor Ablauf von 2 Jahren der Fall, kann man Herabsetzung der Rente als Arzt empfehlen, mit der dann meist der Patient den Arzt als seinen besten Feind, nicht als seinen auch mit schmerzhaften Bougierungen es wohl meinenden Freund und Helfer anzusehen beginnt.

Bei einer jahrelang bestehenden Harnfistel sahen wir den Verdacht gegen den Verletzten rege werden, daß er künstlich seine Fistel offen hielte und das war auch ärztlicherseits angenommen worden. Daß dies möglich ist, wird man meines Erachtens nicht annehmen können, wohl aber betonen müssen, daß die Spontanheilung von Harnfisteln nicht selten zeitlebens ausbleibt.

In solchen Fällen ist bei der Rentenabschätzung nicht bloß der Arbeitsbehinderung durch chronische Ekzeme an den Genitalien und den Beinen, sondern auch dem Rechnung zu tragen, daß solche Menschen durch den üblen Geruch ihrer stets durchnäßten Kleider für gemeinsames Arbeiten unbrauchbar werden und daß sie der Hautpflege mehr als gewöhnlich Zeit und Mühe opfern müssen. Ferner ist auch die Depression der Psyche durch solches chronisches Leiden neben leichten, vom Blasenkatarrh bedingten Gesundheitsstörungen mit $z u$ veranschlagen.

Endlich wird auch bei der Begutachtung gelegentlich unterschätzt die Schädigung des allgemeinen Gesundheitszustandes, die solche Schwerverletzte durch langdauernde Bettruhe, Eiterungen, intercurrente Lungenentzündungen, Erysipele erfahren. Lungenund Nierenerkxankungen sind im Gefolge von Beckenbrüchen ein nicht gar seltenes Ereignis, auf deren Folgezustände bleibt also ebenfalls zu achten. 